\title{
WestVirginiaUniversity
}

THE RESEARCH REPOSITORY @ WVU

Graduate Theses, Dissertations, and Problem Reports

2017

\section{Studies in European Integration and Institutional Change}

\author{
Danko Tarabar
}

Follow this and additional works at: https://researchrepository.wvu.edu/etd

\section{Recommended Citation}

Tarabar, Danko, "Studies in European Integration and Institutional Change" (2017). Graduate Theses, Dissertations, and Problem Reports. 6775.

https://researchrepository.wvu.edu/etd/6775

This Dissertation is protected by copyright and/or related rights. It has been brought to you by the The Research Repository @ WVU with permission from the rights-holder(s). You are free to use this Dissertation in any way that is permitted by the copyright and related rights legislation that applies to your use. For other uses you must obtain permission from the rights-holder(s) directly, unless additional rights are indicated by a Creative Commons license in the record and/ or on the work itself. This Dissertation has been accepted for inclusion in WVU Graduate Theses, Dissertations, and Problem Reports collection by an authorized administrator of The Research Repository @ WVU.

For more information, please contact researchrepository@mail.wvu.edu. 


\title{
Studies in European Integration and Institutional Change
}

\author{
Danko Tarabar \\ Dissertation submitted to the \\ College of Business and Economics \\ at West Virginia University \\ in partial fulfillment of the requirements \\ for the degree of \\ Doctor of Philosophy \\ in \\ Economics

\begin{abstract}
Andrew T. Young, Ph.D.
Arabinda Basistha, Ph.D.

Department of Economics

2017
\end{abstract} \\ Bryan C. McCannon, Ph.D. \\ Joshua C. Hall, Ph.D., Chair \\ Morgantown, West Virginia
}

Keywords: Culture, Transition, Market Reforms, Institutional Convergence, EU Integration, Entrepreneurship 


\begin{abstract}
Studies in European Integration and Institutional Change
\end{abstract}

Danko Tarabar

This dissertation is a collection of empirical essays studying the drivers of institutional change and the effects of economic and political integration across countries, with a special focus on the European setting. Chapter 2 examines the drivers of market-institutional change within transition countries, the early post-communist economies undergoing an economic system switch from socialism to a market order in the immediate aftermath of communism's collapse, between 1989 and 2001. I hypothesize that the effectiveness of political liberalization, a factor identified to be the major driver of economic reform in transition countries, is conditional on the underlying cultural attitudes that influence how voters may legitimize particular institutional arrangements. By considering the interaction term between culture and democracy, I disaggregate the marginal effect of democracy on market reform adoption by the cultural environment from which democracy emerged. I find that in societies that foster individualistic and politically egalitarian attitudes, the positive effect of democracy on reforms is amplified. Chapter 3 considers the impact of EU integration on institutional quality in a set of European countries between 1970 and 2010. EU integration can promote institutional improvement via at least two mechanisms: the pre-membership accession process, during which countries are mandated to implement reforms as a condition for joining, and the membership stage, in which new member states are ushered in a common market of unrestricted mobility. On the latter, it is argued that the presence of the common market encourages competition between members in adopting better policies and institutions with the aim of attracting capital and labor or risk their exit. The main finding is that integration with the EU often has a statistically negligible impact on institutional improvement, and that when the impact is significant, it is generally modest. Chapter 4 considers how the intensity of EU member countries' economic activity with the EU's common market along with their institutional conformity with EU law relate to entrepreneurial activity, measured by the prevalence of microfirms and the rate of self-employment between 2004 and 2012. It is shown that the deepening of economic and political integration with the EU stimulates entrepreneurial activity in member countries by expanding opportunities for specialization, promoting a healthy competitive environment, and reducing transaction costs of operating a business. Chapter 5 summarizes the findings of this dissertation and offers concluding remarks. 


\title{
Studies in European Integration and Institutional Change
}

\author{
Danko Tarabar \\ Dissertation submitted to the \\ College of Business and Economics \\ at West Virginia University \\ in partial fulfillment of the requirements for the degree of \\ Doctor of Philosophy \\ in \\ Economics
}

Department of Economics

APPROVAL OF THE EXAMINING COMMITTEE

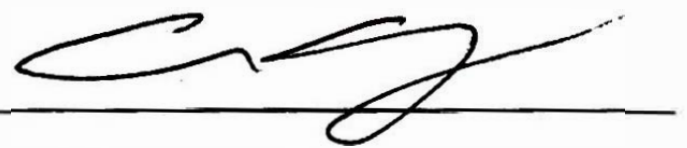

Andrew T. Young, Ph.D.

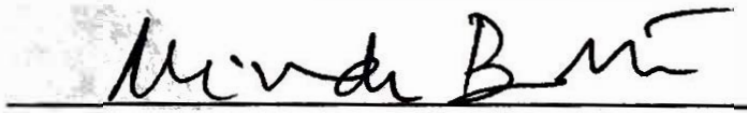

Arabinda Basistha, Ph.D.

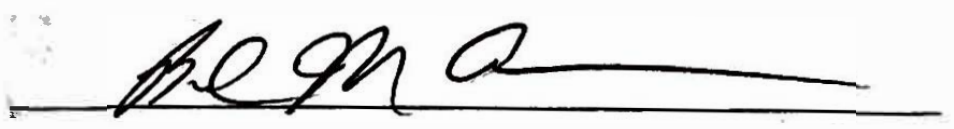

Bryan C. McCannon, Ph.D.
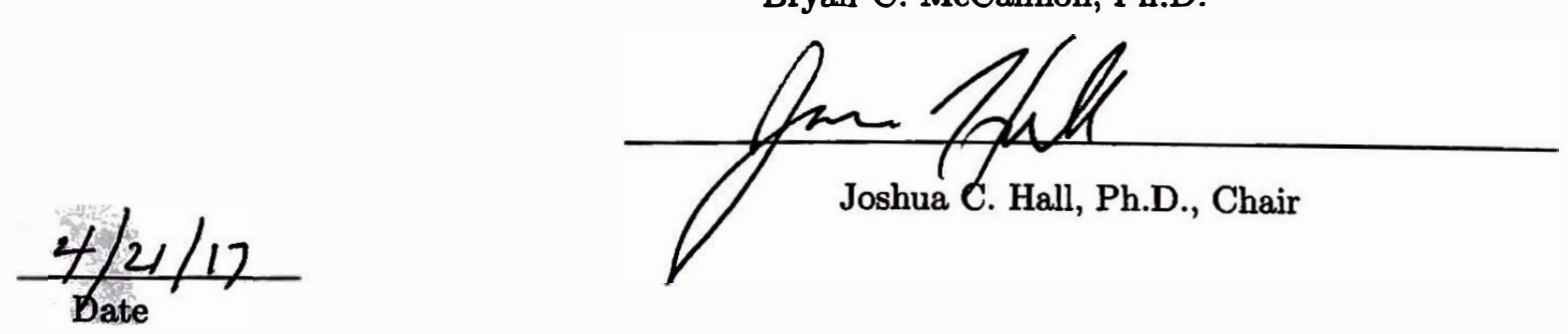


\section{Acknowledgements}

The past five years at West Virginia University made me into a scholar I had hoped to become since my undergraduate days. I owe so many of my achievements to Dr. Joshua

Hall, whose teachings, mentorship, and guidance instilled in me the love for economics since my earliest academic days, and to Dr. Andrew Young, who forged me into an independent researcher and inspired me to study the issues in the economics of development.

I am also indebted to the remaining members of my committee, Dr. Arabinda Basistha and Dr. Bryan McCannon, from whom I learned so much over the years and whose invaluable comments, guidance, and suggestions helped make this dissertation possible.

Lastly, I am deeply grateful to old friends as well as all the wonderful people I had met along the way who made my graduate school experience more enjoyable than I could ever have hoped for: Ethan, Canberk, Serkan, Imran, Zach, Jamie, Masha, Suzanne, and others too many to mention. I will always remember your friendship, company, and unwavering support.

I dedicate this dissertation to my family, who never stopped believing in me. 


\section{Contents}

Acknowledgements $\quad$ iv

List of Figures vii

List of Tables $\quad$ viii

1 Introduction 1

2 Culture, Democracy, and Market Reforms: Evidence from Transition Countries 5

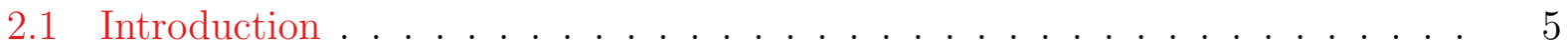

2.2 Theoretical Considerations . . . . . . . . . . . . . . . . . . . 8

2.3 Empirical Framework . . . . . . . . . . . . . . . . . . . . . . . . . . . 11

2.4 Data . . . . . . . . . . . . . . . . . . . . . . . 15

2.4.1 The Dependent Variable . . . . . . . . . . . . . . . . . . . 15

2.4 .2 Cultural Variables . . . . . . . . . . . . . . . . . . . . . . 16

2.4 .3 Control Variables . . . . . . . . . . . . . . . . . . . . . . 21

2.5 Results . . . . . . . . . . . . . . . . . . . . . . . . . . . 23

2.6 Robustness Checks . . . . . . . . . . . . . . . . . . . . . . . . 26

2.6 .1 Cultural Distance . . . . . . . . . . . . . . . . . . . . . 26

2.6 .2 Social Capital . . . . . . . . . . . . . . . . . . . . . 28

2.6 .3 IV Estimates . . . . . . . . . . . . . . . . . . . . . . 30

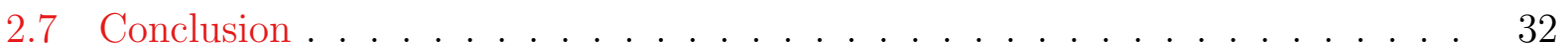

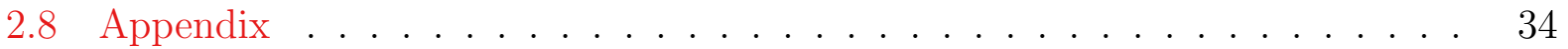

3 Liberalizing Reforms and the European Union: Accession, Membership, and Convergence $\quad 54$

3.1 Introduction . . . . . . . . . . . . . . . . . . . . 54

3.2 The Mechanisms of EU Integration . . . . . . . . . . . . . . . . 58

3.3 Data and Empirical Framework . . . . . . . . . . . . . . . . . . 62

3.4 Results . . . . . . . . . . . . . . . . . . . . . . . 67

3.5 Concluding Discussion . . . . . . . . . . . . . . . . . 70

3.6 Appendix . . . . . . . . . . . . . . . . . . . . . 73 
4 Integration and Entrepreneurial Activity in the European Union: Some Country-Level Evidence

4.1 Introduction . . . . . . . . . . . . . . . . . . . . . 79

4.2 Background and Literature Review . . . . . . . . . . . . . . . . . . 82

4.3 Globalization and Entrepreneurship: Theory and Evidence . . . . . . . . . . 84

4.4 Data and Methodology . . . . . . . . . . . . . . . . . . 88

4.5 Empirical Results . . . . . . . . . . . . . . . . . . . . . . . . . . . . . . . . . . . 92

4.5.1 Main Estimates . . . . . . . . . . . . . . . . . . 92

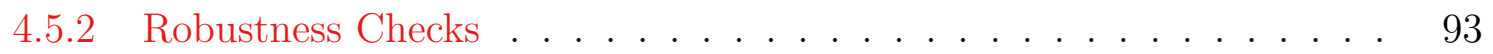

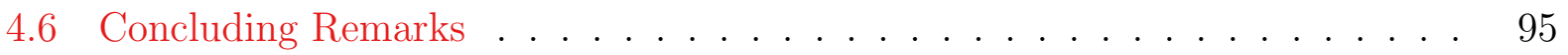

4.7 Appendix . . . . . . . . . . . . . . . . . . . . . 96

$\begin{array}{llr}5 & \text { Conclusion } & 100\end{array}$

$\begin{array}{ll}\text { References } & 102\end{array}$ 


\section{List of Figures}

2.1 Evolution of the CH reform index by country, 1989-2001. . . . . . . . . . . 38

2.2 Evolution of democracy as measured by the Polity IV index by country, 19892001. . . . . . . . . . . . . . . . . . . . . . . . . . 39

2.3 Scatter plot of the relationship between $2001 \mathrm{CH}$ index (vertical axis) and individualism vs. collectivism (horizontal axis). . . . . . . . . . . . 40

2.4 Scatter plot of the relationship between $2001 \mathrm{CH}$ index (vertical axis) and power distance (horizontal axis). . . . . . . . . . . . . . . . . . . . . 41

2.5 Scatter plot of the relationship between $2001 \mathrm{CH}$ index (vertical axis) and uncertainty avoidance (horizontal axis) . . . . . . . . . . . . . . 42

2.6 Scatter plot of the relationship between $2001 \mathrm{CH}$ index (vertical axis) and long-term orientation (horizontal axis) . . . . . . . . . . . . .

2.7 Scatter plot of the relationship between $2001 \mathrm{CH}$ index (vertical axis) and indulgence vs. restraint (horizontal axis) . . . . . . . . . . . . . . . . 44

2.8 The marginal effect of democracy conditional on the level of individualism. . 44

2.9 The marginal effect of democracy conditional on the level of power distance. 45

2.10 The marginal effect of democracy conditional on the level of uncertainty avoid-

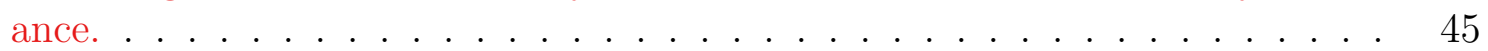

4.1 Average share of micro firms in total number of firms per country, 2004-2012. 96 


\section{List of Tables}

2.1 Descriptive statistics, explanatory variables . . . . . . . . . . . . . . 36

2.2 Cultural dimensions correlation matrix. . . . . . . . . . . . . . . . . 37

2.3 The effect of individualism vs. collectivism on reforms in 21 transition economies, 1989-2001. . . . . . . . . . . . . . . 46

2.4 The effect of power distance on reforms in 21 transition economies, 1989-2001. 47

2.5 The effect of uncertainty avoidance on reforms in 20 transition economies,

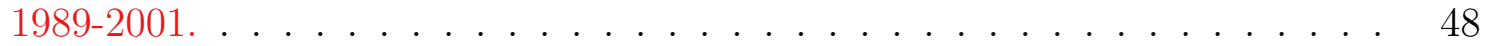

2.6 The effect of long-term orientation on reforms in 21 transition economies,

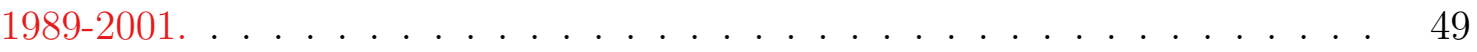

2.7 The effect of indulgence vs. restraint on reforms in 21 transition economies,

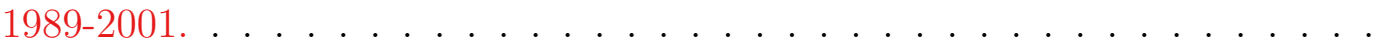

2.8 The effect of cultural distance from the U.S. on reforms in 21 transition

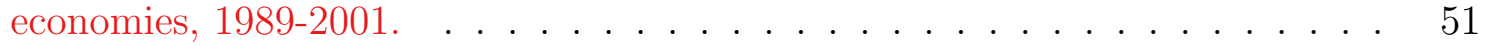

2.9 The impact of cultural dimensions controlling for generalized social trust within countries. . . . . . . . . . . . . . . . . 52

2.10 2SLS estimates (second stage) of the effect of culture on market reforms in 21 transition countries, 1989-2001. . . . . . . . . . . . . 53

3.1 Summary statistics of liberalizing reforms, full sample, 1970-2010. . . . . . 73

3.2 Summary statistics for regression subsample. . . . . . . . . . . . . . . 74

3.3 Fixed effect estimates of EU membership and accession on the 5-year changes in liberalizing reforms, 1970-2010. . . . . . . . . . . . . 75

3.4 Fixed effect estimates of EU membership and accession on 5-year convergence in liberalizing reforms, 1970-2010. . . . . . . . . . . . . 76

3.5 Fixed effect estimates of EU membership and accession on 5-year convergence in liberalizing reforms, 1970-2010. . . . . . . . . . . . . . 77

3.6 Arellano-Bover/Blundell-Bond panel GMM estimates of length of EU membership on the levels of liberalizing reforms, 1970-2010 . . . . . . . . 78

4.1 Summary statistics for regression subsample variables. . . . . . . . . . . . 97

4.2 Fixed effects regressions of micro firm density on EU economic and political integration indices for 24 EU countries, 2004-2012 . . . . . . . . . . . . 98

4.3 Fixed effects regressions of other entrepreneurial measures on EU economic and political integration indices for 24 EU countries, 2004-2012. . . . . . . . 


\section{Chapter 1}

\section{Introduction}

The costs and benefits of European integration have re-entered policy spotlight in recent years with the ongoing Eurozone crisis and the 2016 "Brexit" referendum. Since its founding as a free trade area at the 1957 Treaty of Rome, the European Union (EU) evolved over six decades and several subsequent enlargements into a political and economic supranational union, in which its 28 member states and over 500 million people share common foreign, trade, and (to a large extent) monetary policies; also, legislative and adjudicative institutions, as well as the largest common market in the world in which goods, services, capital, and labor flow freely.

The welfare consequences of political and economic integration are well-known in the empirical economics literature. For example, increases in intensity of cross-national trade and capital flows, important "symptoms" of globalization, were found to promote economic growth across countries and over time (Dreher, 2006). In a similar vein, a growing body of literature documents the positive effect of joining the EU's common market on income levels

and growth among European countries (e.g., Campos et al., 2014; Crespo Cuaresma et al., 2008; Badinger, 2005).

Joining EU also entails an institutional dimension of integration, under which member states become a part of a political structure resembling market-preserving federalism (Weingast, 1995), characterized by a clear separation of federal and sub-federal governments, whereby the lower layers of government maintain primary responsibility over own economies 
and coexist within a common market of unrestricted mobility. Public finance literature suggests that such a political structure ensures that sub-federal "jurisdictions" (i.e., member states) compete for economic activity by providing bundles of better policies and institutions or risk the "exit" of capital and labor (Tiebout, 1956).

In this dissertation, I examine the factors contributing to European institutional change over time and the economic effects of EU integration. Chapter 2 begins with transition countries, a group of early post-communist economies located in Eastern Europe (including a small number in Central Asia), and investigates the role of culture as a potential determinant of their market-institutional reform, a necessary condition for EU membership, in the immediate aftermath of communism's collapse. Transition countries differed widely in the extent to which they implemented market reforms. I examine an unbalanced panel of up to 21 transition countries over the period 1989-2001 and estimate the relationship between different cultural attitudes based on Hofstede (1980); Hofstede and Hofstede (2001) typologies and transition countries' reform efforts. I report that a sense of individualism and intolerance for unequal dispersion of power within societies are robustly associated with greater market reform efforts. Only limited evidence exists for the influence of other cultural dimensions.

In Chapter 3, jointly authored with Andrew Young, we take the long-run view of EU integration and ask how might integration with the EU affect institutional quality in a wide sample of European countries between 1970 and 2010. The European Union may promote reforms to policies and institutions through at least two distinct mechanisms. First, accession to the EU requires applicant countries to undertake reforms. Second, the EU common market may promote Tiebout jurisdictional competition. We empirically evaluate these two mechanisms using an unbalanced panel of up to 45 European countries during 1970-2010 and find that relationships between EU accession/membership and measures of policies/institutions are often statistically insignificant. Furthermore, when the estimated effects are statistically significant they are generally modest.

Chapter 4 explores entrepreneurial activity as a potential channel through which EU integration may promote economic prosperity within member states. Recent literature highlights the role of economic integration in promoting the resurgence of entrepreneurship across 
the world. This chapter empirically tests the link between regional integration and entrepreneurial activity, measured as the prevalence of micro firms between 1 and 9 employees in size, in an unbalanced panel of 24 European Union countries observed between 2004 and 2012. Evidence from fixed effects regressions report that, all else equal, micro firms per labor levels mostly increase in the level of EU economic and political integration. The finding is robust to a number of control variables and alternative proxies for entrepreneurship.

The central contribution of this dissertation is three-fold. First, it accounts for the cultural narrative of institutional change among transition economies of Eastern Europe and Central Asia. I show that the effectiveness of democratization on the adoption of market reforms was conditional on the underlying culture from which democracy emerged. In that respect, I argue that culture provides for an important lens through which the impact of political liberalization on various socio-economic outcomes can be better understood and predicted.

Second, jointly with Andrew Young, I find only small effects of EU membership and accession on institutional improvement in member and aspirant countries. Moreover, the effects of the two mechanisms of EU integration diverged based on which dimensions of institutions we observe. While membership encouraged convergence in institutions of economic freedom via Tiebout competition, the process of accession promoted openness and cross-border economic flows. In that respect, the benefits of EU integration, however modest, clarify one potential channel through which the EU fosters an institutional environment conducive to economic growth.

Lastly, I present preliminary evidence speaking to the conjecture that cross-country economic and political integration stimulate entrepreneurial activity, an important correlate of economic progress. Observing integration through the lens of European regional cooperation and employing a novel index of EU integration, I argue that intra-EU flows of goods, services, and people, as well as greater institutional conformity with the common market laws and regulations, created an environment conducive to entrepreneurial learning, innovation, and intentions. Evidence suggests that one way through which the EU can promote growth lies in deepening the scope of member countries' reliance on the common market and promoting an institutional environment of fair competition and lower transaction costs of operating a 
business. 


\section{Chapter 2}

\section{Culture, Democracy, and Market Reforms: Evidence from Transition Countries}

\section{$2.1 \quad$ Introduction}

What was the role of informal institutions in formal institutional change within transition countries? Can differences in market reform be attributed to differences in culture? This chapter empirically investigates the role of culture in the early experiences of post-socialist transition characterized by dismantling of central planning and institutional convergence towards free markets and private property.

The development experience of transition economies differed from that of many other developing countries in that it involved a simultaneous liberalization of both the economy and the political system. The disintegration of the Soviet Union provided economists with unprecedented insights into the problems involved with transitioning from command structures to markets. Although the countries of Central and Eastern Europe (CEE) and the former Soviet Union (FSU) began their transition from similar institutional structures, they ended up with outcomes that differed, sometimes drastically so. Today, the CEEs have largely joined the ranks of the advanced market economies in the European Union. Alternatively, 
many FSU and some Balkan countries still lack substantive political and economic freedoms (see, e.g., reports by Fraser Institute and Freedom House).

Transition reforms generally included regulatory and legislative efforts to liberalize prices, wages, finances, foreign exchange, trade, and property laws (see Kornai, 1992). These efforts were designed to structurally transform the centralized command structures in which virtually all aspects of economic (and political) activity were directly controlled by the sole (communist) party in power. Hence, apart from their economic dimension, transition reforms were also the carriers of sweeping formal institutional change. Given the significance of pro-market policies and institutions in improving living standards across CEE and FSU (see, e.g., Babecky and Havranek, 2014), it remains a puzzle, then, as to why these countries varied in the pace of reform implementation in the aftermath of communism's collapse. This chapter argues that reform adoption, i.e., institutional change towards an economic system fostering free markets and private property, was partly dependent on the transition countries' informal institutions.

We can refer to a country's informal institutions as its culture. Following Guiso et al. (2006), culture consists of those commonly accepted and shared conventions, values, norms of behavior, and codes of conduct adhered to by citizens and exhibiting high inertia or persistence over time. ${ }^{1}$ A growing literature suggests that culture is an important determinant of economic development. For example, Williamson (2009) reports higher living standards in countries that exhibit higher levels of trust, respect, individual self-determination, and obedience, and that formal institutions are also beneficial in that respect if they are grounded in these informal constraints. Guiso et al. (2003) link religiosity with preference towards thriftiness. Closely related studies empirically document the linkage between different culture, economic performance (Gorodnichenko and Roland, 2016, 2011; Alesina et al., 2015; Tabellini, 2010; Guiso et al., 2009), and institutions (Gorodnichenko and Roland, 2015; Klasing, 2013; Licht et al., 2007).

Within the context of transition, Pejovich (2003) proposes that the formal institutions of a market-oriented economy require an appropriate cultural undercurrent that encourages

\footnotetext{
${ }^{1}$ They define culture as "those customary beliefs and values that ethnic, religious, and social groups transmit fairly unchanged from generation to generation" (p. 23).
} 
"self-interest, self-determination, self-responsibility, and free market competition" (p. 350). Clashes between culture and formal institutions will raise the transaction costs associated with accepting, monitoring, and enforcing of the latter (p. 351). In a similar vein, Voigt and Engerer (2002) note that complementarity between "internal" institutions (i.e., conventions, ethical rules, customs, private rules) and "external" institutions (i.e., state laws) will mean that "the state has to provide fewer resources for the enforcement of its institutions" (p. 136). In other words, where informal norms conflict with the formal institutions, enforceability and implementation of these rules is more likely to become unsuccessful or incomplete. ${ }^{2}$

The adoption of market reforms in transition economies has attracted a great deal of attention from economists. Yet despite a rich literature on market-institutional transition, few empirical works have focused on the role of informal institutions as a determinant of reform performance. The existing research has largely focused on the linkage among reforms, macroeconomic performance, initial conditions, and measures of various political variables and constraints (see, e.g., Campos and Horváth, 2012; Falcetti et al., 2006, 2002; Fidrmuc, 2003; Merlevede, 2003; Fish, 1997). More recent exceptions examine the impact of resource and institutional endowments, religion, public support, and European Union (EU) integration (BenYishay and Grosjean, 2014; Landier et al., 2008; Di Tommaso et al., 2007; Beck and Laeven, 2006; Kim and Pirttilä, 2006). ${ }^{3}$

I build on these studies and provide, to my knowledge, the first direct evidence of the relationship between specific cultural/cognitive models and the extent of market reform in transition economies. Based on an unbalanced panel of 21 transition economies over the 1989-2001 period, I find that the cultural traits of individualism and low tolerance for an unequal distribution of power significantly moderated the effectiveness of democratization in promoting market reform.

The remainder of the chapter proceeds as follows. Section 2.2 outlines related literature and the theoretical considerations on the role of informal norms in formal institutional change. Sections 2.3 and 2.4 outline the empirical methodology and describe the data. Sec-

\footnotetext{
${ }^{2}$ For more on a relationship between the changes in formal and informal rules in the context of transition, see Chavance (2008).

${ }^{3}$ See Grosjean (2011) and Dimitrova-Grajzl (2007) for more on the consequences of institutional/historical legacies in the countries of Central and Eastern Europe.
} 
tion 2.5 presents results, and section 2.6 sensitivity checks. Section 2.7 offers concluding remarks.

\subsection{Theoretical Considerations}

Economists agree that institutions matter, but the profession has only recently begun to unbundle the "black box" of informal institutions - the unwritten and privately enforced norms and constraints that shape repeated human interaction. As North (1992) observed at the time, "ideology plays no role in neoclassical economic theory" (p. 477). However, at least since the seminal work of Weber et al. (1930), social scientists have recognized the importance of informal institutions in accounting for the differences in economic outcomes. More recent empirical studies show that diverse informal institutions such as social capital (Tabellini, 2010; Guiso et al., 2004; Zak and Knack, 2001; Knack and Keefer, 1997), religion (Bjørnskov and Méon, 2013; Guiso et al., 2006; McCleary and Barro, 2003), and individualism (Gorodnichenko and Roland, 2016, 2015, 2011; Klasing, 2013; Licht et al., 2007) matter for institutional and economic performance. ${ }^{4}$

Social scientists generally regard culture as a stable and self-perpetuating system of shared patterns of behavior, preferences, customs, norms, and beliefs that is transmitted primarily vertically, from parents to children. If culture is rooted in history and hence persistent, then it determines socio-economic development more so than the other way around (Beugelsdijk et al., 2015, p. 226). While in the long-run, economic and political development certainly feed back into cultural changes, social norms developed over centuries tend to remain "locked in" and constrain the future development of formal institutions, norms of governance, and allocation of scarce resources (Williamson, 2000). In other words, while simultaneity is a concern, institutional change is path-dependent, and the evolution of formal institutions may be in large part conditional on the set of existing informal institutions.

Complementarity between informal and a proposed set of new formal institutions is regarded as a major determinant of success in formal institutional change. Pejovich (2003)

\footnotetext{
${ }^{4}$ For an exhaustive review of literature on the interplay between culture and socio-economic outcomes, see Roland (2015) and Alesina and Giuliano (2015).
} 
and Voigt and Engerer (2002) highlight the role of transaction and coordination costs of acceptance, monitoring, and enforcement of formal institutions. Where the newly introduced formal institutions are in conflict with existing informal ones, the magnitude of these costs will be larger, making it more difficult for formal institutions to take root. Their findings suggest that formal institutions that are put in place from above (or by fiat) will often be ineffective. In a related strand of literature, Boettke et al. (2008) provide a theoretical framework for understanding institutional path dependence, and create a new taxonomy of institutions based on their "stickiness." Within this framework, the success or failure of newly introduced formal institutions will be a function of how well they map onto local knowledge, skills, culture, and norms that spontaneously emerge from repeated life interactions. ${ }^{5}$

Apart from costs in implementing new formal institutions, the dominant cultural values can also determine underlying worldviews and social preferences for different institutional arrangements. In this context, adherence to certain cultural worldviews informs and prescribes behaviors that legitimize corresponding sets of social relations and institutions (Rosenbaum, 2001, p. 906). According to the Grid-Group theory in cultural anthropology (Thompson et al., 1990), an individualistic mindset takes life as a net-positive game and cultivates beliefs that discrepancies between material needs and scarcity can be overcome through individual efforts rather than central planning. ${ }^{6}$ In that respect, an individualistic mindset may provide for a fertile soil for the introduction of private property rights and markets as the "institutionalized form of the invisible hand" (Rosenbaum, 2001, p. 900). An egalitarian way of life teaches that resource redistribution is a zero-sum game; total amount of available resources cannot be increased, so individual efforts aimed at personal gains necessarily create inequalities and are hence unwelcome, whereas a hierarchical mindset presupposes that needs and resources must be managed top-down (by experts and hierarchical organizations) without interference from individual decision-making (p. 900).

Based on the foregoing considerations, this paper conjectures that historically rooted cultural attributes played a role in determining the extent of transition market reform. Early

\footnotetext{
${ }^{5}$ For more on the interplay between formal rules, informal rules, and economic performance, see Winiecki (2001).

6 "Grid" here refers to how individuals within a society take on different roles given their similarities or differences in skills or abilities. "Group" refers to the degree of mutual embeddedness and bond of individuals within a society.
} 
post-socialist countries exhibited significant variation in the pace of dismantling of centralized economic structures characterized by a lack of private property, government control over all aspects of economic activity, and little freedom of choice and exchange. One possible avenue for exploration in this direction may lie in understanding that a sustained market-based institutional change requires not just an introduction of new formal rules and laws, but also acceptance of an entirely new ethos promoting as main values meritocracy, competition, as well as acceptance of the possibility of previously unprecedented economic phenomena such as income inequality, employment uncertainty, and hard budget constraint. Whether market reforms will be implemented may well depend on whether policymakers anticipate that proposed changes in the formal "rules of the game" will be welcomed or decried by broad cross-sections of society. ${ }^{7}$

In summary, existing research stresses that successful institutional changes are largely conditional on the proximity between the proposed formal and existing informal institutions. If formal institutions are grounded in and compatible with local culture, they are more likely to become commonly accepted and sustained. Given the transformative nature of institutional change during transition, any evidence on the impact of culture on formal institutional reform might be evident there with high clarity. Did individualistic countries more easily develop a national consensus to undergo market transition? Did societies less comfortable with the uncertainties of transition resist market reforms? An answer in either direction can add to the understanding of the variation in reform performance amongst these countries.

\footnotetext{
${ }^{7}$ Related to present arguments, North (2005) noted in a 1997 lecture to UNU-WIDER titled The Contribution of the New Institutional Economics to an Understanding of the Transition Problem: "If the institutional matrices of economies did not result in path dependence (that is, were not characterized by complementarities, economies of scope, and network externalities) and if instrumental rationality characterized the way choices were made, then institutions would not matter, and overnight the policy maker could impose efficient rules upon an economy and overnight alter its direction to a productive economy." Further, "The Eastern European demise of communism in 1989 reflected a collapse of the perceived legitimacy of the existing belief system and consequent weakening of the supporting organizations. The result was the destruction of most of the formal institutional framework, but the survival of many of the informal constraints. Policy makers were confronted not only with restructuring an entire society, but also with the blunt instrument that is inherent in policy changes that can only alter the formal rules but cannot alter the accompanying norms and even have had only limited success in inducing enforcement of policies" (p. 16).
} 


\subsection{Empirical Framework}

The empirical analysis draws from an unbalanced panel of 21 transition countries $(N=$ 21) observed over the time period 1989-2001 $(T=13) .{ }^{8}$ The first decade of transition, on which this paper primarily focuses, was marked by a gradual dismantlement of command economic structures through liberalization of the economy and privatization of state-owned enterprises. Following the loosening of the political grip by central communist parties in and around 1989, the nations behind the Iron Curtain gained the rights of self-governance and multi-party pluralism that allowed for participation of reform-minded interests in the political arena. The implementation of structural reforms during this period and later on has been linked to long-run increases in living standards and, later on, the EU accession of many former socialist states. ${ }^{9}$

In addition to economic reforms, the political transition during the 1990s brought about the abolishment of the one-party system as well as the emergence of political interests whose survival became contingent on conforming to the preferences, worldviews, and ideology of the voters. Given the historical and cultural diversities of transition countries, one might expect that voter preferences likewise differed between them. Indeed, in an early comparative study on transition performance, Fish (1997) finds that the extent of reforms at the end of 1995 was significantly influenced by the outcome of the first post-communist elections. As reform adoption is ultimately the matter of policy, i.e., political will and government efforts, the interplay between the democratic process and voter characteristics/preferences may play an important role in explaining the cross-national variation in reform adoption.

A society's culture can act as a potential determinant of voting choices and outcomes by informing voters' worldviews and preferences, and by extension, government's reform efforts. However, as this paper concerns with accounting for the evolution of reform paths over time,

\footnotetext{
${ }^{8}$ These countries are: Albania, Armenia, Azerbaijan, Belarus, Bulgaria, Croatia, Czech Republic, Estonia, Georgia, Hungary, Kyrgyzstan, Latvia, Lithuania, FYR Macedonia, Moldova, Poland, Romania, Russia, Slovakia, Slovenia, and Ukraine. Due to data limitations, the remaining transition countries of Bosnia, Kazakhstan, Serbia, Tajikistan, Turkmenistan, and Uzbekistan are omitted from the analysis.

${ }^{9}$ In a meta-analysis, Babecky and Havranek (2014) review 60 empirical studies since 1996 and reaffirm the positive effect of reforms on long-run economic growth in transition economies. Eleven transition economies joined EU in three subsequent enlargements in 2004, 2007, and 2013, while four more are either candidates or currently negotiating.
} 
then culture as a stable (or at least highly persistent) phenomenon cannot by itself explain the within variation of reform adoption. The assumption therefore is that culture influences reform efforts only as it participates in the political process through appropriate legislative and executive channels. Hence, the nature of political liberalization (democratization) in transition countries may be especially consequential for its effectiveness on encouraging market reform.

Although recent empirical literature finds mixed support for the hypothesis that democracy encourages regulatory reform around the world (Amin and Djankov, 2014), in the case of transition countries the linkage between democratization and market reform is considered as robustly positive (Fidrmuc, 2003). Yet as Fidrmuc (2003) notes, "one can only speculate why democracy encourages liberalization" (p. 601). ${ }^{10}$ The underlying mechanism in the relationship between democracy and market reforms remains not fully understood, especially in light of the ambiguous effect of democracy on economic development (Barro, 1996).

At the very least, democracy works to enhance government accountability and to facilitate monitoring of government actions by citizens. However, this description says little about possible implications of the establishment of democratic institutions vis-à-vis reform adoption. The imposition of checks and balances on the executive branch and the predominance of the legislature in guiding policy is not likely to be sufficient in predicting a country's reform stance. Instead, one might be interested in the actual characteristics of the electorate that does the voting and monitoring; conditional on these characteristics, democratization may lead to different reform outcomes. This paper posits that one way to lend further context to democracy may lie in its interplay with informal institutions; i.e., that the effectiveness of democratization is a function of the underlying culture operationalized by said democratization.

Taking culture into account, democratization allows for voter preferences to marginally

\footnotetext{
${ }^{10}$ Fidrmuc (2003) further writes: "Hence, there are merits to simultaneous democratization and liberalization - democracy facilitates liberalization, which, in turn, improves growth performance. This is an important lesson for those transition economies that remain autocratic (e.g., China, Belarus, until recently, Serbia), those that may now be reversing the initial democratization (e.g., Russia under president Putin) in the hope of improving economic performance, as well as developing countries that may contemplate introducing greater democracy" (p. 602). Yet even after initially becoming democracies, some transition countries (e.g., Balkans) saw strong performance of anti-reform minded political parties in their respective parliaments, contributing to sluggish reform performance.
} 
"impose" themselves on policymaking by forcing the ruling elites to internalize the expected electoral costs of reform choices. Democratization in cultural environments more forthcoming of the changes brought about by market transition could be expected to speed up the adoption of market reforms. Conversely, democratization in environments hostile to market reforms may provide a disincentive for the government to introduce reforms. In that sense, if culture is to be considered as a stable societal characteristic over shorter periods, the impact of culture on reform efforts can only be observable indirectly, through its moderating effect on the process of democratization.

To test the above hypothesis, I estimate the following two econometric models:

$$
\begin{gathered}
R_{i, t}=\beta_{1} \text { Democ }_{i, t}+\beta_{2} \text { Cult }_{d, i}+\beta_{3} \text { Democ }_{i, t} \times \text { Cult }_{d, i}+\boldsymbol{\theta} \boldsymbol{X}^{\prime}+\beta_{0}+\nu_{i}+u_{i, t}, \\
R_{i, t}=\rho R_{i, t-1}+\beta_{1} \text { Democ }_{i, t}+\beta_{2} \text { Cult }_{d, i}+\beta_{3} \text { Democ }_{i, t} \times \text { Cult }_{d, i}+\boldsymbol{\theta} \boldsymbol{X}^{\prime}+\beta_{0}+u_{i, t},
\end{gathered}
$$

where $i$ and $t$ index country and year respectively, $R$ denotes reforms, $C u l t$ is a time-invariant cultural dimension $d$ in country $i$, Democ is a variable capturing the level of democracy, $\boldsymbol{X}$ is the vector of controls, and $u$ is the error term. Equation (2.1) follows the static panel specification that specifies the term $\nu$ as both the country-specific intercept (fixed effect) and as the error term (random effect). To check for robustness, Equation (2.2) introduces persistence by allowing for present reform level to be influenced by past efforts. Additionally, the presence of the lagged dependent variable serves to partially absorb the effects of other unobserved heterogeneity.

The rationale for the above specification is as follows. First, because culture is relatively stable (Roland, 2004), it cannot by itself influence reforms over time. The interaction with time-varying democracy variable extracts culture from the country fixed effect and indirectly lends it within-country variation, making it suitable for longitudinal analysis. Second, cultural attitudes as societal preferences cannot influence policy without active participation in the political process. In that respect, democracy acts as a plausible transmission channel for culture, whereby each step towards democratic consolidation brings the government closer to the electorate. In other words, if culture matters, it should matter more in democracies. ${ }^{11}$

\footnotetext{
${ }^{11}$ For example, Landier et al. (2008) also interact Polity IV with public opinions to tease out the causal
} 
Democracy is thus contextualized by the cultural environment from which it emerged. If a cultural characteristic does moderate the effectiveness of democracy on reforms, then the coefficient of the interaction term of interest should be significant at statistically usual levels.

The full marginal impact of democracy is given by the cross-partial derivative:

$$
\frac{\partial R_{i, t}}{\partial \operatorname{Democ}_{i, t}}=\beta_{1}+\beta_{3} \text { Cult }_{d, i} .
$$

In models with interaction terms the parameter estimates of interacted variables no longer represent unconditional marginal effects and the standard errors of each constituent term are of little individual interest. Instead, the standard error of interest of the marginal effect in Equation (2.3) is given by: ${ }^{12}$

$$
\hat{\sigma}_{\frac{\partial R}{\partial D e m o c}}=\sqrt{\operatorname{var}\left(\hat{\beta}_{1}\right)+C u l t^{2} \operatorname{var}\left(\hat{\beta}_{3}\right)+2 C u l t \times \operatorname{cov}\left(\hat{\beta}_{1} \hat{\beta}_{3}\right)} .
$$

The estimated analytical standard errors given by Equation (2.4) are then used to construct 90 and 95 percent confidence bands around the estimated average marginal effect (2.3). The marginal effects plots are given in the appendix.

To more thoroughly address the empirical question, two sets of panel estimators are employed: static (Equation 2.1) and dynamic (autoregressive) (Equation 2.2), which allows for checking the robustness of results of Equation (2.1) once past reform efforts are accounted for. The dynamic model is estimated using the linear generalized method of moments (system GMM) estimator developed by Arellano and Bover (1995) (AB) and Blundell and Bond (1998) (BB). ${ }^{13}$ The static panel models are fixed effects (FE), random effects (RE), and the mixed effects (ME) estimator, which contains both fixed and random effects. ${ }^{14}$

Different estimators come with different costs and benefits in examining longitudinal data. The FE model abstracts from all observed and unobserved time-invariant heterogeneity effect of opinions on economic outcomes.

${ }^{12}$ See Brambor et al. (2006) for a detailed discussion on the use of interaction terms in econometric analysis.

${ }^{13}$ In the presence of a lagged dependent variable as a regressor, the standard panel estimators are no longer consistent and introduce the dynamic panel bias, also known as the Nickell (1981) bias. The AB/BB estimator allows for consistent estimation in the presence of a lagged dependent variable.

${ }^{14}$ In the context of these models, fixed effects refer to the standard regression coefficients, while random effects imply either random intercepts or random slopes, or both. 
across countries (e.g., colonial and legal origins, historical circumstances, religion, ethnolinguistic fractionalization, etc.) and focuses on explaining only the variation within countries over time. ${ }^{15}$ Alternatively, the RE model incorporates information also from between-country differences, allowing for a consistent estimation of both time variant and invariant parameters if the conditional mean of $\mathrm{RE}$ disturbances given regressors is not significantly different from zero. Using the Hausman specification test, the two models are found to produce sufficiently similar estimates so that the use of RE is preferable to FE. ${ }^{16}$

The ME are a more elaborate class of RE models. In addition to taking into account the information from both within and between variation, they also allow for a more flexible modeling of the random component of the model. In this case, the random effect for each country is specified as a function of time whereby a random trend slope is assigned to each country. This specification allows for a more realistic assumption that countries experience different individual time trends. ${ }^{17}$

\subsection{Data}

\subsubsection{The Dependent Variable}

The extent of transition market reform is captured by newly developed structural reform indices (Campos and Horváth, 2012). The Campos and Horváth (CH) indices, measured on a 0-100 scale (originally 0-1) with higher values denoting greater reform efforts, represent a methodological improvement over the standard transition indicator developed by the European Bank for Reconstruction and Development (EBRD). Although the use of the EBRD indicator in empirical research has been widespread, this indicator has also been subject to criticism insofar as it represents the EBRD's subjective evaluation of countries' progress in reforms as compared against the reference point of a hypothetical industrialized market

\footnotetext{
${ }^{15}$ The AB / BB estimator similarly controls for time-invariant country characteristics by eliminating fixed effects using the Helmert transformation.

${ }^{16}$ Across all estimated specifications the Hausman test consistently fails to reject the null hypothesis of no systematic difference between fixed and random effects ( $p$-values between 0.22 and 0.90 ).

${ }^{17}$ Although parameter estimates are largely robust to the choice of estimator, the ME model serves as the preferred method used in constructing the conditional marginal effect plots.
} 
economy. $^{18}$

The $\mathrm{CH}$ indices represent narrower and more objective metrics for reforms that take into account an array of liberalizing policies under the direct purview of the state; in that respect, they rely not on subjective judgments but on clearly delineated reform inputs, i.e., on what the state has actually done (see appendix for the list of underlying policies). ${ }^{19}$ Unlike the EBRD indicator that describes reform adoption as a smooth process, the $\mathrm{CH}$ indices describe reform adoption with much greater unevenness, providing for a better approximation of reality. ${ }^{20}$

The three original $\mathrm{CH}$ subindices gauge reform progress in the areas of internal (price and wage), external (trade and openness), and ownership (privatization) liberalization. Unweighted average of the three areas was calculated to provide a total measure for market reform and a composite proxy for market-institutional change. Calculated this way, the average $\mathrm{CH}$ index mean and standard deviation from the largest regression subsample equal 47.19 and 25.43, respectively. The average $\mathrm{CH}$ index (Figure 2.1) directly relates to the degree of dismantlement of central planning and the economy's conversion to a market-based resource allocation. Figure ?? below depicts the relationship between real GDP growth rates and the level of average $\mathrm{CH}$ index for the sample in question. The simple scatter plot suggests that the relationship is unambiguously positive.

\subsubsection{Cultural Variables}

The specific mechanism through which informal institutions affect reforms depends on which aspect of culture we observe. Culture, unlike polled opinions, ought to be gauged in terms of broader cognitive models that remain relatively invariant to the influences of different socioeconomic factors over shorter periods. To this end, I use the highly aggregated measures

\footnotetext{
${ }^{18}$ The EBRD index measures reform progress in six different areas of reform as measured against the standards of advanced industrialized economies. The six areas are: large and small scale privatization, governance and enterprise restructuring, price liberalization, trade and forex system, and competition policy.

${ }^{19}$ To minimize measurement error, Campos and Horváth suggest that reform inputs should be separated from reform outcomes because they may come as a result of things other than the implemented reform policies (e.g., tariff levels and trade openness should not enter the calculation of external liberalization reform index together).

${ }^{20}$ For more on the relative benefits of using the $\mathrm{CH}$ indices and the underlying methodology, see Campos and Horváth (2012) and Campos and Horváth (2009) for the working paper version.
} 
of culture based on Hofstede and Hofstede (2001); Hofstede (1980) cultural dimensions. ${ }^{21}$ These dimensions identify common cultural strands that permeate all societies and classify their values into six mutually exclusive aspects of collective mentality: (i) individualism vs. collectivism, (ii) power distance, (iii) uncertainty avoidance, (iv) indulgence vs. restraint, (v) long-term orientation, and (vi) masculinity vs. femininity.

Hofstede's original research, since updated and greatly expanded, used factor analysis on survey responses from interviews with thousands of IBM employees in 30 countries during late 1960s and early 1970s to construct aggregated scores of cultural values and attitudes. Although not without criticism, Hofstede typologies "constitute by far the most used and cited cultural framework in international business, management, and applied psychology" (Alesina and Giuliano, 2015, p. 907). ${ }^{22}$ In economics literature, Hofstede dimensions have been used in many empirical works, such as those by Gorodnichenko and Roland (2015, 2011), Klasing (2013), and Licht et al. (2007, 2005), among others.

In order to ascertain the validity and stability of Hofstede cultural scores, Beugelsdijk et al. (2015) use World Values Survey (WVS) data collected between 1981 and 2008 in order to replicate five of the six cultural dimensions (excluding masculinity vs. femininity) across two non-overlapping generational cohorts born, on average, in 1941 and 1971, covering over 340,000 persons born between 1902 and 1958 (cohort 1) and after 1958 (cohort 2). Using correlation analysis, factor analysis, and reliability analysis, the authors reaffirm the validity of Hofstede's cultural dimensions noting that "Hofstede data...is as relevant now as it was when his work was first published" (p. 224), and that while some intergenerational cultural change can be observed within countries, relative cultural distances between countries remain overall stable over time.

With the exception of data on long-term orientation (for which more data points are available from Hofstede et al. (2010), this paper uses the Beugelsdijk et al. (2015) replicated

\footnotetext{
${ }^{21}$ Although some scholars find that traits relating to individuals' preferences towards the role of the state in the economy, honesty, and youth's trust in the government can be attributed to different legacies (or varieties) of socialist regimes (see Alesina and Fuchs-Schündeln, 2007; Dimitrova-Grajzl and Simon, 2010; Ariely et al., 2015), Roland (2004) suggests that the strong inertia of culture (in the form of overarching national values, beliefs, and ideological commitments) exerts a long-run persistent effect on the establishment and sustainability of political institutions.

${ }^{22}$ Other prominent data sets on aggregated cultural values are likewise available (e.g., Schwartz, 1994), but not used here due to data constraints.
} 
Hofstede scores in the empirical analysis in order to account for a broader cross-section of society, as well as to take advantage of a higher number of observations. ${ }^{23}$ To that end, the simple average of the replicated Hofstede values across the two cohorts is taken as the measure for the overall country culture score.

Within Hofstede framework, culture represents "mental programming" of a nation that takes decades to change (Hofstede et al., 2010). Individualism here refers to a culture of personal responsibility, self-actualization, and personal freedoms. Its opposite, collectivism, emphasizes responsibility towards a tight-knit community and calls for loyalty towards a cohesive group while subordinating own interests to the "common good." Individualistic societies to a greater extent value individual over common interests, greater universalism, encouragement of independent thinking and ideas, and personal choice.

With respect to the matters of the economy, Hofstede et al. (2010) note that "the weaker the individualism in the citizens' mental software the greater the likelihood of a dominating role of the state in the economic system" (p. 125). Individualistic persons may hence be more likely to want to prove themselves and claim reward for their efforts. A market-based order may particularly benefit them in that it operationalizes their ambition by tying income streams to the value of one's marginal product, allowing access to entrepreneurial activities, and enabling of private capital accumulation. The expectation is that more individualistic societies will be more likely to show support for transition reforms, and therefore that the impact of democracy will be reinforced in cultures ranking high on this dimension.

$$
\text { Hypothesis } 1: \frac{\partial R_{i, t}}{\partial \text { Democ }_{i, t}}=\beta_{1}+\beta_{3} \text { Individualism }_{i} \text {, where } \beta_{3}>0
$$

Power distance relates to the degree to which less powerful members of society accept and respect an unequal distribution of authority and power. In a narrower sense, power distance measures people's attitudes towards a person of authority at work and stance towards desiring an autocratic/paternalistic boss as opposed to a consultative, consensus-oriented one. In high power distance countries, centralization at work is popular and an ideal boss acts as a benevolent autocrat Hofstede et al., 2010, p. 76.

\footnotetext{
${ }^{23}$ For replicated Hofstede data, see working paper version (Beugelsdijk et al., 2013).
} 
However, as Hofstede et al. (2010) point out, correlations with power distance also extend beyond the workplace. At school and in family, students and children in high power distance countries tend to be more dependent on authority figures and are generally taught obedience to their elders and teachers (p. 72). In the matters of the state, high power distance cultures see hierarchy and authority as a basic fact of life and accept that "might prevails over right" is a legitimate source of power; as a result, citizenry in high power distance countries tends to be less politically engaged and less likely to resist the established hierarchies based on tradition and unearned privileges (pp. 77-79).

This emphasis on the acceptance and, sometimes, desire for inegalitarianism in authority appears antithetical to the more egalitarian and meritocratic order promoted in the market system. Furthermore, a culture of acceptance of rigid hierarchies may plausibly impede the dismantlement of the centralized system of governance existing under communism, where one paternalistic party (and its apparatchiks) sat at the top of the hierarchy pyramid, with the general populace largely locked out from the levers of power. Therefore, in high power distance transition countries, the entrenched socialist elements may have continued to hold considerable sway in politics even after the nominal collapse of centralized one-party rule. The expectation is that the impact on market reform of democratization is suppressed in high power distance countries.

$$
\text { Hypothesis } 2: \frac{\partial R_{i, t}}{\partial \text { Democ }_{i, t}}=\beta_{1}+\beta_{3} \text { PowerDistance }_{i} \text {, where } \beta_{3}<0
$$

Uncertainty avoidance refers to the degree to which a society feels threatened by unexpected or novel situations. Low tolerance for uncertainty correlates strongly with aversion toward the unknown and more pronounced anxieties in the face of ambiguity. Different is seen as dangerous and uncertainty as a threat to be fought. Cultures ranking highly on this dimension, all else equal, are generally slower to adapt to change and tend to deal with anxiety and stress through more pronounced regulation, distrust of foreigners, nationalism, stifling of innovation, and top-down authority.

Importantly, uncertainty avoidance differs from risk avoidance (Hofstede et al., 2010, p. 197). Whereas risk aversion is attached to a specific object or event with a certain 
probability of occurrence, anxiety associated with this cultural dimension has no object and uncertainty no affiliated probability. Once uncertainty is expressed as risk, anxiety becomes fear of specific, yet potentially manageable events or objects. Rather than reducing familiar risks, uncertainty avoiding societies seek reduction of overall ambiguity through desiring more predictable, structured, and interpretable situations, institutions, and experiences.

The market transition has by its very nature been highly uncertain process. The sudden introduction of market institutions brought about not simply economic ambiguities, but also an entirely novel way of life toward which uncertainty-avoiding societies could plausibly feel strong aversion. Price and wage liberalization, competition, mass privatization, and the introduction of hard budget constraints represented a general shift from state- to individuallevel responsibility in managing one's economic decisions and well-being. ${ }^{24}$ These changes likely exasperated anxieties in the face of uncertainty over the future of one's income and employment prospects.

Related to that argument, Fernandez and Rodrik (1991) link in a theoretical model the adoption of efficiency-enhancing reforms to the ex ante uncertainty about the future distribution of gains and losses post-reforms. This uncertainty in identifying winners and losers of reforms generates the "status quo bias" that prevents reforms from being adopted. Hence, the degree of uncertainty avoidance may plausibly act as one gauge of willingness to undergo market reforms. The prior is that the positive effect of democratization on reform adoption is suppressed with higher levels of uncertainty avoidance.

$$
\text { Hypothesis } 3: \frac{\partial R_{i, t}}{\partial \operatorname{Democ}_{i, t}}=\beta_{1}+\beta_{3} \text { Uncertainty Avoidance }_{i} \text {, where } \beta_{3}<0
$$

Countries ranking highly on the long-term orientation dimension tend to generally focus more on the future and less on immediate gratification. Higher degree of long-term orientation correlates with patience, thrift, and lower focus on leisure. Tradition and established practices in long-term oriented societies are less emphasized and societal change is accepted more readily. In that respect, one may expect that countries scoring high on this dimension may be more likely to view reforms as an investment in the future, and to endure the pains

\footnotetext{
${ }^{24}$ Additionally, Carvalho et al. (2016) show the negative effects of large-scale privatization in transition economies on measures of well-being.
} 
of transition for long-term gains offered by the market order.

On the other hand, the lower end of this dimension (short-term orientation) correlates with greater acceptance of meritocracy, promotion of personal achievement, and thinking for oneself as the core values of one's work ethic. The relationship among long-term orientation, democracy, and reforms adoption may therefore not be straightforward. Nevertheless, the basic assumption is that high levels of long-term orientation exert no inhibiting effect on democratization.

Hypothesis $4: \frac{\partial R_{i, t}}{\partial \text { Democ }_{i, t}}=\beta_{1}+\beta_{3}$ LongTermOrientation $_{i}$, where $\beta_{3} \geqslant 0$

Indulgence vs. Restraint refers to the level of gratification a society allows itself. Indulgent societies feature greater overall happiness, laxer social rules and norms, and more openness towards foreign cultures. Restrained societies are stricter with social norms and place higher importance on maintaining order in the nation. The relationship between market reforms and this dimension is also complex: on the one hand, more indulgent societies may be less willing to give up gratification to undergo the pain of reforms; on the other, restrained societies are likely to impose strict maintenance of order and hierarchical power structures inimical to the culture of the markets. I find no significant empirical results for this variable and do not discuss the matter further.

Figures 2.3-2.7 display simple bivariate correlations between cultural dimensions and end-of-period average reform levels in 2001. Linear best fit lines indicate, prima facie, that individualism and indulgence are positively, while power distance, uncertainty avoidance, and long-term orientation weakly negatively related with the average $\mathrm{CH}$ index. Correlations between different cultural dimensions are presented in Table 2.2.

\subsubsection{Control Variables}

The econometric models used in this paper follow similar baseline specifications used in the empirical transition literature, which include as control variables the level of political freedom/liberalization, real GDP growth rate, initial conditions at the onset of transition, and time trends (see, e.g., Falcetti et al., 2006, 2002; Merlevede, 2003; De Melo et al., 2001). 
For further sensitivity checks, the presence of armed conflict, EU accession dummy, and temporally lagged reform (in the dynamic panel specifications) are added to these models as additional controls.

Democracy levels are measured by the Polity IV index (Center for Systemic Peace). This variable gauges the level of democracy within political regimes on a scale from -10 (strong autocracy) to +10 (fully consolidated democracy) (Figure 2.2). In order to capture the countries' democratic capacity, the composite Polity IV index takes into account: (i) the competitiveness of executive recruitment, (ii) openness of executive recruitment, (iii) constraints on the chief executive, and (iv) competitiveness and regulation of political participation (Marshall et al., 2012). In this framework, a fully consolidated and mature democracy features unrestricted and fully competitive political arena as well as substantial constraints on the chief executive. ${ }^{25}$

Real GDP growth rate (World Bank World Development Indicators) is derived as annual percentage change of real GDP expressed in terms of constant 2005 U.S. dollars. The data on violent conflict are based on the information from the Major Episodes of Political Violence (MEPV) data set (Center for Systemic Peace). The MEPV data set provides information on interstate, societal, and communal violence and warfare. A binary dummy that equals 1 is assigned for each year in which a conflict resulting in over 500 deaths was observed, and 0 otherwise.

The binary EU accession dummy takes the value of 1 in years in which a transition country is undergoing the EU accession process, defined from the moment an application for membership was submitted. This dummy accounts for the total effect of EU integration on reforms. On the one hand, the EU stipulates a functioning market economy and democracy as the necessary conditions for membership; in that sense, the accession process may serve as an anchor for further institutional improvement in applicant countries. However, the acceptance of membership application by the EU may also discourage further reforms because the "carrot" of membership may not be as enticing during the candidacy stage of accession

\footnotetext{
${ }^{25}$ Note that the relevant metric for democracy levels is polity2, which treats interregnum periods as a part of the continuum. Countries that were a part of a unified state between 1989 and its breakup receive the polity2 score of that state (for example, Ukraine receives polity2 score of the USSR for 1989 and 1990, Czech Republic receives polity2 score of Czechoslovakia for 1989-1992).
} 
once increased access to EU structural funds is obtained.

The initial conditions, representing countries' "starting positions" in the transition process, consist of a set of 11 different variables that control for economic and institutional characteristics at the onset of transition. ${ }^{26}$ From data on these variables, country scores are captured by two principal components derived through factor analysis. Together the principal components explain 67 percent of the variation in initial conditions in terms of economic development, market familiarity, and macroeconomic distortions in or around 1989. Data on principle components are borrowed from Falcetti et al. (2002).

The first principal component (initial condition 1) is associated with the degree of market familiarity and initial macroeconomic distortions. The second principal component (initial condition 2) more closely correlates with state capacity and the initial degree of economic development inclusive of the "socialist overhang" commonly associated with overindustrialization in socialist economies. The principal components are time-invariant but they also enter regression equations interacted with the linear trend to allow for their effects to propagate or diminish in importance over time.

Lastly, trend and squared trend are introduced to account for nonlinearities in reform progress, as well as to address concerns regarding the possibility of spurious correlation. Figure ?? below displays the plot of the first (horizontal axis) and second (vertical axis) normalized principal component vectors for the 21 countries in the data set. See Table 2.1 for summary statistics of explanatory variables.

\subsection{Results}

Appendix Tables 2.3-2.7 report parameter estimates from eight specifications by four different estimators for Equations (2.1) and (2.2). The cultural dimensions enter regression equations centered and standardized around the sample mean. In all specifications, estimates

\footnotetext{
${ }^{26}$ These variables are: (i) GDP per capita in 1989, (ii) pre-transition growth rate, (iii) trade dependence on CMEA, (iv) degree of over industrialization, (v) urbanization rate, (vi) natural resources dummy, (vii) years spent under central planning, (viii) distance to EU, (ix) dummy for pre-transition existence as a sovereign state, (x) repressed inflation, and (xi) black market premium. Country scores obtained by multiplying each of the above variables with a factor loading. Initial conditions normalized to have the mean of zero. See Falcetti et al. (2002) and De Melo et al. (2001) for further discussion.
} 
are obtained using cluster (country) robust standard errors.

Of primary interest are the coefficients of the interaction term Democ $\times$ Cult, and the full marginal impact of democracy conditional on different cultural dimensions. Table 2.3 reports regression estimates for individualism vs. collectivism dimension. As per prior expectations, the coefficients of the interaction term for this dimension are positive and statistically significant across different estimators. The result holds even when controlling for past values of reform efforts.

The positive sign of the interaction term here implies that in more individualistic countries the effectiveness of democracy on promoting reforms is amplified. Based on Figure 2.8, at the highest observed individualism level, the positive impact of democracy is several orders of magnitude larger than near the point where the effect loses statistical significance. At the lower extremum of individualism, the marginal effect of democracy becomes negative, implying that democratization in highly collectivist cultures adversely affects market reform adoption, all else equal.

With respect to power distance (Table 2.4), the coefficient of the interaction term stays negative and statistically significant across different specifications. The positive marginal effect of democracy weakens with higher power distance, from two standard deviations of power distance below sample mean at its highest magnitude, until the effect vanishes at about half a standard deviation below sample mean (Figure 2.9). For extreme positive values of power distance (high tolerance for unequal dispersion of power), the effect of democracy likewise reverses and affects reform adoption negatively, all else equal.

Table 2.5 reports the results for the uncertainty avoidance dimension. In line with the expectations, higher uncertainty avoidance suppresses the effect of democracy on reform adoption, and this result similarly holds across specifications. Significant results for the overall $\mathrm{CH}$ index, however, are only found in the dynamic panel model. In static models, only the $\mathrm{CH}$ privatization subindex is significantly associated with this cultural dimension. At extremely high tolerance for uncertain situations, the positive effect on reforms of a unit increase of democracy is about three times as large as compared to uncertainty avoidance levels where the positive effect vanishes (Figure 2.10).

The results for the long-term orientation and indulgence vs. restraint dimensions are 
given in Tables 2.6 and 2.7, respectively. Significant positive result for long-term orientation is obtained only in the dynamic models (borderline significant at $p=0.102$ for the full controls specification). The coefficients for the interaction term for indulgence vs. restraint dimensions are of expected negative sign, but are statistically insignificant at usual levels.

Overall, the results are broadly consistent with the hypotheses, even after controlling for the presence of armed conflict, EU accession process, and other time-invariant characteristics such as institutional and economic heritage. A culture fostering individualistic worldviews may provide for a fertile soil for the emergence of markets. Where citizens prioritize the pursuit of private interest over common good, the demand for market based institutions is likely greater, and the political costs of reforms, enforcement, and monitoring by the government lower.

Alternatively, the preference for centralized economic and political systems is likely more pronounced in cultures scoring high on the power distance dimension. In these countries, the elites' turnover rate after the advent of democracy post-1989 may have been lower, allowing for the entrenched elements of the old communist guard to remain influential in policymaking and thus slow down reform progress. Casual observation seems to lend some support to this assertion. Whereas Czech Republic, a relatively low power distance country (power distance 0.50 standard deviations below mean) was quick to enact lustration laws banning former communist officials from political engagement, in Moldova, a relatively high power distance country (power distance one standard deviation above that of Czech Republic's), the Party of Communists of the Republic of Moldova won absolute majority in the 2001 parliamentary elections.

Uncertainty avoidance is also found to mute the positive effect of democracy, although statistically significant results were obtained mostly for privatization efforts (specifications 16). Cultures that exhibit low tolerance for the unknown may be more likely to resist policies that tend to disturb the status quo. Privatization was certainly one such policy. Introduction of the hard budget constraint in state-owned enterprises meant that inefficiencies and redundancies needed to be cut for continued operation. Mass layoffs following privatization were a major source of unemployment shocks and declining living standards for many, as well as anxiety for those that remained employed. 
The empirical results so far suggest that democracy's impact on market reform may not have been as robustly positive as previously hypothesized. In societies where culture fosters pursuit of individual interests, acceptance of uncertainty, and intolerance for traditional power hierarchies, democracy provided for a mechanism to tie the state apparatus to the will of the electorate that likely viewed the market order more favorably. Among cultures that foster contrary sentiments, democratization, at best, may not have necessarily generated popular pressures on the state to implement reforms. At worst, democratization generated perverse incentives for the political parties to compete in promoting the undoing any existing reform progress. For instance, such political parties enjoyed significant popularity in the Balkans during the 1990s and 2000s.

\subsection{Robustness Checks}

So far the empirical evidence suggests that the impact of democracy was significantly moderated by the cultural environment from which it emerged. In order to further corroborate the importance of culture in market transition, this section subjects the baseline results to sensitivity checks in three different ways: first, by employing a measure for transition countries' composite cultural similarity with the United States; second, by considering the confounding influence of social capital and its relationship with Hofstede cultural dimensions; and third, by teasing out the causal influence of culture on reforms using instrumental variable methods.

\subsubsection{Cultural Distance}

Table 2.8 introduces new empirical estimates from identical econometric specifications using cultural distance instead of individual cultural dimensions. Cultural distance $(C D)$ combines data from all five cultural dimensions to establish the degree of composite cultural relatedness between different country pairs. The computed cultural distance score between countries $i$ 
and $j$ is based on the well-known formula developed by Kogut and Singh (1988):

$$
C D_{i}=\frac{1}{5} \sum_{n=1}^{5}\left[\left(I_{i, n}-I_{j, n}\right)^{2} / V_{n}\right]{ }^{27}
$$

where $n$ is one of the five cultural dimensions, $i$ is a transition country, $j$ is the reference country, and $V$ is the sample (including country $j$ ) variance of the $n$th cultural dimension. In this paper country $j$ is chosen to be the United States due to its long and established history of having market institutions. In that respect, the assumption is that greater cultural distance to the United States also speaks to country $i$ 's potentially lesser familiarity with the market system and lower proclivity for reform.

Similarly to other cultural variables, $C D$ is time-invariant and standardized around the sample mean, and enters the regression equations interacted with the time-variant Polity IV democracy levels. ${ }^{28}$ The expectation is that the effectiveness of democratization on reforms will be diminished with greater cultural distance from the U.S.:

$$
\text { Hypothesis } 5: \frac{\partial R_{i, t}}{\partial \operatorname{Democ}_{i, t}}=\beta_{1}+\beta_{3} C D_{i} \text {, where } \beta_{3}<0 \text {. }
$$

The empirical results from Table 2.8 provide support for the hypothesis that cultural dissimilarity to the U.S. matters for the effectiveness of democratization on market reform adoption.

Hence, individual cultural dimensions likely operated synergistically in their total effect on reform adoption: in countries ranking highly on individualism and low on power distance and uncertainty avoidance (i.e., countries more culturally similar to the United States), market reforms proceeded more robustly after democratization, all else equal. The models predict that countries which democratized more extensively will also be more economically reformed if they possess the "right" mix of cultural attitudes. The FSU countries, which on average lagged behind those in CEE in both political and economic liberalization, exhibited,

\footnotetext{
${ }^{27}$ Note that uncertainty avoidance data for Kyrgyzstan are missing; for this country, cultural distance score has been computed using the remaining four dimensions of individualism, power distance, long-term orientation, and indulgence vs. restraint.

${ }^{28}$ The mean and standard deviation of the non-standardized $C D$ scores are 6.19 and 1.94, respectively, with the minimum of 1.99 and the maximum of 9.49 .
} 
on average, relatively higher levels of collectivism, uncertainty avoidance, and power distance. Among some of the CEE countries that democratized relatively quickly and fully after 1989, those more culturally similar to the U.S. (e.g., Czech Republic, Croatia, Poland) generally tended to be more reformed by 2001 than more culturally distant countries (e.g., Bulgaria, Romania).

\subsubsection{Social Capital}

By now a sizable literature links economic development with the amount of social capital within countries (see, e.g., Tabellini, 2010; Zak and Knack, 2001; Knack and Keefer, 1997. Introduced by Bourdieu in 1972 and widely popularized by Putnam et al. (1994), social capital is broadly defined as the collection of social and civic behaviors, beliefs, and norms that facilitate cooperation, reduce collective action problems, and encourage socially valuable activities between individuals (Nannicini et al., 2013; Guiso et al., 2010; Durlauf and Fafchamps, 2005).

Chief among these traits is social trust, which enables individuals to more readily interact, engage in contracts, and solve prisoner's dilemma type problems, leading to more efficient economic outcomes (Tabellini, 2010). ${ }^{29}$ Most empirical studies on social capital use as proxies for social capital different measures of generalized trust toward others whom the survey respondents do not know (Alesina and Giuliano, 2015). Higher levels of trust within societies also coincide with well-established norms of reciprocity that require individuals to regularly follow through on their commitments.

How do Hofstede cultural dimensions relate to aspects of social capital such as trust? Although there is some conceptual overlap, ${ }^{30}$ norms of trust and reciprocity more closely resemble the Northian notion of behavioral constraints, while the more highly aggregated Hofstede cultural dimensions may also envelop societal preferences for particular social or

\footnotetext{
${ }^{29}$ Other proxies for social capital in the empirical literature included blood donations or electoral participation rate.

${ }^{30}$ For example, Gorodnichenko and Roland (2012) note that more individualistic societies are also more trusting in part because the individualistic independent self interacts with everyone in the same way whereas the collectivist self assumes different behaviors when interacting with in-group relative to the out-group with whom relationships are less important of frequent (p. 17). Hofstede et al. (2010) note that a related individualism dimension correlates with trustworthiness and tolerance of others across countries.
} 
institutional orders. In the context of transition, the degree of trust can inform the state's estimate of the transaction and enforcement costs of supplying market-based institutions that delegate economic transactions and cooperation to freely acting individuals and firms. However, trust operates primarily at a passive level (between citizens only), and hence may be less likely to directly influence political demand for institutions, as well as normative views on governance and policymaking.

To check whether cultural dimensions exert influence over reform adoption independently of social capital, I introduce as an additional control variable a measure of generalized trust within societies obtained from the WVS database. The WVS survey question (item A165) asks: Generally speaking, would you say that most people can be trusted or that you can't be too careful in dealing with people? Trust levels within transition countries are measured by the share of people who responded that most people can be trusted (inclusive of the small number of people who responded with "Don't know").

Since 1981, the WVS conducted surveys over several 5-year waves during which a nationally representative sample of people is contacted within a country. ${ }^{31}$ Because surveys may be administered across countries in different years within the same wave, the data on trust for transition countries are unbalanced and highly irregular. To provide for the broadest possible measure of trust levels, I pool the data for the most relevant time frame from up to two consecutive waves ranging between 1990 and 2004. Hence, the percentage of trusting individuals Trust is a time-invariant metric for generalized social trust during the early period of market transition. ${ }^{32}$

The truncated results in Table 2.9 show that the coefficient estimates of variable Trust never enters statistically significantly in static panel models (fixed, random, and mixed effects), and that previously obtained results hold. However, trust is positively and significantly associated with reform efforts in most dynamic panel specifications. Of these, the statistically significant results for the effects of uncertainty avoidance vanish once trust is accounted for.

\footnotetext{
${ }^{31}$ These waves took place during the time periods 1981-1984, 1990-1994, 1995-1998, 1999-2004, 2005-2009, and 2010-2014. Only 1990-1994, 1995-1998, and 1999-2004 waves are used in the calculation of trust scores for countries in the study.

${ }^{32}$ Trust unconditional mean $=26.3$ percent, st. dev. $=6.1$ percent
} 


\subsubsection{Estimates}

Lastly, a potential source of bias may arise from the feedback effect from economic reforms to democratization, although recent evidence from a wide sample of countries shows that is not the case. ${ }^{33}$ Nevertheless, to find a more exogenous source of variation for democracy, I follow a related approach as in Giuliano et al. (2013) in employing a country's neighbors' democracy scores in instrumenting for domestic democracy. The intuition is that the stability of fledgling democracies across post-communist Europe and Asia will be influenced by political experiences of their neighbors. ${ }^{34}$ Furthermore, while democracy in neighboring countries may affect domestic democracy, it is unlikely to influence the adoption of domestic market reforms directly.

In order to construct an instrument for domestic Polity IV index, I calculate a convex combination of $N$ contiguously neighboring countries' Polity IV scores as the instrument for domestic democracy in country $i$ :

$$
\begin{gathered}
\operatorname{Democ}_{i, t}^{I V}=\sum_{j=1}^{N} \alpha_{i, j} \operatorname{Democ}_{j, t}, \\
\sum \alpha_{i, j}=1,{ }^{35}
\end{gathered}
$$

where weights $\alpha$ are shares of neighbor $j$ 's borders in total border length of country $i{ }^{36}$ The idea is that countries sharing longer common border also carry greater importance in influencing each other's democracies. In that sense, one might expect that Poland's democracy will be to a greater extent influenced by neighboring Germany than by likewise neighboring Russia's Kaliningrad Oblast.

Another way to mitigate concerns over endogeneity of culture is to strengthen the argument for its temporal stability by considering only the cultural attitudes of the 1941

\footnotetext{
${ }^{33}$ See, e.g., Giuliano et al. (2013); also, Grosjean and Senik (2011) for a similar argument regarding transition countries.

${ }^{34}$ See Leeson and Dean (2009) for a related argument on the "contagiousness" of democracy across the world.

${ }^{35}$ Note that countries belonging to a federation before its dissolution share the same Polity IV score. After the common federation's break-up, the countries' domestic democracy score is re-calculated to reflect the weighted average.

${ }^{36}$ The data on border lengths obtained from CIA World Factbook.
} 
generational cohort. The trade-off is that although fewer respondents are used to compute the countries' overall culture scores, the focus on the elder cohort decreases the likelihood of cultural change as worldviews of people born between 1902 and 1958 will be less malleable than those of younger generations during the observed 1989-2001 time period.

In all structural equations the domestic Polity IV variable appears twice: standing alone and also as a constitutive part of the interaction term with other cultural dimensions. Hence there are two variables to be instrumented, Democ and Democ $\times C_{u l t}^{1941}, 37$ and two excluded instruments $D e m o c^{I V}$ and $\operatorname{Democ}^{I V} \times \mathrm{Cult}_{d}^{1941}$, in an exactly-identified model. Table 2.10 reports second-stage 2SLS estimates for four cultural dimensions (individualism, power distance, uncertainty avoidance, and long-term orientation), each estimated using fixed (FE) and random (RE) effects, for the total of eight specifications. ${ }^{38}$

The results mostly conform to those presented in the preceding section. However, in contrast to the dynamic model of Equation (2.2), the coefficient of the interaction term between long-term orientation and democracy is negative and statistically significant. ${ }^{39}$ Moreover, similar coefficients for uncertainty avoidance are statistically insignificant in both FE and RE models. (The same holds true for when the privatization $\mathrm{CH}$ subindex is used as the dependent variable.)

On the other hand, the coefficients and significance of the interaction terms with individualism and power distance are robust to these alternative specifications. In fact, using the cultural dimension values from the 1941 cohort, magnitudes of the effects are significantly larger, sometimes several times the size compared to those from the inter-generational simple average. To the extent that voting preferences and worldviews of the older cohort carry greater weight in influencing reform policy, the results from original specifications might be understated.

\footnotetext{
${ }^{37}$ The results remain unchanged if the original interaction term between averaged cultural score and democracy is specified as endogenous.

${ }^{38}$ First stage results available upon request. Recall that no generational data exist for long-term orientation; for this dimension, the overall culture score is used.

${ }^{39}$ However, the marginal effect of democracy conditional on the level of long-term orientation is not statistically different from zero across given levels of this cultural dimension.
} 


\subsection{Conclusion}

During the last decade of the 20th century, countries across Central-Eastern Europe and Central Asia shed their centralized political and economic systems and began their transition towards markets and democracy. Yet even early during transition, these countries differed in terms of the pace and extent of the adoption of market reforms. The literature on institutions has emphasized the role of informal norms as a complement to the introduction of new formal rules or institutions. Pejovich's analysis of culture's role as a determinant of transition outcomes provides a useful theoretical framework for the understanding of the necessity of the "capitalistic mindset" in the successful creation of an order based on free markets and private property. In this framework, if the existing culture clashes with proposed formal market institutions, the transaction costs of adopting new formal rules will be higher.

This paper builds on the literature on transition market reforms to provide an empirical account of whether and how different cultural dimensions affected the creation of market institutions in transition economies. In doing so, I examine the effects of Hofstede cultural dimensions on reform performance in an unbalanced panel of 21 transition countries observed between 1989 and 2001. The basic premise is that culture affected reform adoption by moderating the impact of democratization; conditional on a country's predominant cultural values, the effectiveness of political on economic liberalization differed.

The overall results provide empirical evidence in support of Pejovich's "interaction thesis:" culture mattered in the process of market transition. The results of the preceding sections are overall indicative of the predominance of two cultural dimensions in influencing institutional transition from centralized to market economy. Where culture fosters behavioral incentives that favor pursuit of private interests and desire for political egalitarianism, the pressures on the government to implement reforms are likely higher.

What are the implications for the behavior of political elites? In economically and politically unfree countries where leadership is aware of prevailing cultural attitudes, the reform-minded executive may feel more comfortable implementing political and economic liberalization in tandem if local culture exhibits more friendly attitudes toward economic 
reform. ${ }^{40}$ In societies where culture imposes additional costs in implementing reforms, the reform-minded executive can find democratization to decrease prospects of incumbency. In that case, the executive may withhold from political liberalization and proceed with economic reforms only. Alternatively, the executive may choose partial democratization but engage in populist rhetoric or ideological engineering in an attempt to change the underlying culture.

The results from this chapter suggest that democratization may be the underlying transmission channel connecting culture to economic development, and that culture is one way to contextualize the impact of political on economic reform. Naturally, one must refrain from value judgments when discussing an "ideal" mix of cultural attitudes. As in Gorodnichenko and Roland (2011), the same caveat applies here: there are no "best" cultures, only the implied trade-offs in undergoing as drastic of an institutional change as was the market transition.

\footnotetext{
${ }^{40}$ In a comparative study on the effects of democratization on the support for market economy (and market development on the support for democracy) in 28 transition countries in the year 2006, Grosjean and Senik (2011) provide empirical evidence in support of the former, but not the latter. They suggest that the demand for democracy is not stimulated through market development, but rather that the public support for a market economy comes about as the result of democratization. Hence, political followed by economic liberalization appeared to have been the recommended reform sequencing for countries at the onset of market transition. Using longitudinal data, the present study extends their conclusion to argue that the effectiveness of such sequencing is conditional on the levels of several stable cultural attributes that may, broadly speaking, be conceptually linked to the support for creation of market institutions.
} 


\subsection{Appendix}

Policy input variables underlying the CH indices (Source: Campos and Horváth, 2012):

\section{Internal liberalization index}

1. Number of goods subject to price regulation (basket of 15 goods)

2. Wage regulation

\section{External liberalization index}

1. Compatibility with Article VIII

2. Controls on commercial credit

3. Controls on foreign direct investment

4. Controls on liquidation of FDI

5. Documentation requirements for release of foreign exchange for imports

6. Exchange rate taxes

7. Export duties as \% of tax revenue

8. Export licenses

9. Export taxes

10. Import licenses and quotas

11. Import tariff rate

12. Interest rate liberalization

13. Investment transactions

14. Multiple exchange rates

15. OECD membership

16. Permission for foreign exchange accounts held abroad by residents

17. Permission for foreign exchange accounts held domestically by residents

18. Permission of foreign exchange accounts for non-residents

19. Repatriation requirements

20. Repatriation requirements for invisible transactions

21. Surrender requirements

22. Surrender requirements for invisible transactions

23. Tariff code lines 


\section{Privatization index}

1. Share of small firms privatized

2. Total number of enterprises privatized

3. Total number of small and medium-sized enterprises privatized

4. Total number of large enterprises privatized

5. Share of foreign-owned banks in total number of banks

6. Total number of private enterprises 
Table 2.1: Descriptive statistics, explanatory variables

\begin{tabular}{lcccc}
\hline \hline Variable & Mean & St. Dev. & Min & Max \\
\hline Individualism vs. Collectivism & 42.6 & 78.1 & 17.0 & 76.0 \\
Power Distance & 78.1 & 10.6 & 52.5 & 99.0 \\
Uncertainty Avoidance & 81.9 & 10.6 & 50.5 & 97.0 \\
Long-Term Orientation & 65.1 & 13.3 & 38.0 & 86.0 \\
Indulgence vs. Restraint & 39.5 & 12.6 & 11.0 & 62.5 \\
Polity VI Democracy & 4.8 & 5.1 & -9 & +10 \\
Real GDP Growth (\%) & -0.93 & 9.62 & -44.90 & 13.30 \\
Armed Conflict & 0.16 & 0.36 & 0 & 1 \\
EU Accession & 0.29 & 0.45 & 0 & 1 \\
Initial Condition 1 & -0.38 & 2.06 & -3.53 & 3.24 \\
Initial Condition 2 & 0.21 & 1.35 & -3.08 & 1.94 \\
\hline \hline
\end{tabular}

Notes: descriptive statistics consistent with regression subsample observations in specification (4). $N=230$. 
Table 2.2: Cultural dimensions correlation matrix.

\begin{tabular}{lccccc}
\hline \hline & IND & PDA & UA & LTO & IR \\
\hline Individualism vs. Collectivism & 1 & & & & \\
Power Distance & -0.5324 & 1 & & & \\
Uncertainty Avoidance & 0.0936 & -0.1519 & 1 & & \\
Long-term Orientation & 0.055 & -0.1163 & -0.0327 & 1 & \\
Indulgence vs. Restraint & 0.2131 & -0.3811 & -0.1987 & -0.4005 & 1 \\
& & & & & \\
\hline \hline
\end{tabular}

Notes: $\mathrm{IND}=$ individualism vs. collectivism; $\mathrm{PDA}=$ power distance; $\mathrm{UA}=$ uncertainty avoidance; LTO $=$ long-term orientation; IR $=$ indulgence vs. restraint. 
Figure 2.1: Evolution of the CH reform index by country, 1989-2001.
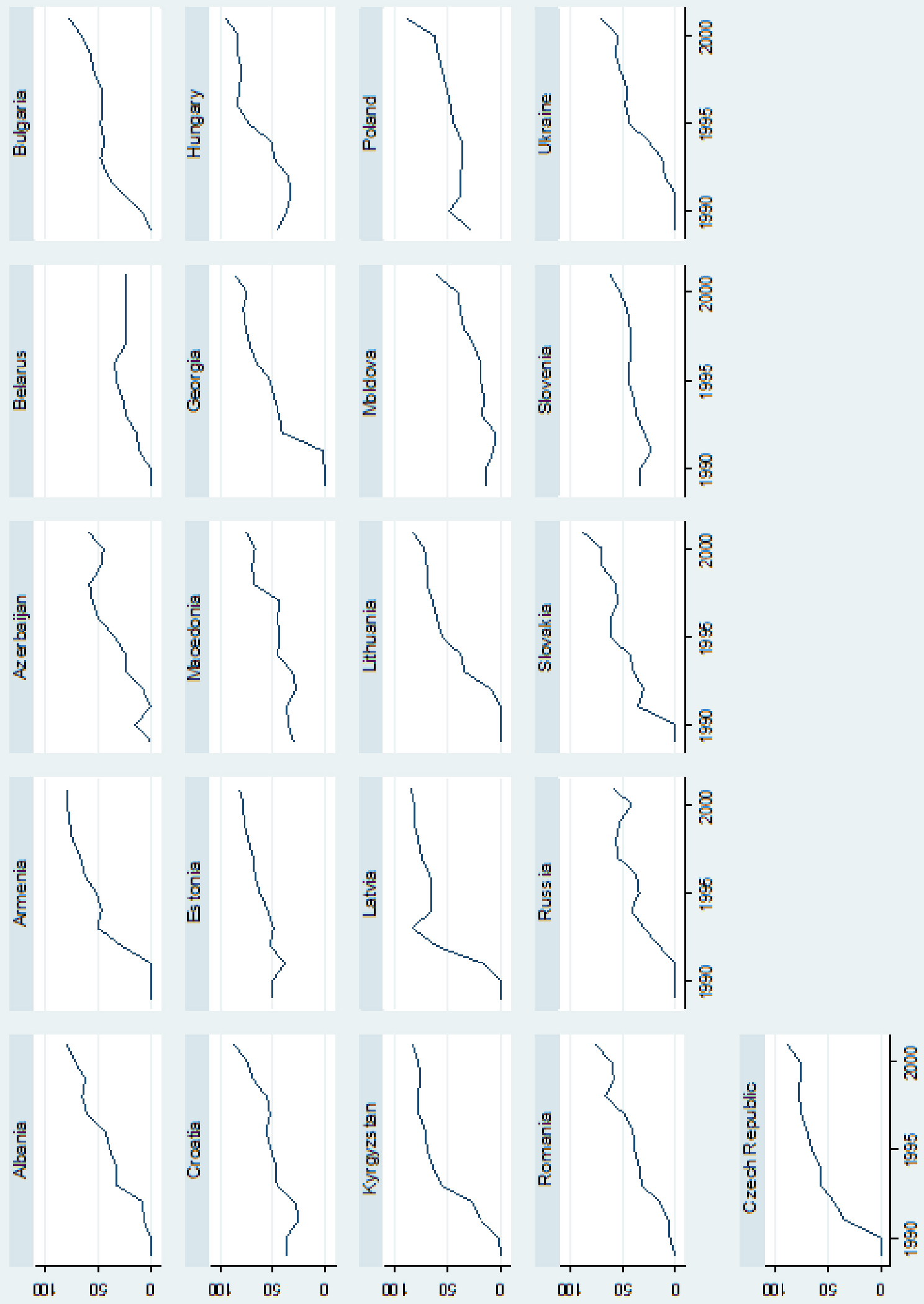
Figure 2.2: Evolution of democracy as measured by the Polity IV index by country, 19892001.
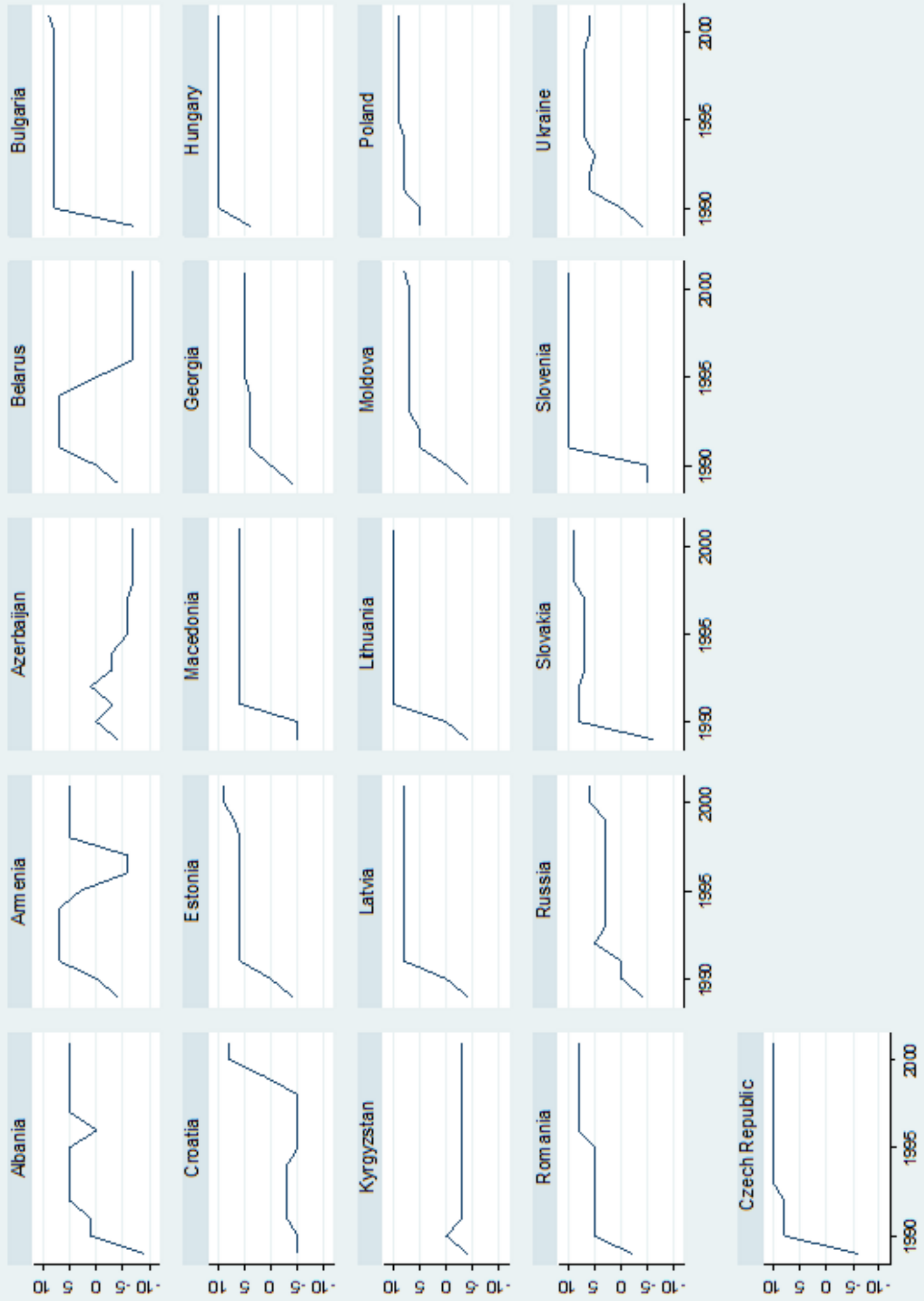
Figure 2.3: Scatter plot of the relationship between $2001 \mathrm{CH}$ index (vertical axis) and individualism vs. collectivism (horizontal axis).

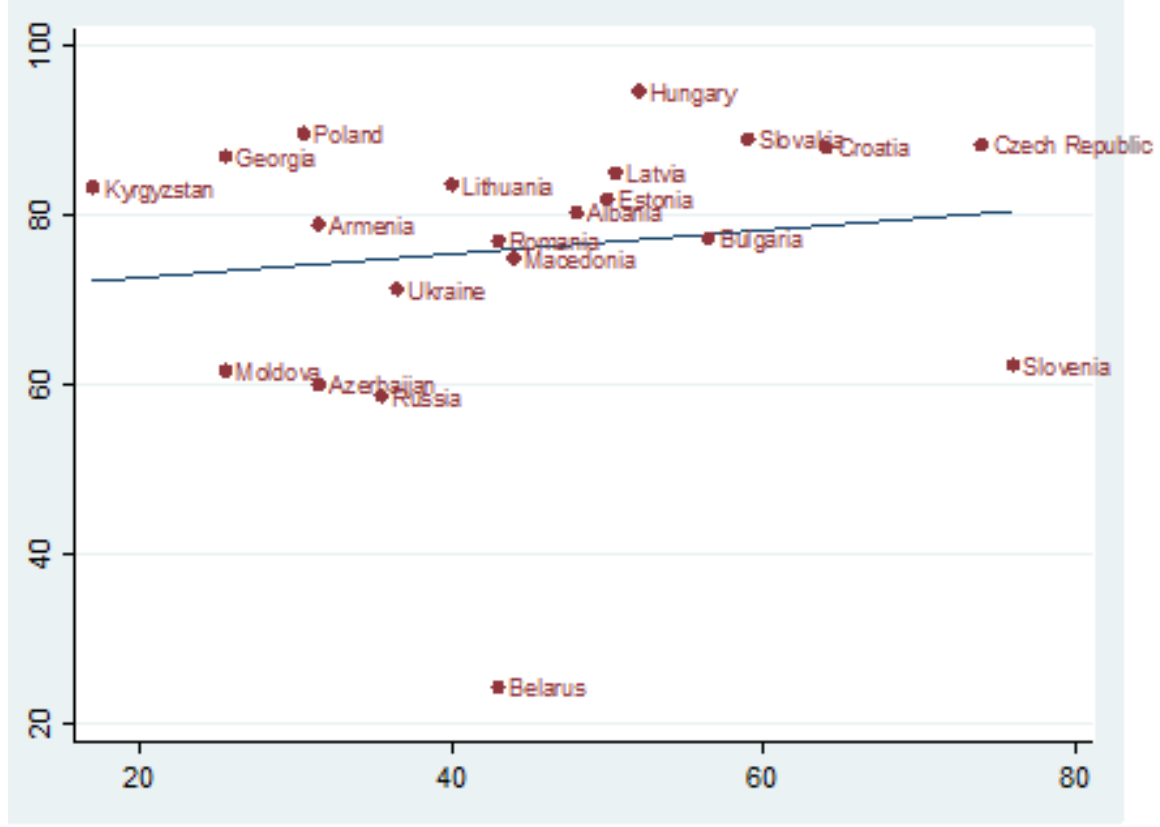


Figure 2.4: Scatter plot of the relationship between $2001 \mathrm{CH}$ index (vertical axis) and power distance (horizontal axis).

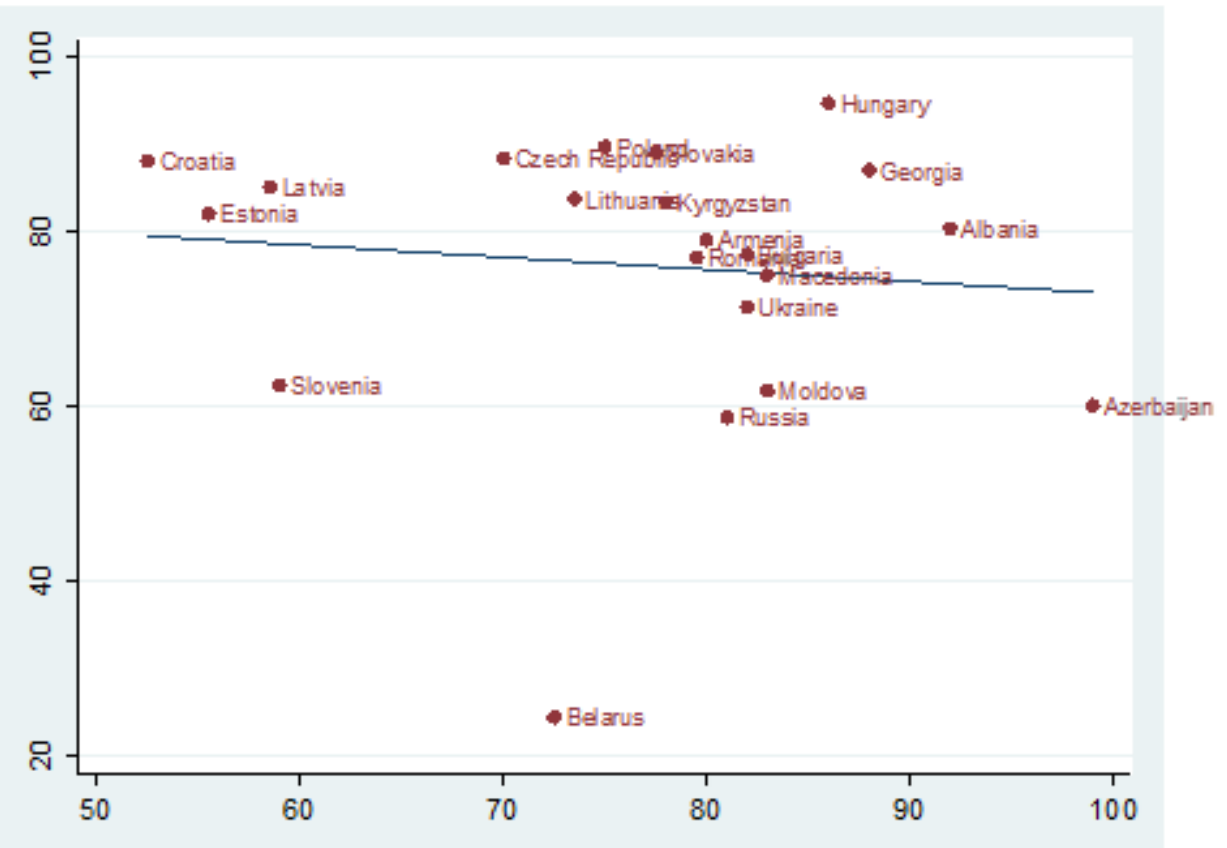


Figure 2.5: Scatter plot of the relationship between $2001 \mathrm{CH}$ index (vertical axis) and uncertainty avoidance (horizontal axis)

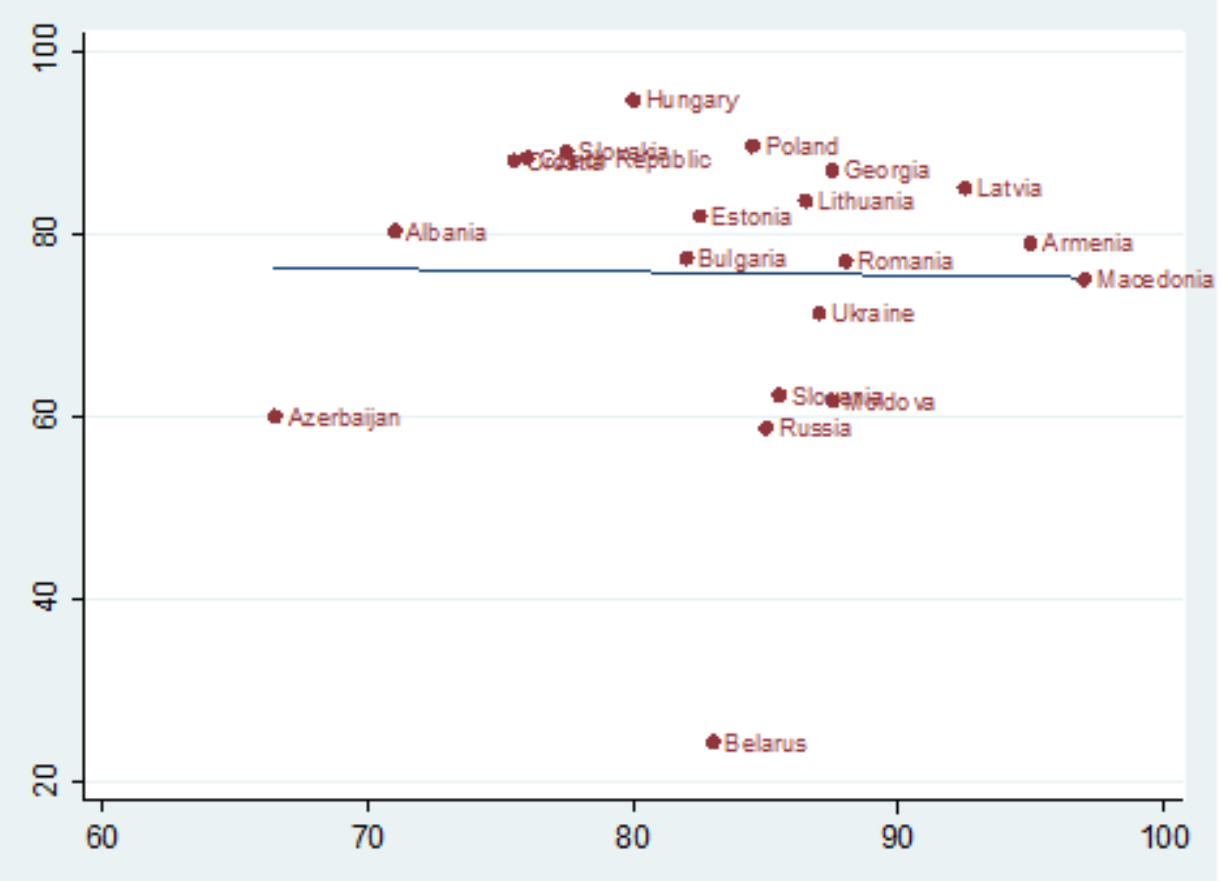


Figure 2.6: Scatter plot of the relationship between $2001 \mathrm{CH}$ index (vertical axis) and longterm orientation (horizontal axis).

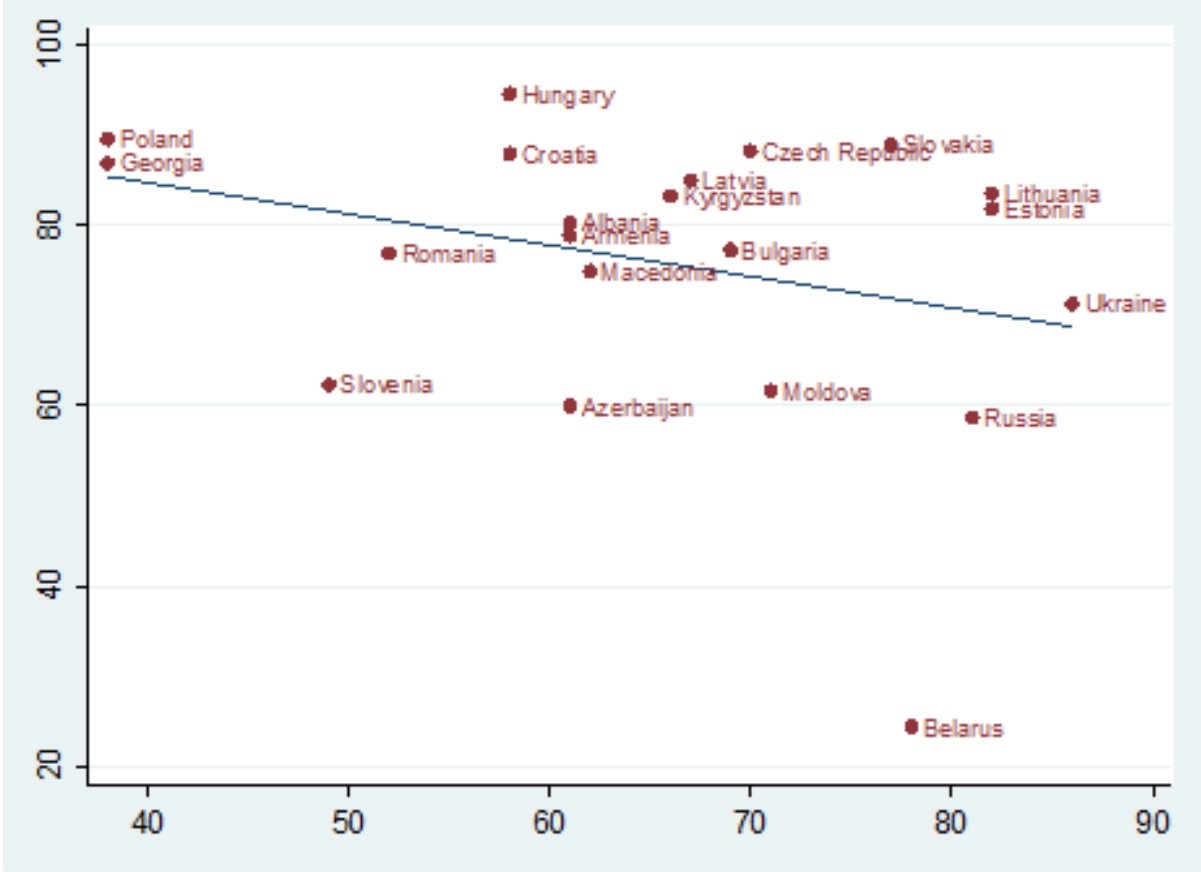


Figure 2.7: Scatter plot of the relationship between $2001 \mathrm{CH}$ index (vertical axis) and indulgence vs. restraint (horizontal axis).

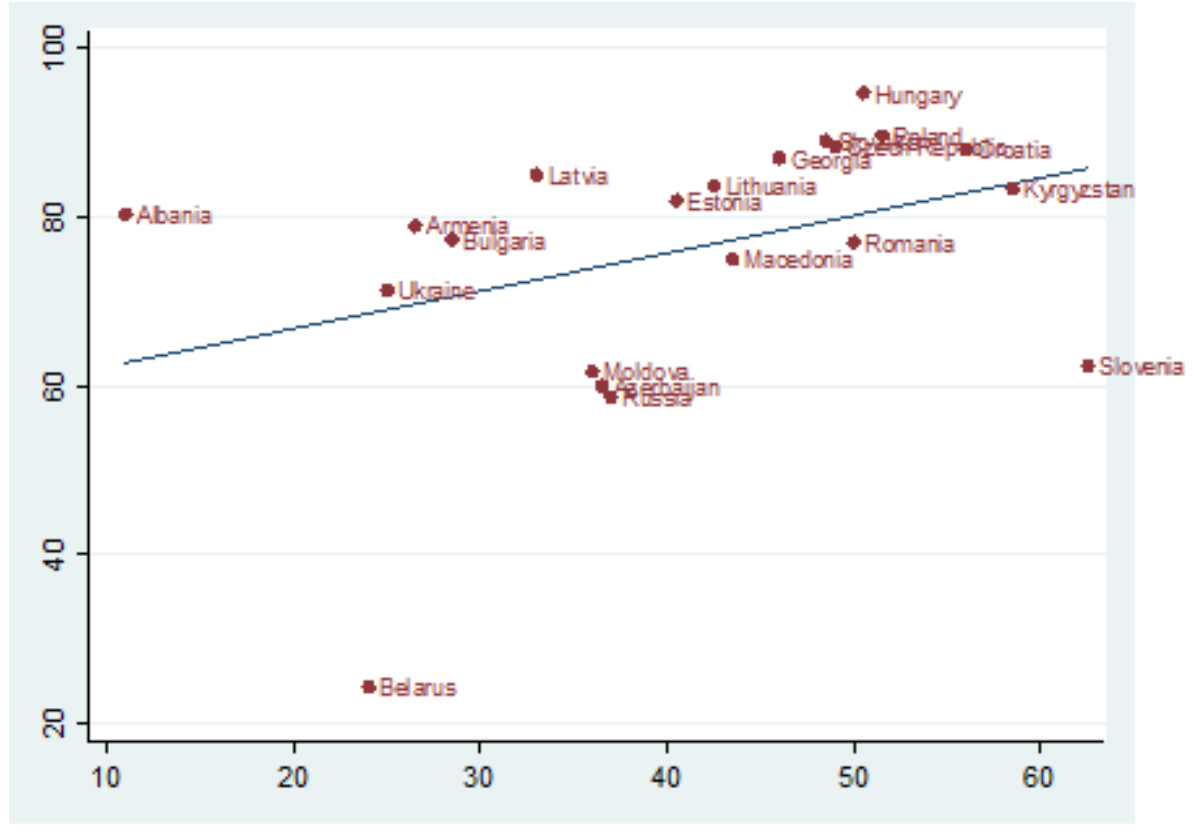

Figure 2.8: The marginal effect of democracy conditional on the level of individualism.

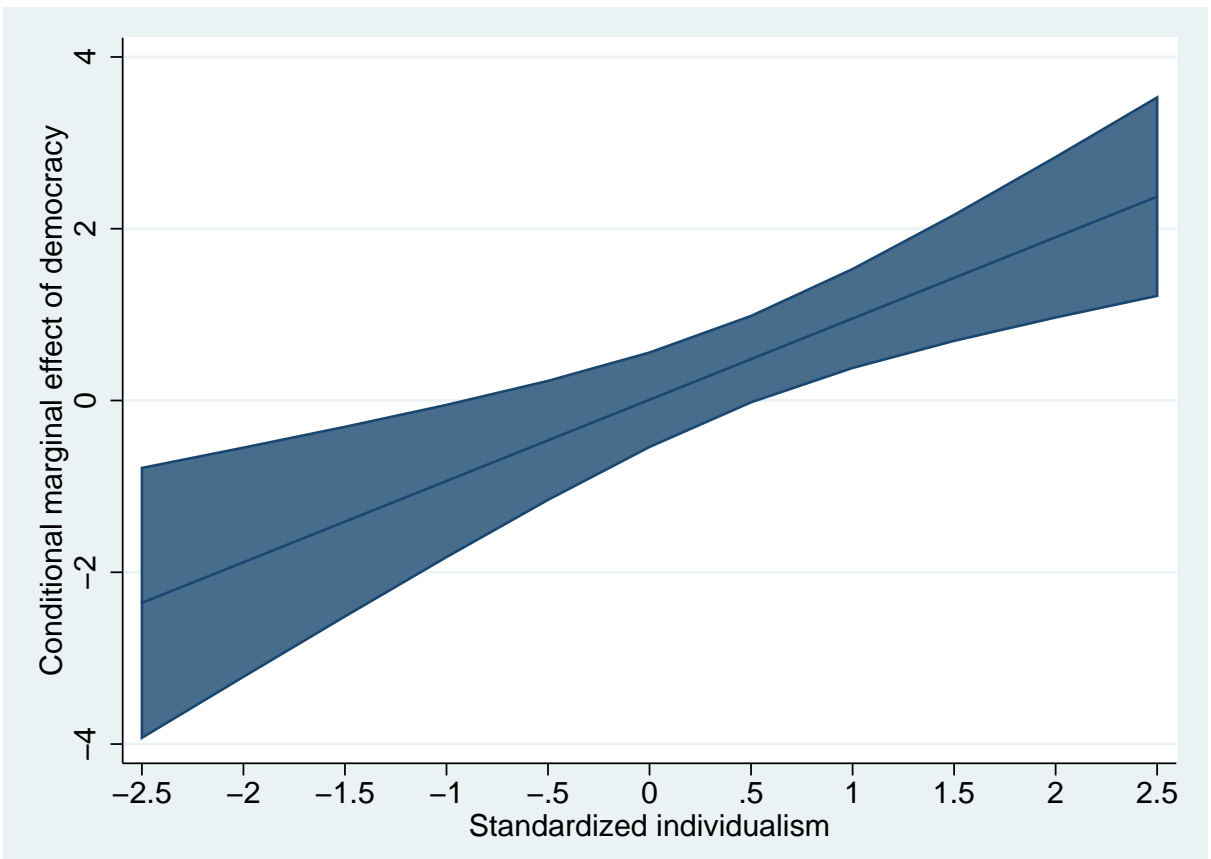


Figure 2.9: The marginal effect of democracy conditional on the level of power distance.

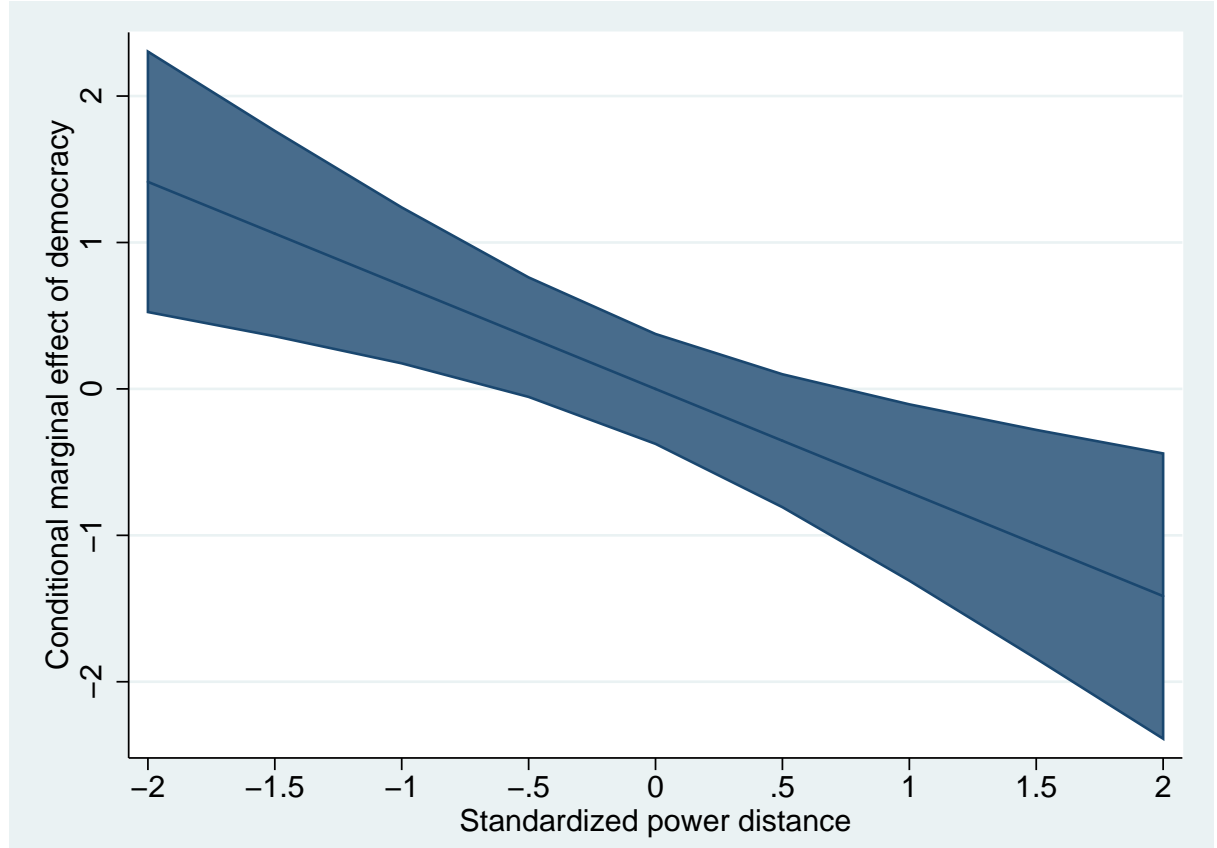

Figure 2.10: The marginal effect of democracy conditional on the level of uncertainty avoidance.

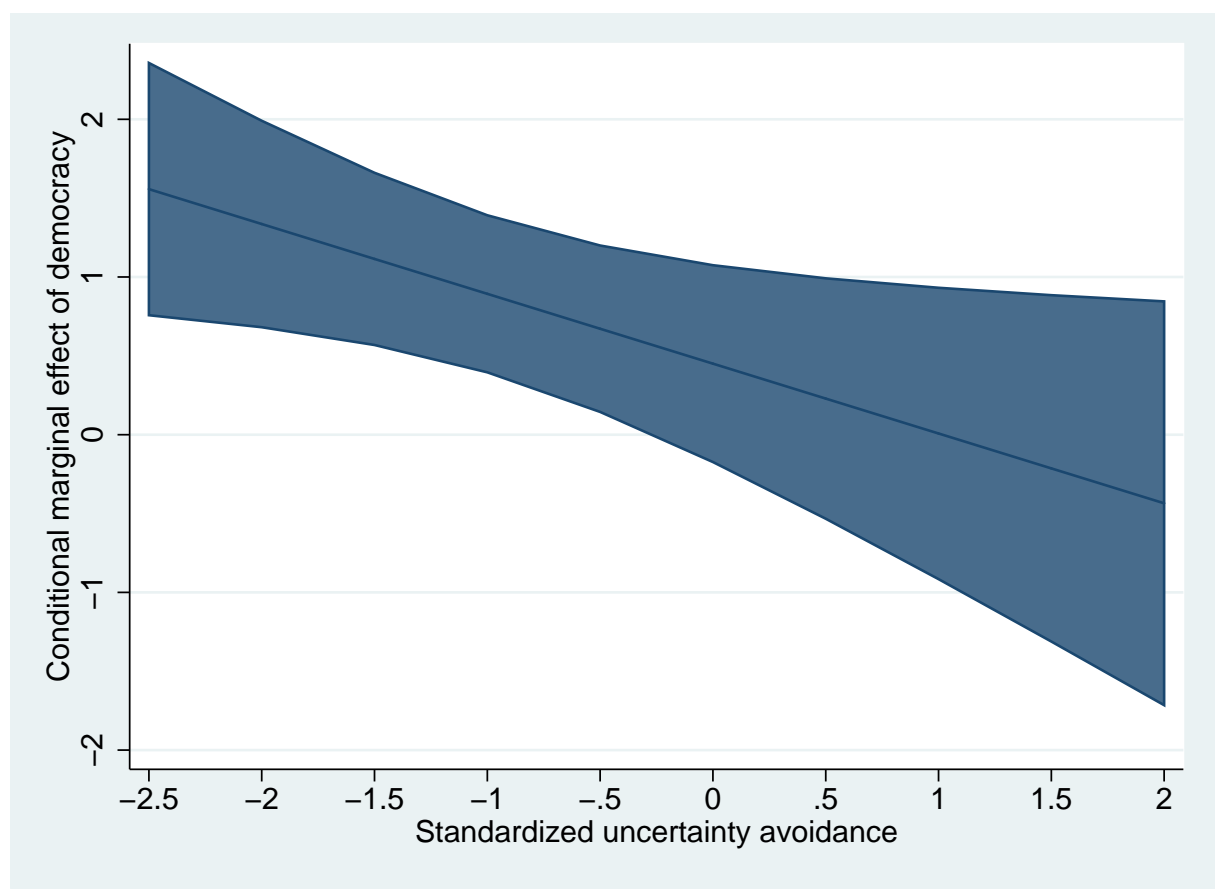




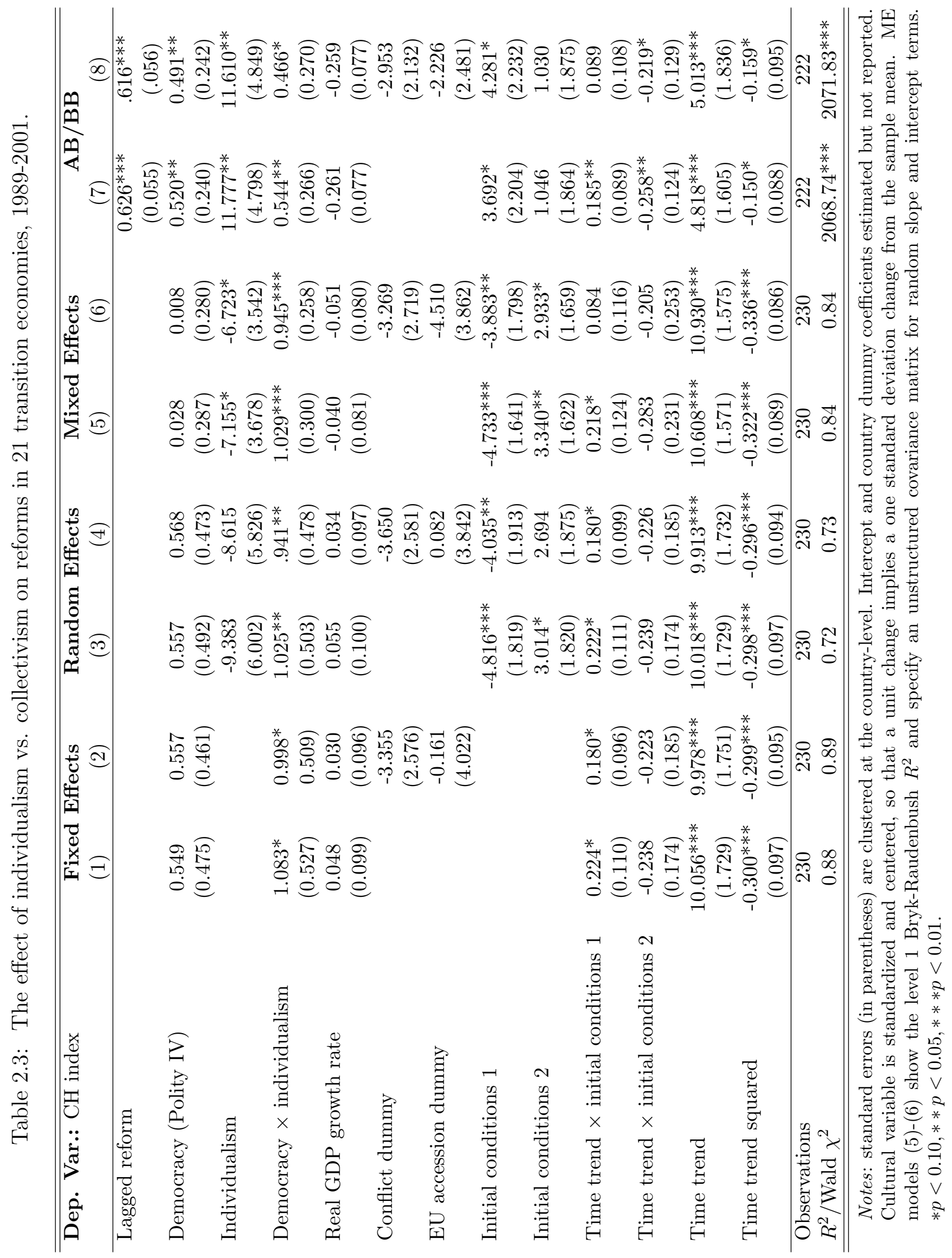




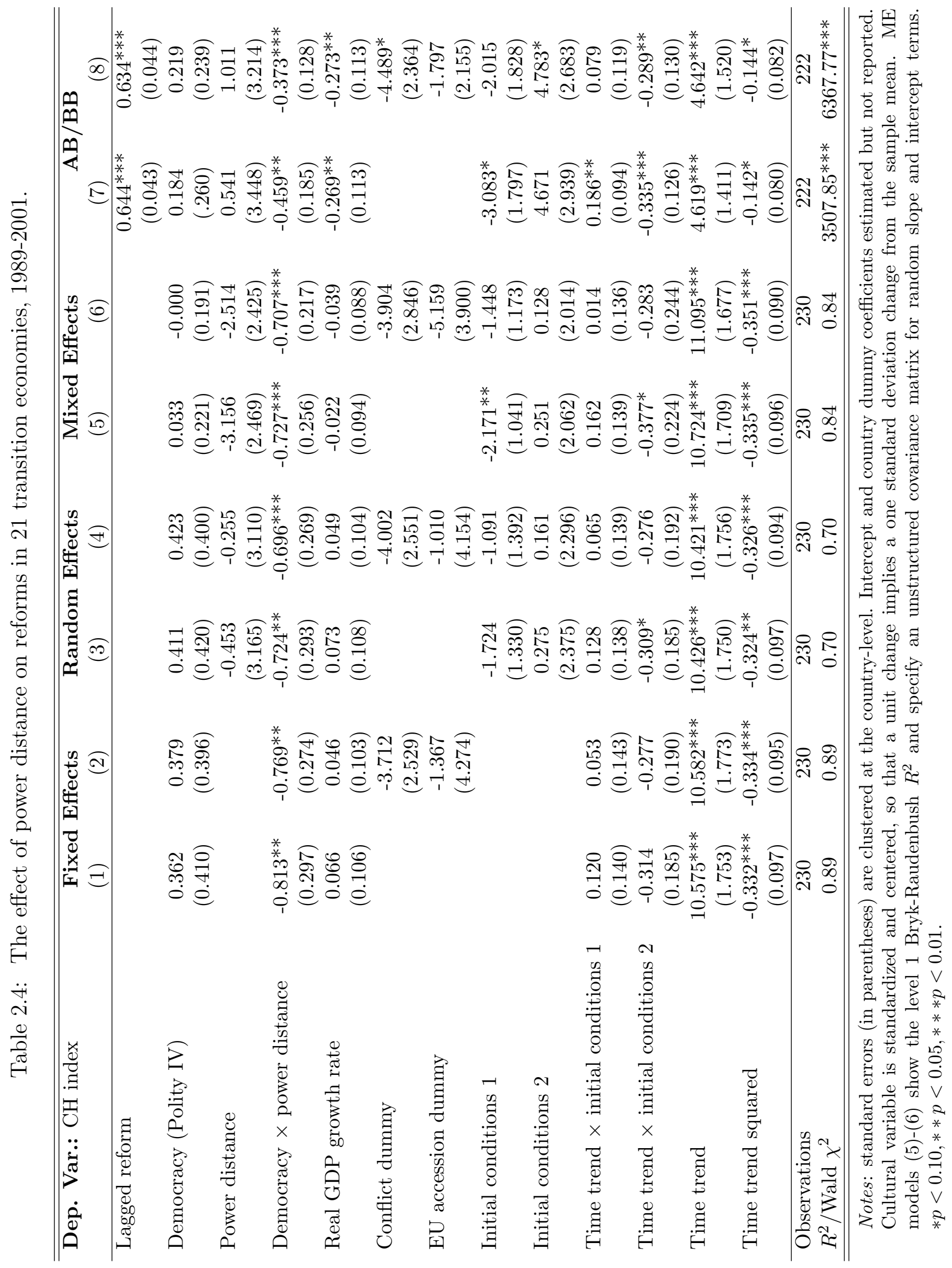




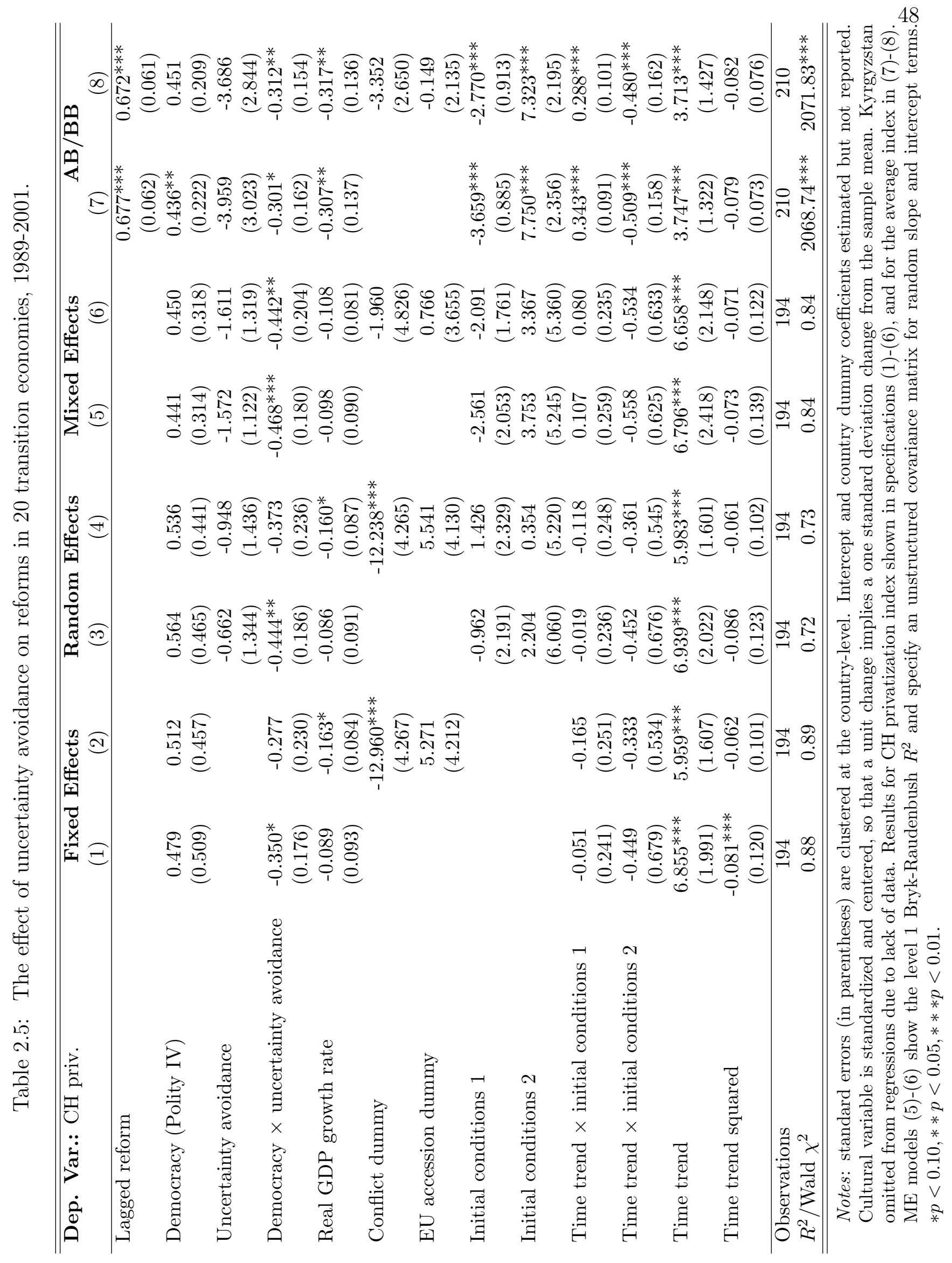




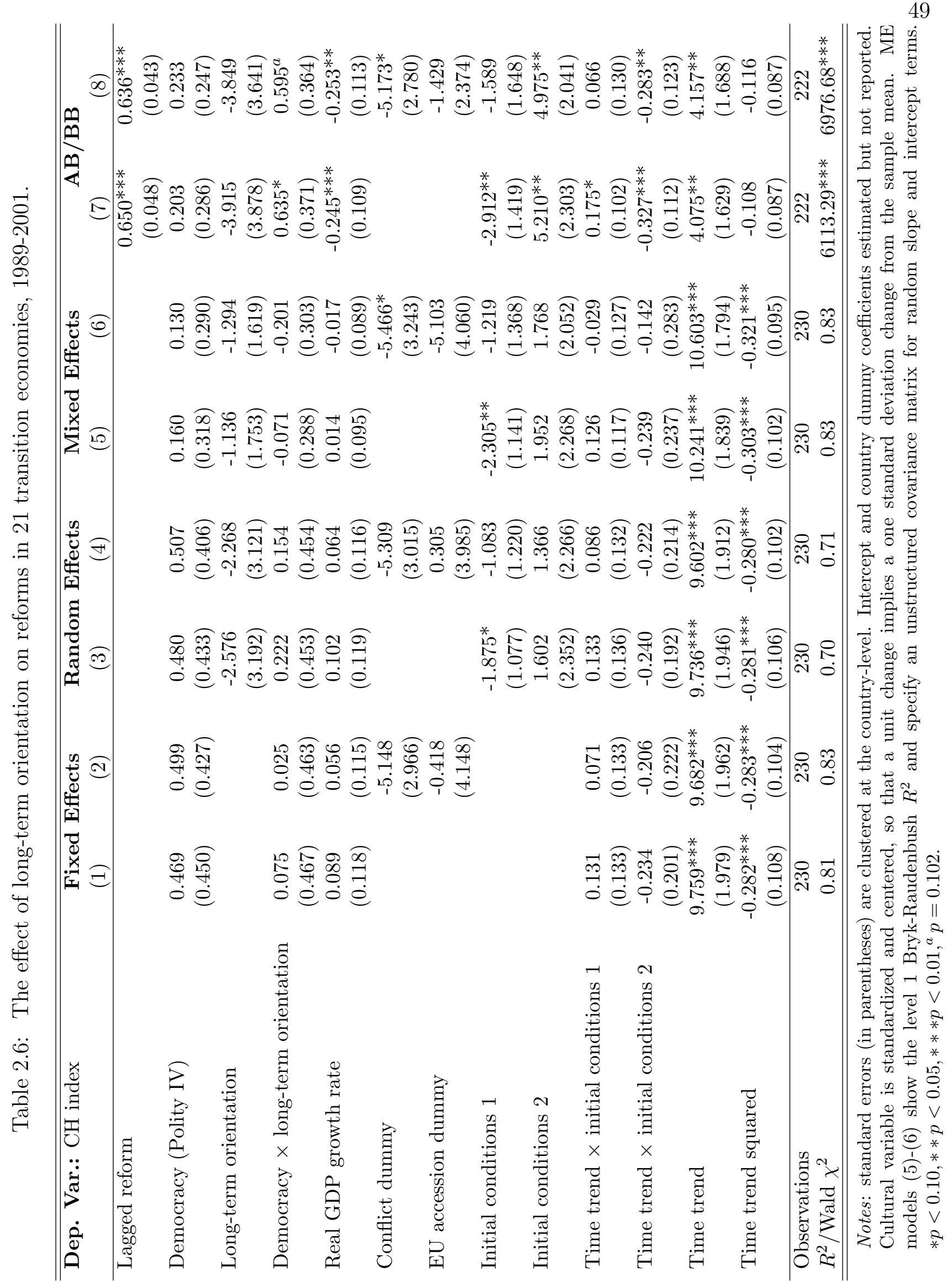


50

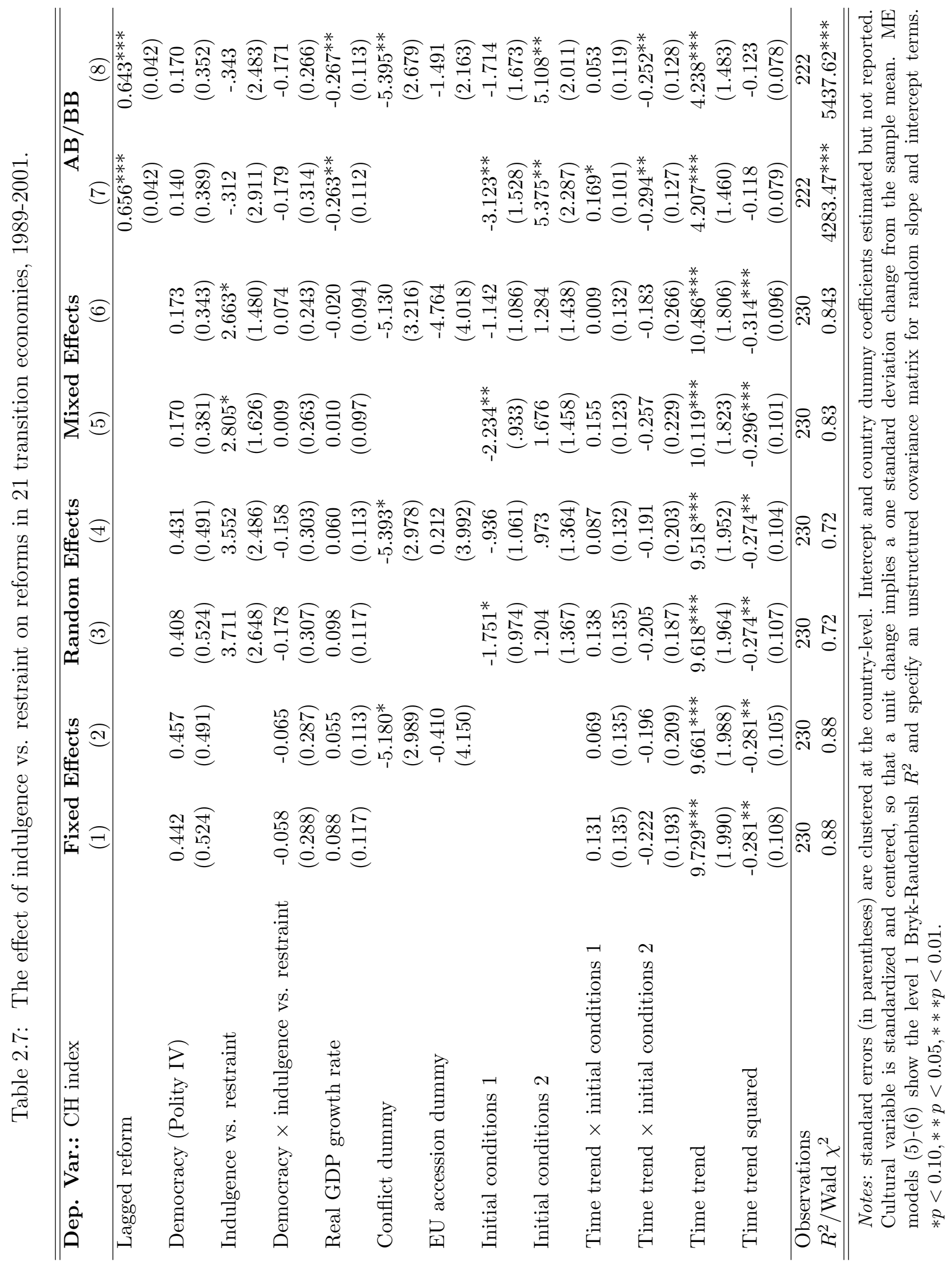




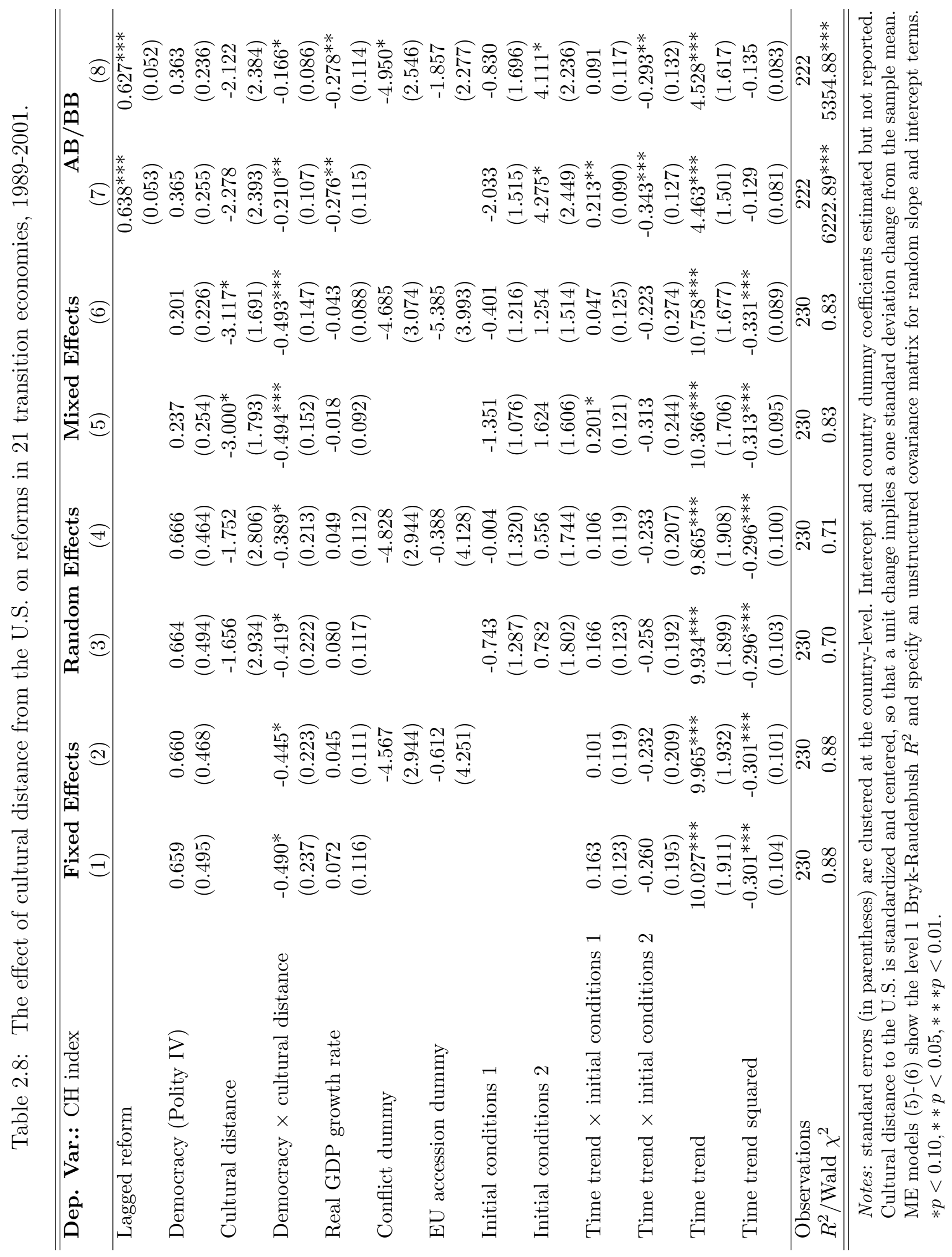




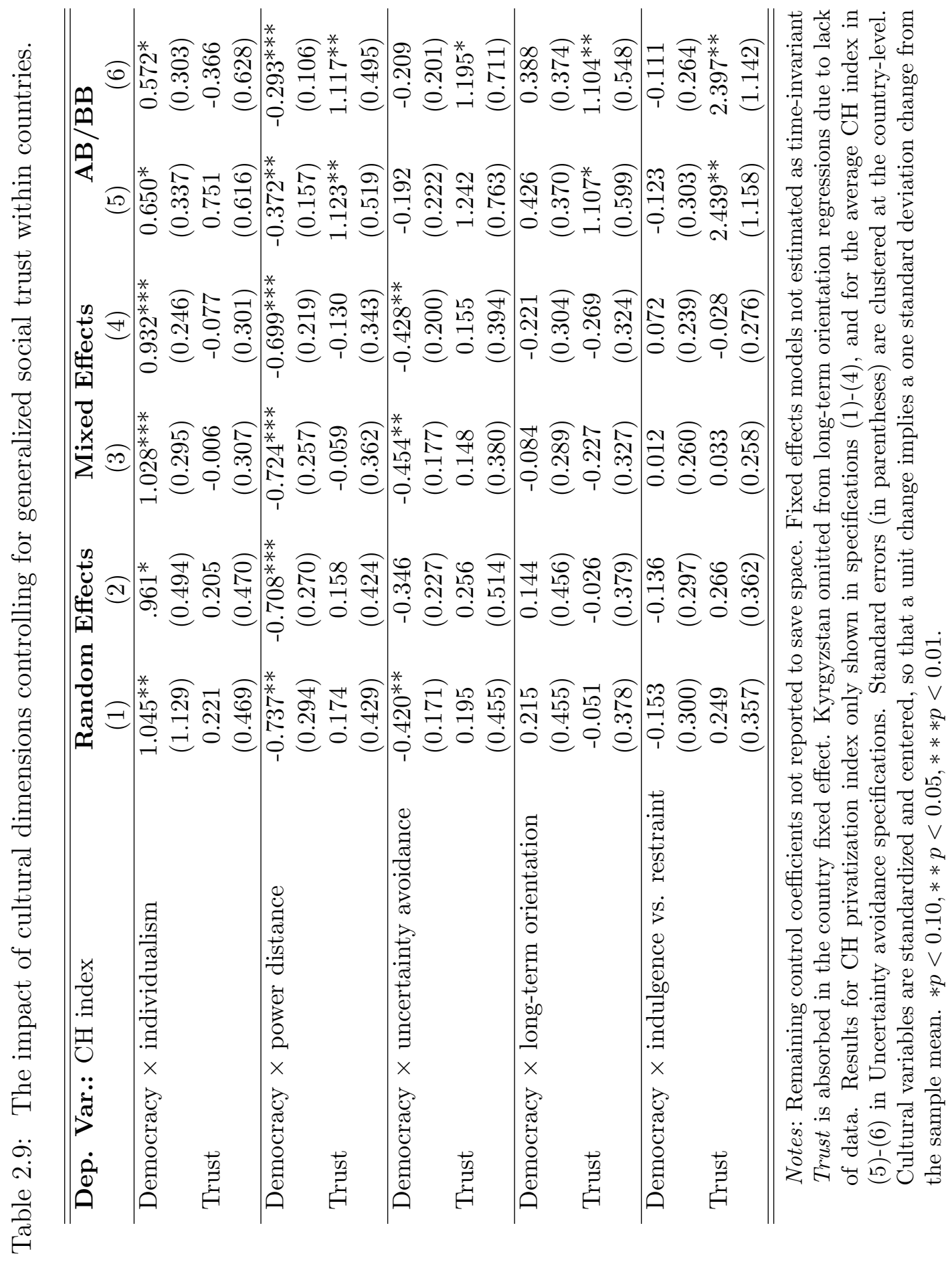









\section{Chapter 3}

\section{Liberalizing Reforms and the European Union: Accession, Membership, and Convergence}

\subsection{Introduction}

In 1957 the Treaty of Rome established the European Economic Community (EEC), subsequently known under the 1993 Treaty of Maastricht as the European Union (EU). The EEC began as a group of only six countries (Belgium, France, Italy, Luxembourg, the Netherlands, and West Germany). Today the EU has expanded to 28 countries with the latest member, Croatia, joining in 2013. The EU's broad purpose is to promote peace, cooperation, and prosperity amongst its member countries. However, the desirability of the EU has been called into question by Britain's decision to exit ("Brexit") the EU in June 2016, and the suggestion that other countries such as Austria, Finland, France, Hungary, and the Netherlands will soon follow. ${ }^{1}$

The reasons behind support for Brexit and the discontentment of some other countries with the EU are numerous and complex. Understanding those reasons and whether or not they are based on accurate perceptions is a matter of great interest to, among others,

\footnotetext{
${ }^{1}$ http://www.telegraph.co.uk/news/2016/06/25/european-leaders-fear-brexit-vote-could-herald-eucollapse-unles/
} 
European citizens, policymakers, and global financial market participants. To do so, in turn, involves an understanding of the economic and political consequences of EU accession and membership. In this chapter we make a contribution to this understanding by estimating the relationships between EU accession and membership and changes in the quality of a country's policies and institutions.

As part of an economic union, EU countries share a customs union and a uniform trade policy. Goods, capital, and people can move freely across borders within the EU. As part of a political union its members work through shared institutions such as the European Council, the European Commission, the Council of Ministers, and the European Parliament to collectively set foreign policy and, to a limited extent, aspects of domestic policy as well. The conditions for accession to the EU include political reforms that foster democracy and the rule of law; also economic reforms that promote well-functioning markets. In this chapter we are concerned with liberalizing economic reforms and explore the separate roles of the EU accession process and EU membership in bringing them about and determining whether or not they endure.

Membership in the EU and the process of accession to membership can affect the likelihood and pace of economic reforms through distinct mechanisms. First, accession involves a candidate country fulfilling the so-called Copenhagen criteria. Formalized at the 1993 European Council and following former communist countries' expression of intent to accede, these criteria stipulate demonstrable commitment to the rule of law and a well-functioning market economy. Potential admission to the EU is a "carrot" that provides incentives for candidates to undertake reforms. Second, once membership has been attained a country becomes part of the EU common market. The common market may facilitate Tiebout-type (1956) jurisdictional competition amongst members. Being able to move freely across the EU, individuals can "vote with their feet," exercising their exit option when institutions and policies are inconsistent with their preferences (Hirschman, 1978). This creates incentives for members to undertake reforms in efforts to preserve their tax bases. ${ }^{2}$

\footnotetext{
${ }^{2}$ Tiebout competition will be limited to the extent that individual member governments can extract rents from fixed factors (Epple and Zelenitz, 1981). However, intra-EU labor and capital mobility limits that possibility. However, Epple and Zelenitz highlight land as the fixed factor, of course, this is still the case of EU members.
} 
Have these two mechanisms been operative and to what extent? This is an empirical question that we bring to the data. Table 3.1 presents summary statistics for three European country-specific measures of policy and/or institutional quality at five-year intervals from 1970 to 2010. The three measures are (i) the Fraser Institute's Economic Freedom of the World (EFW) index, (ii) the KOF economic globalization index, and (iii) the European Bank for Reconstruction and Development (EBRD) transition indicator score. Numerous studies have reported that EFW and KOF index scores correlate positively with desirable economic outcomes, such as per capita income growth. (See section 3.2 below and the citations therein.) The EBRD transition indicators were developed specifically to gauge the progress of reforms in Eastern European and former communist economies (Stern, 1997). Prima facie the evidence reported in Table 3.1 is consistent with one or both of the mechanisms described above being operative. The average EFW, KOF, and EBRD scores across European countries have all increased over time, in particular from 1990 onward. CrossEuropean country unconditional convergence has occurred (also mostly since 1990) judging by both the standard deviations and the coefficients of variation.

Of course, the observed improvement in measured institutional and policy quality could have occurred despite any roles on the part of the EU. Furthermore, the improvement and convergence in measures has not been uniform. The dispersion of EFW scores generally increased from 1970 through 1990 and then subsequently fell. Similarly, the dispersion of KOF scores remained stable through 1990 and then subsequently fell. (The EBRD indicators are only available since 1989.) Most importantly from the point of view of the present study, Table 3.1 tells us little regarding whether the incentives associated with EU accession or the jurisdictional competition associated with EU membership accounts for the observed improvements and convergence. In this chapter we empirically assess the role that each of these mechanisms may play.

Only a handful of studies explore the relationship between EU accession and/or membership and economic policy/institutional reforms. ${ }^{3}$ Sell (2005) reports that economic freedom

\footnotetext{
${ }^{3}$ Alternatively, there exists a sizable empirical literature on the direct effect of EU membership/integration on economic welfare within member countries. The consensus is that being a part of the EU directly correlates with living standards by positively affecting members' GDP levels and growth rates. See, e.g., König (2015), Crespo Cuaresma et al. (2008), Badinger (2005). In this chapter, the correlation between 5-year real GDP per capita growth rate and EU membership is 0.56 and statistically significant.
} 
(EFW) scores are generally higher in EU versus non-EU countries. However, Sell's analysis is unconditional; it does not take into account other observable differences in countries aside from EU membership. Hall et al. (2011) provide a more formal analysis and report that EU membership has a small but positive impact on the levels of economic freedom between 1970 and 2010. Di Tommaso et al. (2007) report a positive correlation between EU association agreements and a multidimensional latent variable captured by the EBRD scores for 25 transition economies over the 1989-2002 period. Schweickert et al. (2011) also study 25 transition countries and find that entering association agreements with the EU as well as the pre-accession NATO Membership Action Plan (MAP) positively contributed to governance quality (measured by the aggregate World Bank Governance Indicators) between 1996 and 2008. ${ }^{4}$ More recently, Ugur (2013) also examines EU's effect on governance quality (measured through the ICRG and World Bank Governance Indicators) among the Central and Eastern European countries. Lastly, Mrak and Rojec (2013) provide an unconditional analysis of the accession process and transition indicators, concluding that they are positively related.

None of the above studies provide a longer-run conditional analysis of the roles of EU membership in the determination of policy and institutional reforms while considering the full sample of European countries. In this chapter, we estimate the effects, separately, of EU accession and EU membership on changes in measures of policy and institutional quality, as well as cross-country convergence in those measures. We employ a panel of up to 45 European countries - both EU and non-EU members - covering the 1970-2010 period. As measures of policy and institutional quality, we employ the EFW, KOF, and EBRD scores described above briefly (and more thoroughly in section 3.3 below). Relative to previous studies, we control for a more comprehensive set of potential additional correlates, as well as country and time fixed effects. In this way, we attempt to isolate the separate effects of EU membership and accession from those of a number of other factors that may influence the spread of good policies.

\footnotetext{
${ }^{4}$ The association agreements represent the first formalization of relations between the EU and third countries, and set up a framework for future cooperation. Although a pre-condition for an eventual EU application, these agreements do not imply a commitment to join or to begin accession negotiations. Among other countries, the EU signed association agreements with Morocco, South Africa, and Chile.
} 
The results of our analysis are dependent on the particular measure of policy/institutional quality that we consider. We find that being an EU member is associated with increases in the economic freedom index while being in the accession process is associated with decreases in trade barriers and increases in trade and FDI flows. These findings suggest that the spread of policies relating to the spread of economic freedom broadly is encouraged by EU membership, while the accession process tends to promote policies relating to international trade openness in particular. However — and importantly — all significantly estimated effects are quantitatively modest.

This chapter proceeds according to the following roadmap. In section 3.2, we elaborate on the characteristics of EU membership and the process of accession to the EU. In doing so we highlight the mechanisms that potentially link membership and accession to policy and institutional change; also how our study improves upon existing literature in estimating their importance for liberalizing reforms. In section 3.3 we describe our data and empirical models. The results of estimating those models are reported in section 3.4. In section 3.5 we offer some concluding discussion.

\subsection{The Mechanisms of EU Integration}

The EU is a supranational entity of 28 independent European states that share a common foreign and defense policy, maintain a unified intergovernmental legislature (the European Parliament), and relegate final adjudication of disputes between members to the European Court of Justice. Since 1957 the EU has gone through seven different enlargements, and any European country is eligible to join following the fulfillment of membership conditions. The EU common market allows for what the EU refers to as the "four freedoms of movement": people, capital, goods, and services.

Prior to the dissolution of the Warsaw Pact, EU membership was open only to the nations of Western, Mediterranean, and Scandinavian Europe. The United Kingdom, Denmark, and Ireland joined in 1973; Greece followed in 1981, Spain and Portugal in 1986, and Austria, Finland, and Sweden in 1995. Prior to joining the EU, these countries already enjoyed relatively high living standards and were reasonably well-functioning democracies. Once former 
Eastern Bloc countries expressed their desires to join the union, conditions for membership were formalized at the 1993 EU summit in Copenhagen, Denmark. These Copenhagen Criteria mandate that applicant states fulfill three sets of membership conditions:

- political criteria: stability of institutions guaranteeing democracy, the rule of law, human rights and respect for and protection of minorities;

- economic criteria: a functioning market economy and the capacity to cope with competition and market forces;

- administrative and institutional capacity to effectively implement the Acquis Communautaire (the total body of EU law) and ability to take on the obligations of membership.

In essence, applicants to the EU are expected to establish a consolidated democracy, a decentralized market economy, and the rule of law before joining. Candidate countries accede to the EU once they are evaluated to have undertaken sufficient reforms and judged ready to implement and enforce the EU body of law. The process of EU accession officially begins when a country submits an application for membership. This process entails a commitment on the part of prospective members to structural reforms and policy harmonization. The conditions for submitting the membership application are only that the country is geographically located in Europe and that it respects the basic precepts of human rights and rule of law. Upon submitting the application, prospective members are expected to pursue reforms of policies and institutions - both political and economic - while adjusting their laws and regulations to bring them into full conformance with EU standards. Among the former communist applicants the process of accession coincided with transition, during which markets gradually replaced central planning in their economies. Perceived success in market transition contributed to former communist countries achieving membership in 2004, 2007 , and 2013.

The European Commission (EC) receives membership applications and issues opinions whether applicant countries are ready to obtain candidacy status, which is then granted by the European Council. As the candidate demonstrates commitment to reforms, the EC and EU member governments allow for the opening of official accession negotiations. During these negotiations the EC and other EU bodies track the progress in further policy harmonization and assess whether the candidate country is ready to fulfill the obligations 
associated with implementation of the Acquis. At the closing of the negotiation chapters, the candidate country has at least de jure incorporated the basic EU law into own legal framework and reached EU-appropriate standards of political, economic, and administrative development. 5 Typically, there are 30-35 negotiation chapters that take on various policy areas that the candidate is required to address prior to joining. Accession negotiations address topics ranging from company law and taxation, to industrial policy and education.

As described above, one would expect to see the process of accession to the EU correlate with institutional and policy reforms. However, for a number of reasons this may not be the case. For example, the EC and other EU bodies may take into account considerations other than - and perhaps at the expense of - the Copenhagen criteria. Also, monitoring of candidates' progress in fulfilling the Copenhagen criteria may be imperfect. Furthermore, candidates may desire to be part of the EU but not to actually undertake the reforms required for membership. They may merely feign the appearance of reforms or they may focus narrowly on particular reforms requested by the EC while ignoring or even backsliding in other policy/institutional areas. These factors may negate a positive relationship between EU accession and reforms, or at least weaken it significantly.

Following accession, EU membership may itself promote institutional and policy reforms. Along a number of dimensions the EU resembles a market-preserving federalist system (Qian and Weingast, 1997; Weingast, 1995). The EU governing bodies are seated atop a hierarchy of governments where, below them, individual member country governments maintain primary regulatory responsibility for their respective jurisdictions. ${ }^{6}$ In the joining the EU, however, individual member governments transfer foreign, international trade, and monetary policy authorities to the supranational governing bodies. The common market fosters jurisdictional competition between member countries; individuals and capital are able to move towards

\footnotetext{
${ }^{5}$ The incentives to reform and comply with the Acquis may attenuate once the "carrot" of membership is removed after joining EU. For instance, Trauner (2009) notes the shortcomings in enforcement of EU law in Romania and Bulgaria, which received an "unusually high number" of official "letters of formal notice" from the European Commission pointing out problems in incorporation of EU law into domestic legislation after joining. Furthermore, they have "refrained from completing [reforms] in the first years of membership" (p. 11).

${ }^{6}$ The EU permits its member states to exercise primary regulatory and legislative authority over their own economies so long as that authority conforms to the laws and the minimum prescribed standards set at the federal level. Failures in regulatory compliance are duly noted and taken to the European Court of Justice, the principal EU regulatory overseer.
} 
those jurisdictions that offer them better (higher return) institutional/policy environments. Furthermore, in that jurisdictional competition members are in principle constrained from "cheating" by transferring their losses to other members. Participation in the monetary zone and the European Exchange Rate Mechanism (ERM) helps to impose a hard budget constraint on individual member governments. These institutions limit members' access to the "printing press" to cover losses at the expense of their fellow members.

If liberalizing economic reforms are associated with "good" outcomes (e.g., higher income levels and growth rates) then we expect that EU member states involved in jurisdictional competition with one another will make such reforms in order to retain and attraction additions to their tax bases. ${ }^{7}$ As with accession, however, there are caveats to this expectation. Notably, if the rules of the monetary union are not adhered to then the EU may serve to actually soften the budget constraints of its member country governments. This may be the case with the breakdown of the Stability and Growth Pacts fiscal constraints and monitoring, evident in the post-2008 bailouts of Greece, Portugal, Spain, Ireland, and Cyprus. If a member government has a soft budget constraint, then it can impose the costs associated with its bad policies onto other members. As such, a member government can compete for increases to its tax base by enticing labor and capital from other members with policies for which the costs are externalized to other members.

Note that neither EU accession nor membership is necessary to promote liberalizing reforms. For example, Switzerland, Norway, Iceland, and several other European microstates, have achieved high levels of economic and policy integration with the EU despite themselves not being members. ${ }^{8}$ These countries may be to a large extent effectively part of the jurisdictional competition between EU member countries. That being said, it is still of interest to know whether or not accession and/or membership on the margin facilitates liberalizing economic reforms. Our analysis below will attempt to shed light on this issue.

\footnotetext{
${ }^{7}$ Whether or not liberalizing reforms are associated with "good" outcomes is, of course, an empirical question. See the citations in section 3.3 below for evidence that liberal economic environments are associated with particular outcomes (again, e.g., higher income levels) that are often considered to be desirable.

${ }^{8}$ On average, between 1970 and 2010, Norway had an EFW score of 6.77 and KOF scores of 71.77. Iceland's average scores are 6.55 for EFW and 63.41 for KOF. Switzerland's average scores are 8.13 for EFW and 79.32 for KOF. For the entire dataset, averages are 6.66 for EFW and 62.70 for KOF.
} 


\subsection{Data and Empirical Framework}

Our dependent variables are indicators of policy and institutional quality for which higher values indicate more liberal policies and institutions. The first indicator that we consider is the Fraser Institute's Economic Freedom of the World (EFW) index (Gwartney et al., 2016). The EFW index gauges how supportive a country's institutions and policies are of well-defined and enforced property rights, individual choice, voluntary exchange, and competitive markets without barriers to entry. Countries are scored using 42 variables to examine five different dimensions of economic freedom: (i) size of government, (ii) legal system and property rights, (iii) access to sound money, (iv) freedom to trade internationally, and (v) the degree of regulation in the economy. Numerous studies report that country EFW scores correlate positively with "good" economic outcomes. ${ }^{9}$ Since we are constructing a cross-country panel we use the chain-linked EFW index values. For a recent survey of the literature using the EFW index see Hall and Lawson (2014).

The second indicator that we consider is the KOF economic globalization index. The economic globalization index is one component of the overall KOF globalization index which measures the extent to which a country is globalized along economic, social, and political dimensions (Dreher, 2006). Globalization is here conceived of as "a process that erodes national boundaries, integrates national economies, cultures, technologies, and governance and produces complex relations of mutual interdependence" (Dreher, 2006, p. 3). As with the EFW index, a number of studies have linked higher KOF index scores to "good" outcomes. ${ }^{10}$ The economic globalization specifically gauges a countries (i) restrictions on international trade, capital, and income flows and (ii) the actual flows. Hence it is a measure of international economic openness.

\footnotetext{
${ }^{9}$ The EFW index has been positively linked to income levels and growth rates (Young and Sheehan, 2014; Dawson, 2006; Gwartney and Lawson, 2006; De Haan and Sturm, 2000; Heckelman and Stroup, 2000; Gwartney et al., 1999; Ayal and Karras, 1998), life expectancy and other health outcomes (Stroup, 2007), political freedoms (Lawson and Clark, 2010), levels of trust within a population (Berggren and Jordahl, 2006), labor shares (Young and Lawson, 2014), and measures of subjective well-being (Nikolaev, 2014; Gehring, 2013; Ovaska and Takashima, 2006).

${ }^{10}$ These outcomes include lower poverty (Bergh and Nilsson, 2014), better entrepreneurial policies (Norbäck et al., 2014), higher spending on secondary and tertiary education (Baskaran and Hessami, 2012), greater gender equality (Potrafke and Ursprung, 2012), and higher rates of income growth and convergence (Villaverde and Maza, 2011). For a review of literature using KOF see Potrafke (2015).
} 
The third and final indicator that we consider is the EBRD transition indicator. This metric gauges the extent of market reform mostly among the formerly communist economies of Central-Eastern Europe and Central Asia. Countries are ranked according to their institutional/policy proximity to a market economy versus a centrally planned one. Six areas of reforms are considered: (i) large-scale privatization, (ii) small-scale privatization, (iii) governance and enterprise restructuring, (iv) price liberalization, (v) trade and foreign exchange system, and (vi) competition. Countries are rated for each area on a scale from 1 to " $4+$ ", where 1 indicates little movement away from a centrally planned economy and " $4+$ " indicates industrialized market economy institutions and policies. ${ }^{11}$ The overall EBRD indicator is the average of area scores. Babecky and Havranek (2014) review 60 empirical works on reforms in transition countries published between 1996 and 2013 and report that the reforms captured by the EBRD indicator on average are linked to higher rates of economic growth. ${ }^{12}$

The literature suggests that the EFW, KOF, and EBRD indicators gauge policies and institutions that are positively related to higher incomes and other desirable outcomes. Conditional on this being the case, if the EU approximates a market-preserving federalism then we expect that jurisdictional competition will lead to increases in and convergence of indicator scores. Furthermore, to the extent that higher EFW, KOF, and EBRD scores indicate policies and institutions that are consistent with the Copenhagen criteria then we expect that accession to the also involves increases in and convergence of the scores.

We relate changes in country EFW, KOF, and EBRD indicators to participation in the EU accession process and actual membership in the EU. To this end, we employ an unbalanced panel of up to 45 European countries for the 1970-2010 time period taken at 5-year intervals $(1970-1975 ; 1975-1980 ; \ldots ; 2005-2010)$. Alternatively, we also relate EU membership and accession to two measures of cross-country convergence in EFW, KOF, and EBRD indicators. The first convergence measure that we consider is the change in a country's institutional/policy measure $(Y)$ taken as a percentage of the initial gap between its score

\footnotetext{
${ }^{11}$ EBRD states that the indicator ranges from "1 to $4+$ ". As of now, the highest score given to any country for a given area is 4.33. More at: http://www.ebrd.com/what-we-do/economic-research-anddata/data/forecasts-macro-data-transition-indicators.html.

${ }^{12}$ While Babecky and Havranek report that studies generally find the long-run effects on growth to be positive, the ERBD indicator reforms tend also to impose short-run costs on the adopting economies. For references to additional studies employing the EBRD indicator see Fidrmuc (2003) and Falcetti et al. (2002).
} 
and that of the leader country in the sample $(L E A D E R)$ :

$$
C O N V E R G E N E_{1}(Y)=\frac{Y_{i, t}-Y_{i, t-1}}{L E A D E R_{t}-Y_{i, t-1}}
$$

The second convergence measure that we consider is the end-of-period gap between a given country and the leader relative to the initial gap:

$$
C O N V E R G E N C E_{2}(Y)=\frac{L E A D E R_{t}-Y_{i, t}}{L E A D E R_{t-1}-Y_{i, t-1}}
$$

Convergence measure (3.1) captures what percentage of the gap between a given country and the leader is eliminated over the course of a 5-year period. Alternatively, convergence measure (3.2) captures the end-of-period gap as a percentage of the initial gap. ${ }^{13}$

Participation in EU accession $(A C C)$ and EU membership $(E U)$ enter the estimations as dummy variables that correspond to the start of a 5-year period and take the value of 1 if, respectively, a country is in the accession process or a member. ${ }^{14}$ All estimations also include a country's 5-year growth rate of real (2005 constant U.S. dollars) per capita GDP and the natural log of its population, a NATO membership dummy, and a set of variables that capture political institutions and government ideology. ${ }^{15}$

We include a NATO dummy because alliance members commit to promoting political and economic liberties as well as mutual defense. The Study on NATO Enlargement (1995) stipulates that new members "must commit themselves [...] [to] contribute to the development of peaceful and friendly international relations by strengthening their free institutions, by bringing about a better understanding of the principles upon which these institutions are founded, and by promoting conditions of stability and well-being." ${ }^{16}$ All but six EU

\footnotetext{
${ }^{13} \mathrm{Up}$ to five extreme outliers in convergence variables were excluded from the estimations of (3.4) and (3.5). These outliers arise due to a negligible difference between leader and individual observation, producing nearzero values in the denominator in dependent variable formulae. From the continuum of observed values in $C O N V E R G E N C E_{1}$ and $C O N V E R G E N C E_{2}$ we remove those maxima and minima that markedly stand out so that individual observations remain within statistically reasonable levels of between $\pm 4-7.5$ standard deviations away from the mean, depending on the distribution of the variable.

${ }^{14}$ The accession dummy accounts for countries that applied EU membership for but later withdrew their application. These countries are Iceland (applied 2009; withdrew 2013), and Norway (applied 1969; withdrew 1972).

${ }^{15}$ Data on income and population come from the World Bank's World Development Indicators (WDIs).

${ }^{16}$ Source:Study on NATO Enlargement. 1995. The North Atlantic Treaty Organization. Available at URL: http://www.nato.int/cps/en/natohq/official_texts_24733.htm.
} 
countries (Sweden, Austria, Malta, Finland, Cyprus, and Ireland) are currently in NATO. While membership in NATO is not a formal criterion for EU membership, most countries that joined the EU at some point also became a part of NATO in the years prior to joining.

We also control for countries' democracy levels, government ideologies, and population sizes. Democracy levels are captured using the Polity IV index (Marshall et al., 2012). ${ }^{17}$ To the extent that political institutions are more democratic, this may correlate with the tendencies towards liberalizing economic reforms. The ideological tendencies of government may also be correlated with tendencies towards such reforms. Our estimations include two controls for government ideology based on data from the Comparative Political Data Set (CPD) (Armingeon et al., 2013) and the World Bank's Database of Political Institutions (DPI) (Beck et al., 2001). ${ }^{18}$ The CPD ideology metric codes executive cabinet ideology on a scale from 1 (hegemony or right wing and center parties in the executive branch) to 5 (hegemony of social-democratic and left-leaning parties). The DPI metric codes the chief executive's party orientation with respect to economic policy based on the right-center-left scale $\left(1,2\right.$, and 3 , respectively). ${ }^{19,20}$ Although measuring the same thing in principle, the DPI and $\mathrm{CPD}$ metrics differ in terms of the time period observed and the sample of countries.

All estimations also include country fixed effects and most estimations include period fixed effects as well. Table 3.2 reports the summary statistics for all variables included in the estimations.

We estimate four different empirical models:

$$
\Delta Y_{i, t}=\beta_{1} Y_{i, t-1}+\beta_{2} E U_{i, t-1}+\beta_{3} A C C_{i, t-1}+\boldsymbol{\theta} \boldsymbol{X}^{\prime}+\beta_{0}+\alpha_{i}+\delta_{t}+u_{i, t},
$$

${ }^{17}$ The Polity IV index gauges the extent and quality of a democracy within political regimes by considering their (i) competitiveness of executive recruitment, (ii) openness of executive recruitment, (iii) constraints on the chief executive, and (iv) competitiveness of political participation. Democracy levels are measures on a continuum from -10 (total autocracy) to +10 (consolidated democracy).

${ }^{18}$ The relationship between regulatory quality and government/citizen ideology has been documented across a sample of countries (Bjørnskov, 2005), Canadian provinces (Bjørnskov and Potrafke, 2012), German states (Potrafke, 2013), and U.S. states (Bjørnskov and Potrafke, 2013).

${ }^{19}$ The score of zero is assigned when the executive party does not match the above criteria.

${ }^{20}$ For countries that were formerly part of the USSR we set pre-1990 government ideology and Polity IV values to the USSR values. For the former Yugoslav republics we set the pre-1990 values to those of the Socialist Federal Republic of Yugoslavia; for Germany we use West Germany for 1990 and earlier; for Czech and Slovak Republics we use Czechoslovakia for 1993 and earlier. 


$$
\begin{aligned}
& C O N V E R G E N C E_{1}(Y)=\beta_{1} Y_{i, t-1}+\beta_{2} E U_{i, t-1}+\beta_{3} A C C_{i, t-1}+\boldsymbol{\theta} \boldsymbol{X}^{\prime}+\beta_{0}+\alpha_{i}+\delta_{t}+u_{i, t}, \\
& \text { CONVERGENCE } E_{2}(Y)=\beta_{1} Y_{i, t-1}+\beta_{2} E U_{i, t-1}+\beta_{3} A C C_{i, t-1}+\boldsymbol{\theta} \boldsymbol{X}^{\prime}+\beta_{0}+\alpha_{i}+\delta_{t}+u_{i, t}, \\
& Y_{i, t}=\rho Y_{i, t-1}+\beta_{2} Y E A R S \_E U_{i, t-1}+\beta_{3} Y E A R S \_E U_{i, t-1}^{2}+\beta_{4} A C C_{i, t-1}+\boldsymbol{\theta} \boldsymbol{X}^{\prime}+\beta_{0}+u_{i, t},
\end{aligned}
$$

where $Y=\{\mathrm{EFW}, \mathrm{KOF}, \mathrm{ERBD}\}, E U$ is the membership dummy, $A C C$ is the accession dummy, $\alpha_{i}$ and $\delta_{t}$ are country and period fixed effects, respectively, and $\boldsymbol{X}$ is the vector of controls. Note that while we observe our data set since 1970, taking a lag of variables necessarily eliminates one time observation. ${ }^{21}$

Models (3.3), (3.4), and (3.5) are based on three dependent variables (5-years changes and two convergence measures) discussed above. Model (3.6) comes at the topic of interest form a different angle, asking whether or not spending more time as an EU member is associated with more a more market-oriented policy/institutional environment. Rather than relating EU membership to a certain amount of change in that environment, (3.6) allows for the possibility that greater economic integration with the EU that develops over time as a function of time spent within its institutional structures. The variable $Y E A R S_{-} E U$ is defined as the number of years a country has been a member of the EU. (Since diminishing returns to additional time spent as a member may set in, we also include $Y E A R S \_E U$ squared.) Model (3.6) is a typical autoregressive specification and conventional panel estimators will be biased in finite samples (Nickell 1981). Therefore we employ the Arellano-Bover (1995) / Blundell-Bond (1998) system GMM estimator which is designed for dynamic panel models. ${ }^{22}$

\footnotetext{
${ }^{21}$ Although the presence of endogeneity between reform measures and the accession variable is a possibility, we believe this concern is mitigated in a few ways: first, any country on the European continent displaying a modicum of respect for political freedoms and human rights may successfully apply for membership. Second, not all countries achieved identical institutional quality before finishing the accession process and subsequently joining. Lastly, within our empirical framework, the accession variable is time-lagged by 5 years, decreasing the likelihood of a feedback loop from reforms to accession.

${ }^{22}$ The Arellano-Bover / Blundell-Bond estimator performs the forward orthogonal deviations transformation in order to control for bias arising from the presence of fixed effects in dynamic panel models. In that sense, it differs from the Difference GMM (Arellano and Bond, 1991) estimator which differences the levels equation to purge fixed effects.
} 


\subsection{Results}

Tables 3.3 through 3.6 report estimates from Equations (3.3) through (3.6), respectively. All specifications with the exception of those in Table 3.6 include country fixed and period effects. ${ }^{23}$ The explanatory variables of interest are the EU membership and accession dummy variables.

In Table 3.3 we report the results for 5-year changes in EFW, KOF, and EBRD scores. Based on the point estimates from Table 3.3 columns 1-4, being part of the EU is associated with an increase in a country's EFW score of between 0.204 and 0.355 points over 5 years. The sample standard deviation of EFW scores is 1.04 so these point estimates are modest. For perspective, 0.355 points is less than what separated the 2010 EFW scores of France (7.43) and the UK (7.91). Indeed, based on that largest point estimate it would take about 15 years for the cumulative effect on the EFW index to equal one standard deviation. Furthermore, the estimate reported in column 3 is not statistically significant. The estimated EU accession effects are likewise underwhelming. Based on the point estimates, being in the accession process is associated with an increase in a country's EFW score of between 0.055 and 0.359 points. The column 2 and column 4 estimates are not statistically significant.

Turning to changes in the KOF economic globalization index (columns 5 through 8), the association with EU membership is never statistically significant. The estimated EU accession effects are always positive and often (save for column 8 where the CPD government ideology measure is a control) statistically significant ( 5 percent level or better). However, the point estimates (ranging from 2.198 to 4.570 ) again imply very modest effects. The sample standard deviation of KOF economic globalization scores is 16.83. Again for perspective, 4.570 points is a good deal less than what separates the $2010 \mathrm{KOF}$ economic globalization scores of Norway (74.77) and Finland (83.37).

Finally, results based on EBRD score changes are reported in columns 9 through 11. Neither the EU accession nor EU membership dummy variables enter any of the estimations statistically significantly. In summary, then, EU accession and EU membership are in many cases not related statistically significantly to measures of liberalizing economic reforms. Even

\footnotetext{
${ }^{23}$ We do not include period effects in the dynamic panel models as our main variables of interest (trends) are highly correlated with year dummies.
} 
when the estimated effects are statistically significant, the point estimates are quite modest in size.

Beyond the control variables of primary interest, the five-year lag of the dependent variable always enters the Table 3.3 estimations negatively and statistically significantly. This result, then, reflects (i) that there may be diminishing returns to reforms, in the sense that it is easier to make marginal reforms starting from low levels of policy/institutional quality than from high levels and (ii) the bounded-from-above nature of the policy/institutional indices.

Tables 3.4-3.5 report estimates for 5-year convergence in the EFW, KOF, and EBRD scores to that of the leader country (i.e., highest score). Table 3.4 reports results for CONVERGENCE $E_{1}$, while Table 3.5 for CONVERGENCE . Based on Table 3.4, EU membership over 5 years is associated with elimination of the initial EFW gap by between 21.7 and 32.8 percent. We also report statistically significant estimates suggesting that EU accession is associated with elimination of the EFW gap by between 19.4 and 29.5 percent in specifications. These are not necessarily large estimated effects, but they are not negligible either. However, when the CPD government ideology measure is controlled EU accession does not enter significantly (column 4).

Turning to KOF scores, the EU accession is associated with elimination of the gap by between 0.5 and 18.6 percent. In the same vein as with the EFW results accession enters statistically insignificantly when CPD control is introduced although where accession enters significantly the magnitude of the effect is non-trivial (15.2-18.6 percent). The EU membership is never significant in the KOF columns while the accession and membership are likewise unrelated to changes in the EBRD gap.

Based on Table 3.5, EU membership is significantly associated with decreases in the end-of-period gap relative to the initial EFW gap by 11.3-24.5 percent over 5 years. EU accession estimates are likewise associated with decreases in the gap but they enter statistically insignificantly save for DPI column 3 (coefficient $=-16.8$ percent) in which, alternatively, membership becomes insignificant (coefficient $=-11.3$ percent).

Of the 18 countries in the data set that acceded to EU between 1970 and 2010, 13 experienced increases in EFW scores since joining. Those that experienced reversals in 
the EFW scores all joined in 2004 suggesting that, consistent with Table 3.6 results, more time may be required to elapse after joining before noticeable institutional/policy reform. ${ }^{24}$ Importantly, the magnitude of EFW reversals is small (0.24 points average drop). The countries whose EFW scores increased the most since becoming EU members are Ireland $(+1.72$ points $), \mathrm{UK}(+1.98)$, and Greece $(+1.63)$, which joined in 1973, 1973, and 1981, respectively.

Recent political tumults in Turkey notwithstanding, the country also experienced a significant increase in EFW score (+1.46) since applying for membership in 1987 until 2010. Though heavily integrated with the EU, the non-members of Switzerland, Norway, and Iceland experienced since 1970 positive though relatively small increases in the EFW scores of 0.79 on average (-0.11 average point drop since 1990).

Regarding the KOF scores, we find no evidence that membership is significantly related to gap decreases; however, accession is related with decreases of between 11.5 and 13.8 percent except in the CPD column 8. In the EBRD column 9 membership is positively associated with the size of the gap but this effect disappears once additional controls are introduced. We hence find no evidence that either membership or accession are significantly related to this EBRD convergence measure.

Table 3.6 reports the results of the Arellano-Bover/Blundell-Bond regressions based on Equation (3.4). Here we focus on the relationship between duration of EU membership and the dependent variable levels while also controlling for the accession dummy. We find that EU membership duration has an inverse- $U$ relationship with EFW scores. This relationship is always statistically significant. The negative and statistically significant $Y E A R S \_E U$ term suggests that the relationship between EFW scores and EU membership is the strongest during the early years of membership.

Similar to earlier findings, we do not report evidence that membership duration is significantly associated with KOF scores, but accession positively and significantly enters the columns 5 and 7 estimations. Among transition economies we observe a borderline significant positive effect ( $p$-value 0.116 and 0.103 in columns 10 and 11, respectively) of the length of membership on EBRD levels. However, we do find the effect of accession dummy on EBRD

\footnotetext{
${ }^{24}$ The countries that experienced EFW reversals are Cyprus, Estonia, Latvia, Poland, and Slovenia.
} 
to be positive and statistically significant in columns 9,10 , and $11 .^{25}$

Overall this section provides some empirical evidence suggesting positive relationships between the EU and liberalizing economic reforms, but those estimated effects are small. The evidence points to how accession and the jurisdictional competition associated with EU membership may differently affect liberalizing reforms. While membership seems to be associated with economic freedom, as indicated by the policies/institutions measured by the EFW index, accession seems to be associated with the easing of barriers to international financial and trade flows, as well as an actual increase in those flows. With respect to the market reforms measured by EBRD scores, in most specifications we do not find that either membership or accession is significantly associated with improvements among the transition economies. (When considering the EBRD scores we acknowledge that we are constrained by limited sample size. $)^{26}$

An important caveat is that the results are generally sensitive to the choice of government ideology control. While the two metrics (CPD and DPI) are constructed to measure the same concept, they differ in terms of the available sample of time periods and countries. The CPD data run from 1970. (The DPI data runs from 1975.) Also, the CPD data only cover OECD and some current EU members, omitting countries such as Russia or Ukraine.

\subsection{Concluding Discussion}

To become a part of EU countries must undergo a process of structural reform and policy harmonization with the union. Upon joining the EU new members become part of the largest common market in the world. Goods, services, people, and capital move freely within the EU.

\footnotetext{
${ }^{25}$ Note that in the EBRD specifications, the squared term is dropped because the lag of squared $Y E A R S \_E U$ is identical to linear $Y E A R S \_E U$, which means they are perfectly collinear.

${ }^{26}$ We also re-estimated the models in Tables 3.3-3.5 for the EFW and KOF scores to match the 19902010 period as is observed for EBRD specifications. During that period, we find the marginal effects of membership and accession to be of similar sign, size, and statistical significance. For models using EFW as the dependent variable, we find the effect of membership on first differences to be positive and significant in 3 out of 4 specifications. Accession's impact is likewise positive and significant in 2 out of 4 specifications. Both membership and accession effects are positive and significant in all specifications for CONVERGENCE $E_{1}$, and accession effect to be negative and significant in 3 out of 4 specifications for CONVERGENCE (membership significant and negative in all specifications). For the models with KOF globalization index as the dependent variable, we find no statistical significance for membership, while the accession variable is consistently significant and of predicted sign in 3 out of 4 specifications regardless of the estimated equation.
} 
Such an environment may resemble a market-preserving federalism. As such EU countries may be incentivized by Tiebout competition to offer policy and institutional bundles that attract/retain their tax base.

In this chapter we investigate whether EU accession and membership have indeed been associated with changes in policies and institutions that correlate with desirable economic outcomes (e.g., higher incomes). Based on an unbalanced panel of up to 45 European countries over the 1970-2010 period, we report that both membership and accession are either not significantly related to the policy/institutional improvements, or that the related increases are very modest.

When we report statistically significant results they are mostly regarding the association between EU membership and the policies/institutions measured by the Fraser Institute's economic freedom of the world (EFW) index. In particular, EU membership appears to be associated positively with changes in a country's EFW index score; also with measures of convergence towards the EU leader country. Again, however, the estimated effects are quite modest. We also report EU accession period is associated with statistically significant increases in a country's KOF economic globalization index scores; also to measures of convergence to the leader country. Again, the estimated effects are small.

In light of our empirical results, it may be worthwhile to revisit the current debates on the "usefulness" of EU membership recently highlighted by the "Brexit" referendum. On the one hand, a significant concern by Eurosceptic voices is that EU law takes precedence over national law by design, thus suppressing member states own policy-making competencies. On the other hand, our analysis shows that the mechanisms behind EU membership (and accession) provide at most a small benefit in terms of institutional improvements relating to better economic outcomes.

Insofar as these debates persist the consequences of EU membership should be correctly identified and understood. The results of the chapter highlight one potential trade-off in never having been a part of, or leaving EU: EU membership is at best associated with small additional increases as well as convergence in economic freedom scores. (Alternatively, that EU accession is not/is associated with small additional increases as well as convergence in economic globalization scores for aspirant countries.) 
Additionally, the results in this chapter relate to the empirical literature finding the positive effect of EU membership or accession on improved governance quality and market reform within transition countries. In that sense, existing evidence suggest that EU membership/accession at the very least, did not worsen the institutional quality in countries across Europe; alternatively, that these mechanisms encouraged modest liberalizing reforms whose main beneficiaries may ultimately be EU citizens themselves. 


\subsection{Appendix}

Table 3.1: Summary statistics of liberalizing reforms, full sample, 1970-2010.

Table 2.1 Summary statistics of liberalizing reforms, full sample, 1970-2010.

\begin{tabular}{|c|c|c|c|c|c|c|}
\hline Year & Countries & Mean & Std. Dev. & C.o.V. & Min & Max \\
\hline \multicolumn{7}{|c|}{ EFW chain-linked index } \\
\hline 1970 & 19 & 6.41 & 0.94 & 0.15 & 3.49 & 7.59 \\
\hline 1975 & 20 & 5.85 & 1.03 & 0.18 & 3.72 & 7.63 \\
\hline 1980 & 22 & 6.08 & 1.04 & 0.17 & 3.77 & 8.14 \\
\hline 1985 & 25 & 6.05 & 1.16 & 0.19 & 3.46 & 8.30 \\
\hline 1990 & 26 & 6.41 & 1.32 & 0.21 & 3.55 & 8.30 \\
\hline 1995 & 35 & 6.46 & 1.33 & 0.20 & 3.40 & 8.32 \\
\hline 2000 & 35 & 7.13 & 1.01 & 0.14 & 4.58 & 8.76 \\
\hline 2005 & 35 & 7.40 & 0.62 & 0.08 & 5.74 & 8.40 \\
\hline 2010 & 35 & 7.27 & 0.49 & 0.06 & 5.87 & 8.23 \\
\hline \multicolumn{7}{|c|}{ KOF economic globalization index } \\
\hline 1970 & 30 & 50.15 & 15.09 & 0.30 & 20.26 & 91.87 \\
\hline 1975 & 30 & 51.17 & 15.28 & 0.29 & 20.26 & 92.12 \\
\hline 1980 & 30 & 54.29 & 16.59 & 0.30 & 20.26 & 92.31 \\
\hline 1985 & 30 & 58.19 & 17.54 & 0.30 & 19.04 & 93.68 \\
\hline 1990 & 33 & 58.02 & 18.81 & 0.32 & 19.39 & 94.00 \\
\hline 1995 & 45 & 60.20 & 17.02 & 0.28 & 30.95 & 94.38 \\
\hline 2000 & 45 & 70.06 & 16.39 & 0.23 & 29.84 & 97.76 \\
\hline 2005 & 45 & 73.49 & 14.52 & 0.19 & 38.40 & 95.59 \\
\hline 2010 & 45 & 75.14 & 11.55 & 0.15 & 51.77 & 94.69 \\
\hline \multicolumn{7}{|c|}{ Average EBRD transition indicator } \\
\hline 1990 & 23 & 1.38 & 0.50 & 0.36 & 1.00 & 2.61 \\
\hline 1995 & 23 & 2.67 & 0.67 & 0.25 & 1.17 & 3.72 \\
\hline 2000 & 23 & 3.06 & 0.64 & 0.21 & 1.56 & 3.89 \\
\hline 2005 & 23 & 3.35 & 0.50 & 0.15 & 1.89 & 1.89 \\
\hline 2010 & 24 & 3.47 & 0.42 & 0.12 & 2.22 & 4.10 \\
\hline
\end{tabular}

Notes: C.o.V. denotes the coefficient of variation, calculated as the standard deviation (Std. Dev.) over mean. The EBRD data run from 1990 until 2010 only. For EFW, maximum scores were observed in Switzerland (1970, 1980, 1990-2000, 2010), Luxembourg $(1975,1985)$, and Ireland (2005). For KOF, maximum scores were observed in Luxembourg (1970-2000) and Ireland (2005, 2010). For EBRD, maximum scores were observed in Poland (1990), Hungary (1995-2000), and Estonia (2005, 2010). 
Table 3.2: Summary statistics for regression subsample.

\begin{tabular}{lcccc}
\hline \hline Variable & Mean & Std. Dev. & Min & Max \\
\hline Chained EFW index (EFW) & 19 & 6.41 & 0.94 & 0.15 \\
$\Delta(\mathrm{EFW})$ & 20 & 5.85 & 1.03 & 0.18 \\
$C O N V E R G E N C E_{1}(\mathrm{EFW})$ & 22 & 6.08 & 1.04 & 0.17 \\
$C O N V E R G E N C E_{2}(\mathrm{EFW})$ & 25 & 6.05 & 1.16 & 0.19 \\
& & & & \\
KOF economic index (KOF) & 26 & 6.41 & 1.32 & 8.30 \\
(KOF) & 35 & 6.46 & 1.33 & 8.32 \\
$C O N V E R G E N C E_{1}(\mathrm{KOF})$ & 35 & 7.13 & 1.01 & 8.76 \\
$C O N V E R G E N C E_{2}(\mathrm{KOF})$ & 35 & 7.40 & 0.62 & 8.40 \\
& & & & \\
EBRD transition indicator & 30 & 50.15 & 15.09 & 91.87 \\
(EBRD) & 30 & 51.17 & 15.28 & 92.12 \\
$C O N V E R G E N C E_{1}(\mathrm{EBRD})$ & 30 & 54.29 & 16.59 & 92.31 \\
$C O N V E R G E N C E_{2}$ (EBRD) & 30 & 58.19 & 17.54 & 93.68 \\
& & & & \\
EU membership dummy & 0.48 & 0.50 & 0.00 & 1.00 \\
Accession period dummy & 0.16 & 0.36 & 0.00 & 1.00 \\
Years in EU & 10.18 & 15.10 & 0.00 & 53.00 \\
NATO membership dummy & 0.53 & 0.49 & 0.00 & 1.00 \\
5-year real GDP per cap. growth $(\%)$ & 15.97 & 22.27 & -60.9 & 247.23 \\
Log of population & 15.83 & 1.55 & 12.29 & 18.81 \\
Polity IV index & 7.97 & 4.30 & -9.00 & 10.00 \\
Gov. ideology (CPD) & 2.67 & 1.49 & 1.00 & 5.00 \\
Gov. ideology (DPI) & 1.66 & 1.12 & 0.00 & 3.00 \\
& & & & \\
\hline \hline
\end{tabular}

Notes: summary statistics based on the model containing maximum available observations. 


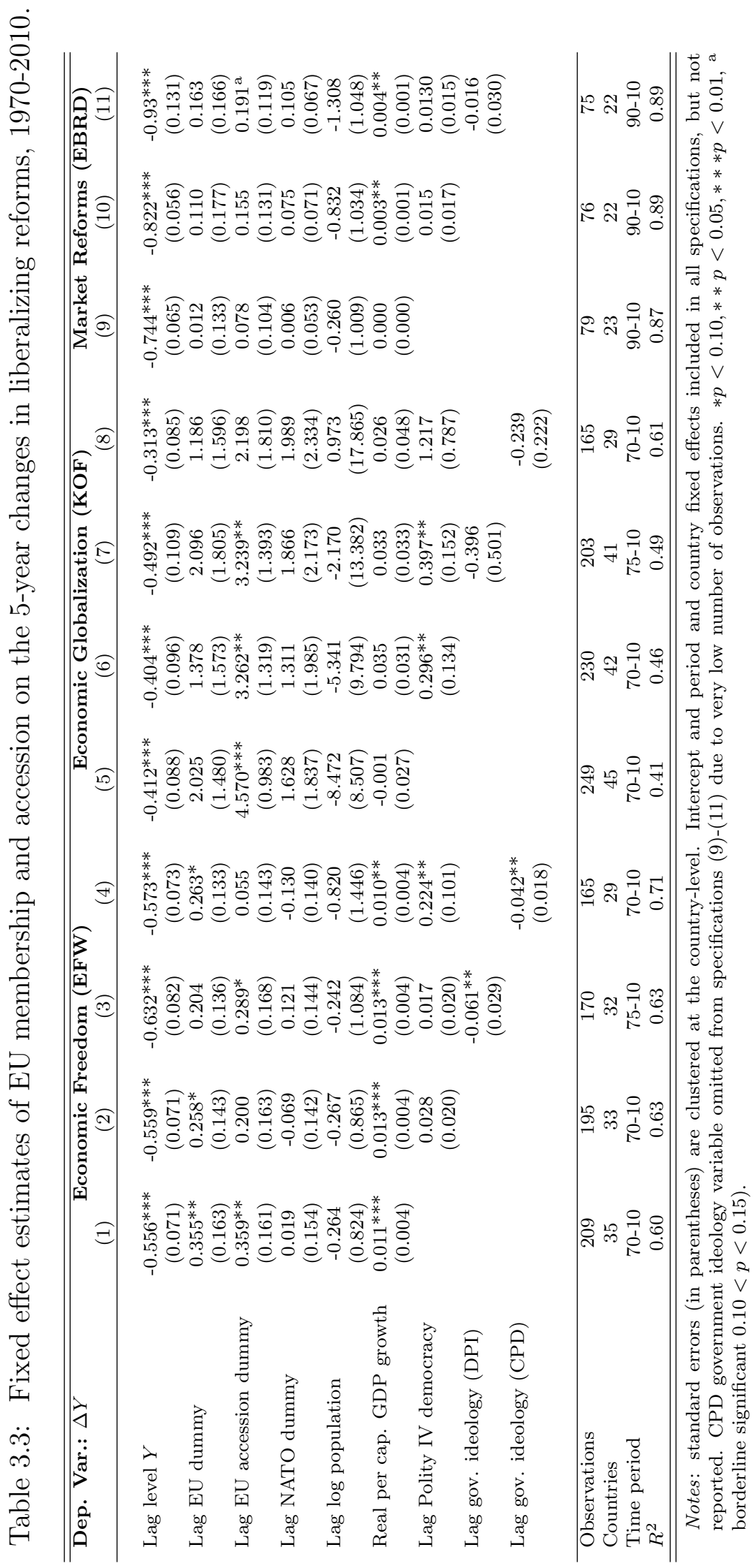




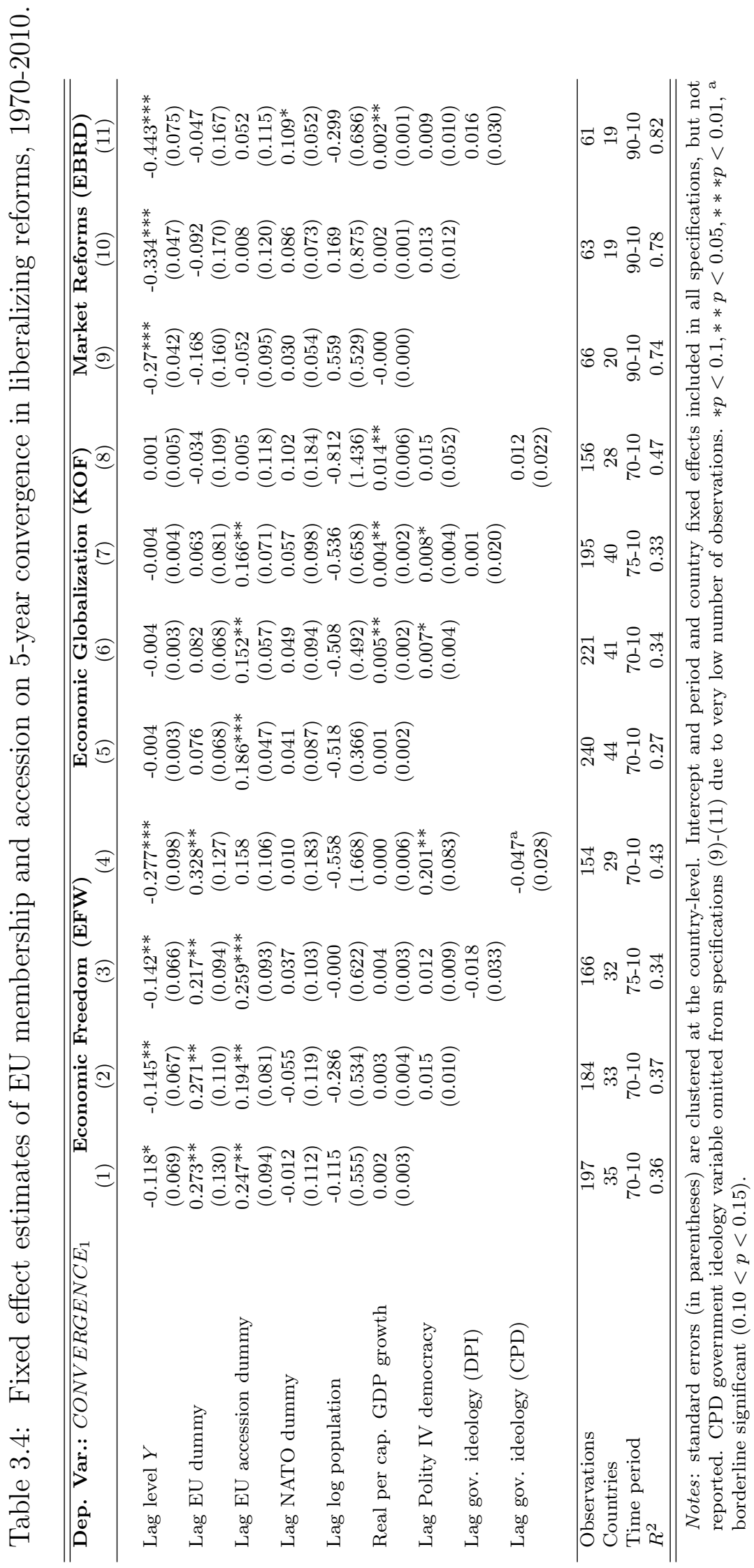




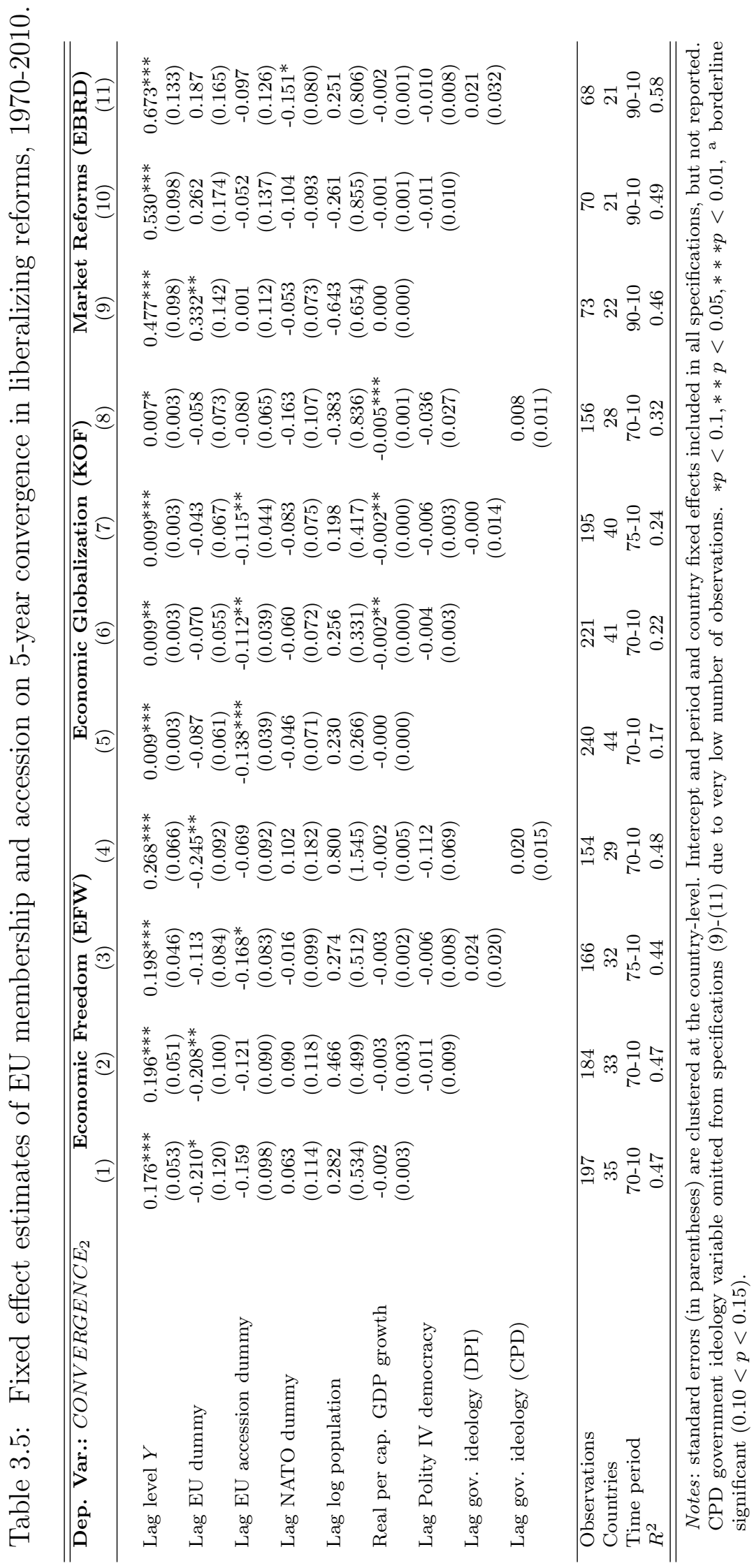




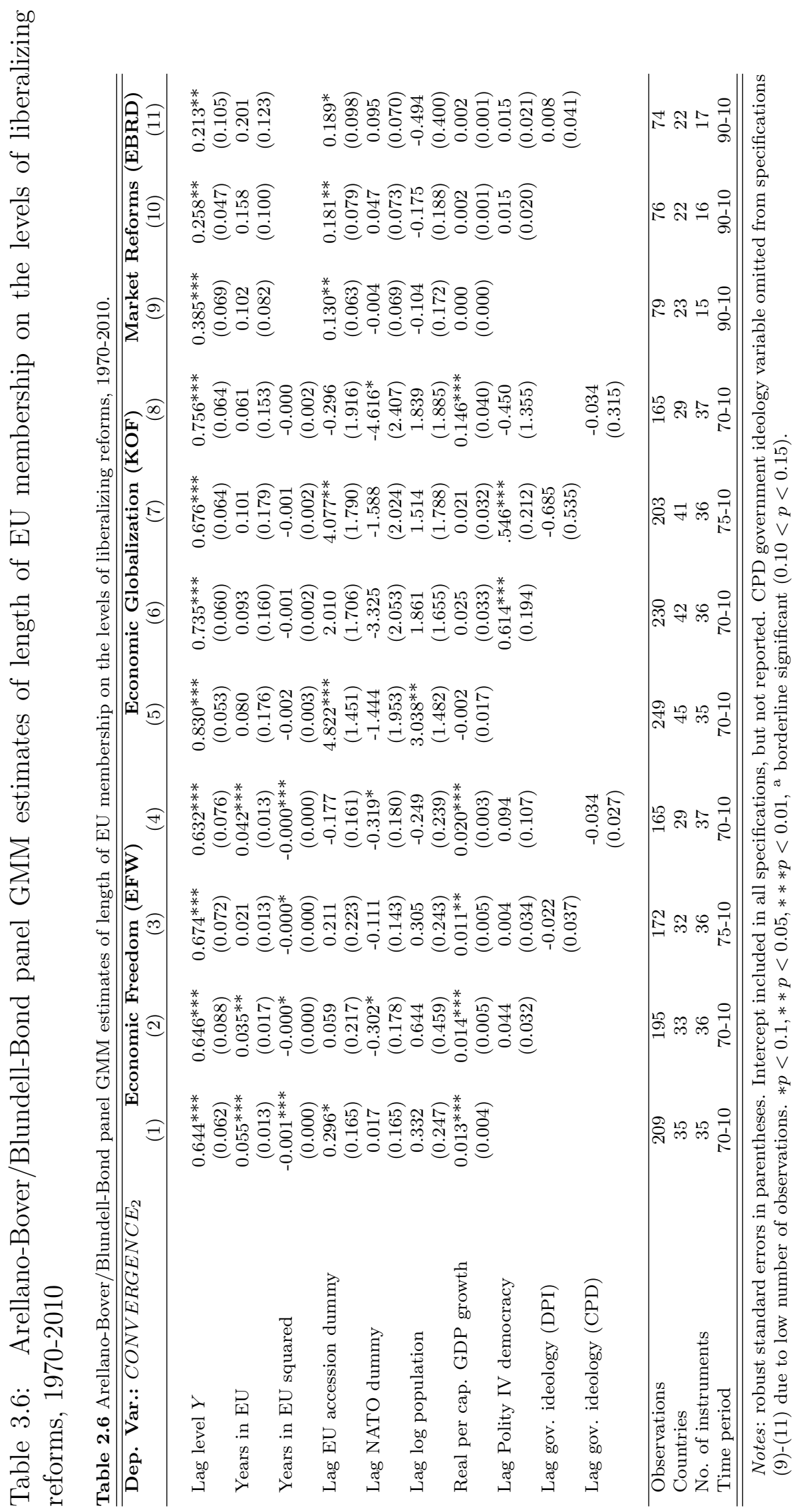




\section{Chapter 4}

\section{Integration and Entrepreneurial}

\section{Activity in the European Union: Some Country-Level Evidence}

\subsection{Introduction}

The past decades saw a surge in research on the driving forces behind and the implications of European Union (EU) integration. The analytical strand of this literature focuses on the present and future of EU's federalism and the political economy of integration (e.g., Spolaore, 2015; Wyplosz et al., 2015; Börzel and Hosli, 2003). Empirical studies emerged more recently with the availability of data. This literature has investigated a wide range of effects of EU integration such as economic growth/convergence (König, 2015; Mann, 2015; Campos et al., 2014; Crespo Cuaresma et al., 2008; Kutan and Yigit, 2007; Badinger, 2005), inequality (Busemeyer and Tober, 2015), and institutional reform (Ugur, 2013; Hall et al., 2011; Schweickert et al., 2011; Di Tommaso et al., 2007).

This chapter contributes to this growing literature by empirically investigating the impact of EU integration on different measures of entrepreneurial activity within EU member states in an unbalanced panel of 24 EU countries observed between 2004 and 2012. As entrepreneurship is a broad concept, I employ different measures of microfirm (1-9 employees 
in size) formation as well as self-employment rate in the empirical analysis. Business startup formation is an important barometer of entrepreneurial activity and is essential for fostering continued dynamism, competition, and innovation in an economy (Klapper et al., 2010). In that sense, entrepreneurship is an important correlate of economic development and stimulating or facilitating entrepreneurial activity has become one of the foremost economic goals of policymaking around the world and in the EU itself.

Established at the Treaty of Rome (1957) as a tariff-free zone the EU today resembles a loose confederation whose de jure sovereign member states share common foreign, trade, monetary, and certain domestic policies. Along many important dimensions the EU approaches the United States in terms of depth of connectedness of its constituent states. Citizens of EU countries are free to cross national borders and work anywhere within the territory of the union without facing discrimination. Goods, services, capital, and people flow freely throughout the EU Single Market. Member states benefit from structural and cohesion funds paid into the common EU Budget. The European Parliament sets EU-wide legislation while the European Court of Justice adjudicates conflicts and ensures members' compliance with EU regulation.

Despite EU's historical prominence, there have been few attempts to quantify the depth of integration, or institutional and economic cooperation, for this and similar regional arrangements. In this study, I employ the recently developed EU Index (König and Ohr, 2013) which gauges the EU member states' degree of economic as well as political integration with the EU. Higher values of the integration indices signal greater economic interdependence as well as institutional proximity with the EU relative to and at the expense of with the rest of the world.

In 2004, 10 new members (eight formerly socialist Eastern European countries along with Malta and Cyprus) joined the 15-member bloc (EU-15) of Western European countries and committed to joint institutional evolution as well as free movement of goods, services, labor, and capital. The subsequent increases in intra-EU trade, FDI flows, and migration brought about an expansion of member states' markets and a re-orientation of economic activity from home toward the largest competitive single market in the world.

Did the deepening of EU integration and the ensuing changes in the economic milieu af- 
fect entrepreneurship within member states? The question appears salient as small business and self-employment are the largest sources of work for EU labor. On the one hand higher levels of integration entail greater competition and macroeconomic volatility that pressure entrepreneurs and small firms to increase efficiency or risk bankruptcy. Along a similar vein, Melitz (2003) formally models a dynamic industry with heterogeneous firms, and concludes that opening up to trade forces low productivity firms to exit. On the other hand, a direct and significant association between EU integration and entrepreneurial measures would be indicative of the positive effects on entrepreneurial activity stemming from knowledge and productivity spillovers, as well as expanded opportunities for specialization. An economy increasingly reliant on the EU's common market can crowd out smaller firms and depress expected profits in an increasingly competitive environment. Alternatively, it can provide an impetus for entrepreneurship by generating knowledge and productivity spillovers arising from increased cross-national flows of goods, capital, and migration that enterprising individuals can exploit.

Has the linkage between EU integration and entrepreneurship been operative, and if so, in which direction? The evidence from country fixed effects regressions indicates that microfirm levels per capita, as well as microfirm net entry rate, the share of microfirms in total firms, and self-employment rate generally increase in the levels of EU economic and political integration. This finding suggests that entrepreneurial learning and opportunities increase with the depth of EU integration, resulting in faster start-up formation and self-employment. Existing literature points to potential "pull" (opportunity) factor of globalization that can influence entrepreneurial individuals to switch to self-employment. In that respect, this chapter provides some preliminary empirical evidence speaking to this assertion, suggesting that, on net, the "pull" factors outweighed potential crowding-out effects of more intense competition in a larger common market, as well as that encouraging entrepreneurship through deepened integration and better policies can be an important conduit for improved economic growth in the EU.

The remainder of the chapter proceeds as follows. Section 4.2 reviews the role of entrepreneurship in economic development its relevance to the EU. Section 4.2 examines the globalization-entrepreneurship nexus and its relation to EU integration. Section 4.4 de- 
scribes data and methodology and section 4.5 presents empirical results. Section 4.6 offers some concluding remarks.

\subsection{Background and Literature Review}

Entrepreneurship is widely recognized as a key ingredient of economic progress (Kreft and Sobel, 2005; Audretsch et al., 2002b). In a Schumpeterian sense, entrepreneurs take risks and innovate whereby they creatively destroy incumbent technologies and products. Aghion and Howitt (1992) take stock of these ideas to formally model the process of creative destruction (vertical innovation) as the underlying source of economic growth. From the Austrian perspective Kirzner (1997) describes entrepreneurs as alertness agents operating in a disequilibrium environment who discover by trial and error previously unknown arbitrage opportunities. These theories argue that entrepreneurs contribute to economic development by discovering optimal product-market combinations, creating knowledge spillovers, reducing production costs, stimulating productivity, and increasing competition.

Comparative macro-level studies generally depict a more heterogeneous picture on the relationship between entrepreneurship and development. Although a positive and significant effect of the levels of entrepreneurship on productivity, income levels, growth has been well documented $^{1}$, differences in defining and measuring standardized entrepreneurial activity complicate broader cross-country analyses (Van Stel et al., 2005). More recently the consensus shifted toward the notion that the linkage between entrepreneurship and development is non-linear, and that more developed countries experience higher entrepreneurship levels (Eeckhout and Jovanovic, 2012; Wennekers et al., 2005; Carree et al., 2002)) but also that entrepreneurship has a stronger positive effect on development in richer countries (Valliere and Peterson, 2009; Van Stel et al., 2005).

Against this backdrop, the EU stands out as a particularly interesting case in that it is a cluster of geographically proximate and sovereign yet highly economically and politically integrated developed economies with relatively good institutional quality and standardized

\footnotetext{
${ }^{1}$ See, e.g., Erken et al., 2016; Carree et al., 2007; Audretsch and Thurik, 2003; Audretsch et al., 2002a. For U.S. state or county-level analyses, see Wiseman and Young (2013), Goetz et al. (2012), and Sobel (2008).
} 
regulations. This is of particular importance for empirical studies on entrepreneurship as its relative definitions vary little within the Union. Furthermore, the relative levels of development of EU countries (21 of 24 observed countries are OECD members as of 2012) along with their relatively sound institutional environment are suggestive of the prevalence of more productive entrepreneurship (Acs, 2010; Sobel, 2008). Indeed, the importance of entrepreneurship as a motor for EU's economies has been recognized by the European Commission (EC), which cites the encouragement of small and medium-size enterprises (SMEs) as one of its policy goals. ${ }^{2}$ According to EC, the SMEs comprise 99 percent of all businesses and account for 85 percent of new jobs in the EU while as many as 37 percent of EU citizens exhibit preference for self-employment..$^{3,4}$

A number of empirical studies employ cross-sectional survey data to explore demographic and cultural determinants of entrepreneurial engagement levels, latent entrepreneurship, and reported self-employment levels for individuals living in the EU-15 or EU-25 (Grilo and Thurik, 2008, 2006, 2005a,b; Grilo and Irigoyen, 2006; Verheul et al., 2006). These microlevel studies generally highlight the perception of administrative complexities and to a lesser extent the lack of financial support as the main obstacles to starting a business. Freytag and Thurik (2007) study similar response variables using country-level data. They find that actual entrepreneurship levels in EU countries cannot be adequately explained with given data but latent entrepreneurship decreases in countries' regulatory burden, life expectancy, and socialist heritage. However, their analysis is also cross-sectional and only concerns the year 2004.

In this study the focus is on the longitudinal variation in country-level entrepreneurship proxied primarily by the number of microfirms (1-9 employees) per labor (microfirm density). The formation of microfirms is indicative of higher entrepreneurial activity within countries, as these startups are primarily inward-oriented (home as opposed to foreign markets) and come about as the result of either self-employment (sole proprietorship) or joint venture (partnership) between few entrepreneurial individuals. In that respect, they may be seen as

\footnotetext{
${ }^{2}$ https://ec.europa.eu/growth/smes/promoting-entrepreneurship/index_en.htm

${ }^{3}$ See, e.g., the EC's Eurostat (2012) report titled "Entrepreneurship Determinants: Culture and Capabilities."

${ }^{4}$ http://ec.europa.eu/growth/smes/
} 
the initial conduit in which entrepreneurial activities are conducted (Audretsch et al., 2002b) and, if successful, may grow in size in the longer-run. ${ }^{5}$ Because entrepreneurship is a broad concept, three additional measures are examined to better capture the its essence within countries: new net microfirm density, the share of microfirms in total firms per country, and the rate of self-employment.

\subsection{Globalization and Entrepreneurship: Theory and Evidence}

The linkage between international economic or political integration (alternatively, globalization) and entrepreneurship is a recent area of research (Koster and Karlsson, 2009). Yet observed trends since the mid-to-late 1970s attest to the accelerated pace of globalizationexpressed through increases in trans-national trade, capital, and labor flows - along with a simultaneous resurgence of entrepreneurship around the world (Verheul et al., 2002). The industrial restructuring from managed toward an entrepreneurial economy, in which small firms command an increasing share of total economic activity, has been even more pronounced in developed countries (Thurik et al., 2013; Audretsch and Sanders, 2008; Audretsch et al., 2002a; Carree et al., 2002; Verheul et al., 2002).

The beneficial impact of globalization on economic development is well documented in the empirical literature (e.g., Dreher, 2006). However, its linkage with entrepreneurship is not yet well explored. According to the Eclectic Theory of Entrepreneurship, the impact of globalization can be both positive and negative (Verheul et al., 2002). On the one hand, increased competition from international markets negatively impacts small firms, either by crowding them out or creating better opportunities for employee rather than self-employment positions. On the other, small firms may be better able to absorb macroeconomic variabilities and adapt to macroeconomic changes in a globalized economy. The observation that the world is shifting from managed toward entrepreneurial economy is not new. However, only

\footnotetext{
${ }^{5}$ Following (Klapper et al., 2010) (p. 131), one may define entrepreneurship as "the activities of an individual or a group aimed at initiating economic activities in the formal sector under a legal form of business."
} 
recently has globalization been considered as a major driver of this shift (Audretsch and Sanders, 2008; Audretsch and Thurik, 2004).

Vinig and De Kluijver (2008), Koster and Karlsson (2009), and more recently Thurik et al. (2013) take stock of existing research to hypothesize potential channels of linkage from globalization to entrepreneurship. The main "pull" — or opportunity-factors are identified as stemming from capital availability, productivity and product knowledge spillovers, ICT revolution, and cross-border movements of people. As countries open to FDI flows, new technologies, managerial, and training practices are transferred between countries. Greater availability of international capital also lowers its cost and provides much needed venture capital necessary for start-up entrepreneurial activity. Entrepreneurs gain and capitalize on product knowledge by more easily imitating or complementing imported products. Higher market volatility and shifts in potential demand due to globalization can also create business opportunities (or risks) that small firms are better able to exploit and adapt to (Verheul et al., 2002).

Another important "symptom" of globalization manifests through the presence of multinational enterprises (MNEs). Larger MNEs not only introduce new technologies to host countries but also play a role in encouraging domestic entrepreneurship by providing imitation role models and productivity and knowledge spillovers (Clercq, Hessels, and van Stel 2006). In an illustrative example, McKeon et al. (2004) provide qualitative evidence that MNEs were an important source of entrepreneurial learning while serving as incubators for budding entrepreneurs in the Irish IT sector.

In a similar vein, there exists a well-documented history of people learning from employment at large corporations, subsequently leaving them to form own start-ups (e.g., Steven Jobs of Apple and Chester Carlsson of Xerox) (Audretsch and Thurik, 2004). Moreover, recent trends in production reorganization provided opportunities for small firms to arise to subcontract and act as local suppliers of non-core services for the MNEs (e.g., security, delivery, catering, cleaning, tailoring, etc.) (Thurik et al., 2013; Verheul et al., 2002).

Greater labor and human mobility in general contributed to knowledge spillovers but also to increases in demand for variety and exposure to other cultures (Verheul et al., 2002). The diversification of demand and preference-learning can act encouragingly on potential 
entrepreneurs to fill in emerging market niches. Smaller firms in particular are better able to adapt to these changes in demand (Verheul et al., 2002).

Despite these descriptive analyses, empirical evidence in this arena is lacking. In a pilot exercise, Vinig and De Kluijver (2008) study the bivariate cross-sectional relationship between the KOF globalization index and rate of nascent and actual entrepreneurship in a sample of 30 countries but find no support to the hypothesis that globalization positively affects entrepreneurship. Eeckhout and Jovanovic (2012) examine the issue from a related angle, asking how openness and international labor market integration relate to occupational choice. In a formal model they posit that in high skilled (developed) economies, a disproportionate share of people switches to managerial positions after integration. Using similar data as Vinig and De Kluijver (2008) as well as own data on the share of managerial positions as the dependent variable, they find that globalization and openness positively influence entrepreneurial activity, especially in richer countries.

In tandem with globalization the EU underwent the process of "Europeanization." Although the two concepts are closely related, Europeanization — or EU-specific globalizationis typically considered to be more "intense" in that it entails cooperation with EU at the expense of third countries. This is not surprising given the perpetual process of institutionbuilding occurring within the union since its formation. From its beginnings as a free trade area, the EU had evolved to a customs union, single market, and ultimately a monetary union by the end of the 20th century. For instance, the process of institutional integration has been linked with long-run trade deepening between EU member countries (Agur, Dorrucci, and Mongelli 2007).

The deepening of integration is designated by EU bureaucrats as an ipso facto goal of making a more "genuine union" (see, e.g., the 2012 Four Presidents Report). Examinations of the economic impact of EU integration recently gained more traction in the empirical literature. Notably, Campos, Coricelli, and Moretti (2014) use synthetic counterfactuals method to find that enlargement countries would have suffered per capita income penalty of 12 percent on average had they not joined the EU. Badinger (2005) finds per capita income penalty of 20 percent for the EU as a whole had integration not taken place. Several studies find that EU economic integration enhances growth and convergence of old and new EU 
members alike (König, 2015; Mann, 2015; Crespo Cuaresma et al., 2008). ${ }^{6}$

Membership in the EU also entails an important political dimension of regional integration. Upon joining, countries become a part of a political structure resembling marketpreserving federalism (Weingast, 1995). This type of federal structure is characterized by the existence of multiple layers of government (federal and state) maintaining separate scopes of authority, with sub-federal governments having primary regulatory control over own economies. These "sub-federal jurisdictions," or in this case EU member states, coexist in a common market in which they are unable to new erect trade or capital barriers with other members or have access to unlimited credit and printing presses.

The economic consequences of market-preserving federalism are well documented in the public finance literature (e.g., Tiebout, 1956). The presence of a common market of unrestricted mobility along with the independence of sub-federal jurisdictions ensures that these jurisdictions compete for capital and labor by providing bundles of new public policies and services. Accordingly, institutional quality within EU member states is subject to pressures to improve over time in order to attract economic activity or suffer losses.

However, for a given level of institutional quality once a country joins EU, further deepening of integration is indicative of de facto increases in economic activity between member states stemming from their increased reliance on the common market. With higher levels of integration, the extent of the market expands within member states as their economies re-orient from home toward the common market. In a Smithian vein, this expansion of the market creates new opportunities for specialization and division of labor that entrepreneurial individuals can exploit.

No empirical study to my knowledge tests how integration relates to entrepreneurship in the EU. Increasing levels of self-employed population and formation of microfirms over time are indicative of a more entrepreneurial and more dynamic economy, all else equal. Micro firms comprise between 69 and 97 percent of total businesses (average of around 90 percent) while the self-employment rates range from 6 to nearly 37 percent (average 16 percent) in largest regression subsamples in this chapter. The economic activity of the self-employed is typically conducted via these microfirms, and their effect on generating future employment

\footnotetext{
${ }^{6}$ See Badinger and Breuss (2011) for an exhaustive review of quantitative effects of EU integration.
} 
and growth is recognized in most recent studies at least among more developed countries (Erken et al., 2016; Thurik et al., 2008; Carree et al., 2007). ${ }^{7}$ Empirical evidence on the topic can help illuminate the effects on entrepreneurship levels as the EU turns inward economically and further integrates institutionally.

\subsection{Data and Methodology}

The primary unit of measurement for entrepreneurial activity used in this chapter is the size of the private startup (microfirm) sector scaled by the size of the labor force, or microfirm density. Micro firms, defined as enterprises employing between 1 and 9 employees, are typically formed through either self-employment (sole proprietorship) or joint venture (partnership) between few entrepreneurial individuals. In that regard, increases in entrepreneurial activity on the margin and over the shorter-run can be initially seen, all else equal, through increased presence of startups as these microfirms are typically at the starting point for entrepreneurial individuals seeking to be own employer. Data on microfirms are obtained from OECD Structural and Demographic Business Statistics database. ${ }^{8}$

As additional robustness checks, three additional measures are considered: (i) the net entry of microfirms per labor (new net microfirm density), (ii) the share of microfirms in the number of total firms in the economy, and (iii) self-employment rate. The World Bank defines self-employed workers as "those workers who, working on their own account or with one or a few partners or in cooperative, hold the type of jobs defined as a 'self-employment jobs,' i.e., jobs where the remuneration is directly dependent upon the profits derived from the goods and services produced."

Data from observed samples show that EU countries did exhibit structural shifts over time toward a more entrepreneurial economy. Simple unreported bivariate regressions against a

\footnotetext{
${ }^{7}$ In an earlier study, Blanchflower (2000) finds that increases in self-employment do not significantly impact growth in OECD countries. However, as Carree and Thurik (2010) point out, his study may be subject to inconsistencies as it uses data of low cross-country comparability.

${ }^{8}$ In general, OECD defines an enterprise as "a legal entity possessing the right to conduct business on its own; for example, to enter into contracts, own property, incur liabilities for debts, and establish bank accounts. It may consist of one or more local units or establishments corresponding to production units situated in a geographically separate place and in which one or more persons work for the enterprise to which they belong."
} 
time trend and country fixed effects report that, on average, the number of microfirms per labor has been increasing at a pace of 4 percentage points per year, and the share of microfirms in total firms by 0.5 percent on average within countries per year between 2004 and 2012. The total number of firms per labor has been rising at a pace of 3.6 percent per year. Appendix Figure 4.1 depicts the average share of microfirms for 24 EU countries between 2004 and 2012. During this period, Greece had the highest average share of microfirms in total number of business in the EU (96.4 percent), while Slovak Republic had the lowest (80.6 percent).

The main explanatory variables of interest are the two components of the EU index developed by König and Ohr (2013). The two indices, the single market and institutional conformity index, respectively measure the depth of economic and political integration with the EU for each member country. The single market index captures the extent to which an EU country relies on the EU Single Market. It combines four indicators of economic integration: the sum of intra-EU imports and exports, inward and outward EU capital (FDI) stock, and (inward) European workers both as the share of the total trade, FDI stock, and foreign employees, as well as GDP and total number of employees. ${ }^{9}$

The institutional conformity (political integration) index captures membership in the Schengen zone (no passport/border checkpoints between EU countries) and monetary union, and the countries' compliance with EU law in the fields of environment and consumer protection, single market compliance, and other sectors. The value of the index increases in the "quantity" of compliance, as well as EMU and Schengen Zone participation. The authors use principal component analysis to calculate the weights of the integration indices that each range from 0 to the maximum of 100 .

The single market indicator closely relates to economic globalization and serves as the share of economic activity conducted with the EU single market as opposed to home or world markets. The distinction is salient given that re-orientation of economic activity toward the single market implies even greater exposure to competition as the common market means EU countries are unable to impose trade and other barriers on other members by virtue of their

\footnotetext{
${ }^{9}$ Intra-EU here refers to the EU-14, the cluster of 14 "old" and more developed Western EU members that joined by 1995 (except Luxembourg).
} 
EU membership. The focus on only the microfirms also mitigates concerns of a feedback loop as these startups primarily operate domestically (they are least likely to compete on the single market) rather than internationally. In that vein, while microfirms are unlikely to themselves influence the extent of trade, capital, and migration flows with the EU Single Market, they are more likely be affected by the changes in the economic environment brought about by economic integration with the EU.

At higher levels of the economic integration index, a member state's economic activity becomes more concentrated on the EU single market relative to domestic and world markets. Greater economic interdependence with the EU expands the size of home markets and can provide opportunities for entrepreneurial learning and specialization, but it also generates greater competitive pressures that crowd out low-efficiency firms and diminish expected profits. Higher shares of EU employees in domestic labor force stimulates demand for variety at home (e.g., ethnic restaurants), and also drives up general demand as EU immigrants tend to also bring their families when settling in other EU countries. Furthermore, immigrants bring new business practices and ideas and, down the line, themselves increase entrepreneurial supply in the host country (Baycan-Levent and Nijkamp, 2005).

Thus far, the discussion has mostly focused on the economic aspect of EU integration; however, an equally important dimension lies in countries' institutional conformity with the EU. The institutional conformity (political) index of EU integration increases in the intensity of EU member's participation in the Schengen zone and monetary union, as well as when a country exhibits better compliance with EU law. The Schengen zone is the EU's area of checkpoint-free travel between member countries. The removal of passport requirements and border checkpoints facilitates transportation, business travel, and tourism within the territory of the zone, potentially increasing demand for variety and profitability of entrepreneurial opportunities.

The adoption of euro as the official currency and joining the European Exchange Rate Mechanism (ERM) can reduce transaction costs of operating a business and lowers exchange and interest rate uncertainty making start-up capital acquisition at home or from abroad less costly. Additionally, institutional conformity signals compliance with various EU regulations that serve to protect consumers and businesses alike from unfair competition practices, 
intellectual property theft, state favoritism of certain firms, as well as other tortious acts.

To test the relationship between EU integration and startup prevalence in $24 \mathrm{EU}$ countries between 2004 and 2012, I estimate the following econometric model:

$$
\ln \left(\frac{M I C R O_{i, t}}{L A B O R_{i, t}}\right)=\alpha+\beta_{1} S M K T_{i, t}+\beta_{2} P O L_{i, t}+\boldsymbol{\theta} \boldsymbol{X}^{\prime}+\nu_{i}+\delta_{t}+u_{i, t}
$$

where MICRO denotes the number of enterprises 1-9 employees in size and LABOR is labor force size (World Bank WDI). The variable SMKT is the economic integration index, POL denotes political integration, $\mathrm{X}$ is the vector of control variables, is the country-specific fixed effect, are the year fixed effects, and is the idiosyncratic error term. Equation (4.1) speaks directly to the relationship between economic and political integration on the one hand, and the growth of the private sector in the domain of micro or startup firms. Controlling for covariates, positive and statistically significant coefficients and are suggestive of integration contributing toward industrial restructuring toward an entrepreneurial economy within EU member countries.

Literature points to the importance of demographic, economic, and institutional factors as determinants of country-level entrepreneurial activity. ${ }^{10}$ Remaining independent variables control for a range of country-level characteristics such as relative levels of development (log of real GDP per capita, World Bank WDI), unemployment rate (World Bank WDI, ILO estimate), institutional quality (the composite Fraser Institute's Economic Freedom of the World Index) ${ }^{11}$, secondary and tertiary education attainment levels (percentage of workingage population, CEPII Institute), population density (people per square kilometer of land area, World Bank WDI), percentage of urban population (World Bank WDI), and labor force participation rate for ages $15+$ (World Bank WDI).

To the extent that entrepreneurial culture matters for entrepreneurship (see, e.g., Wennekers et al., 2007), it will be absorbed in the country-specific fixed effect as cultural attitudes

\footnotetext{
${ }^{10}$ See, e.g., Sambharya and Musteen (2014), Bjørnskov and Foss (2008), Nyström (2008), Verheul et al. (2002).

${ }^{11}$ The composite index ranges from 0 to 10 and is increasing in the quality of institutions proxied by the five dimensions: (i) size of government, (ii) legal structure and property rights security, (iii) access to sound money, (iv) freedom to trade internationally, and (v) regulation of credit, labor, and business. The Economic Freedom of the World (EFW) (Gwartney et al., 2016) index has been cited in hundreds of scholarly studies that find a positive correlation between EFW and various "good" socio-economic outcomes.
} 
can be considered largely time-invariant over shorter periods for most prominent indicators

of national culture (e.g., Schwartz, Hofstede). Other time-invariant determinants of entrepreneurship such as historical circumstances, geography, post-socialist heritage, and legal systems are likewise controlled for by this method. Appendix Table 4.1 reports summary statistics for all variables included in the empirical analysis.

Countries included in the empirical analysis comprise all EU countries that joined by 2004 except Luxembourg which contains many extreme values and is therefore omitted from the calculations of the index (König and Ohr, 2013). The included countries are: Austria, Belgium, Cyprus, Czech Republic, Denmark, Estonia, Finland, France, Germany, Greece, Hungary, Ireland, Italy, Latvia, Lithuania, Malta, Netherlands, Poland, Portugal, Slovakia, Slovenia, Spain, Sweden, and the United Kingdom. Three most recent EU members Bulgaria (2007), Romania (2007), and Croatia (2013) are likewise excluded.

\subsection{Empirical Results}

\subsubsection{Main Estimates}

Appendix Table 4.2 reports Equation (4.1) parameter estimates. The dependent variable is the natural log of microfirms per capita. All estimates are obtained using country and year fixed effects. Standard errors are clustered at the country-level.

Empirical results from the several specifications in Table 4.2 suggest that microfirm density increases in the levels of single market (economic) and political integration, although the coefficient of political integration becomes statistically significant only in the full-controls model. For a unit increase in single market integration, the number of microfirms per capita rises by 1.6 percentage points within countries on average, and by 0.6 percentage points for a unit increase in political integration, all else equal. For a one standard deviation increase in single market integration index (about 10 index points) microfirm density increases by about 16 percentage points. Concurrently, for a one standard deviation increase in political integration (about 12 index point), microfirm density increases by 7.2 percentage points.

The baseline results suggest that EU integration has had a non-negligible impact on 
promoting the shift towards an entrepreneurial economy. Controlling for the economic, demographic, and institutional context, the expansion of economic and institutional proximity with EU positively affects the prevalence of microfirms in an EU economy. This finding suggests that the positive effects of integration due to potential productivity, knowledge, and technology spillovers as well as migration have, on net, outweighed potential crowding-out effects of more intense competition in a larger common market. Consequently, promoting openness as well as membership in common markets and monetary unions could prove useful from a policy standpoint in encouraging domestic startup creation.

\subsubsection{Robustness Checks}

To further test the validity of existing results, three additional models are estimated in Table 4.2:

$$
\begin{gathered}
\ln \left(\frac{\Delta M I C R O_{i, t}}{L A B O R_{i, t}}\right)=\alpha+\beta_{1} S M K T_{i, t}+\beta_{2} P O L_{i, t}+\boldsymbol{\theta} \boldsymbol{X}^{\prime}+\nu_{i}+\delta_{t}+u_{i, t} \\
\frac{M I C R O_{i, t}}{\operatorname{TOTAL}_{i, t}}=\alpha+\beta_{1} S M K T_{i, t}+\beta_{2} P O L_{i, t}+\boldsymbol{\theta} \boldsymbol{X}^{\prime}+\nu_{i}+\delta_{t}+u_{i, t} \\
S E L F L_{i, t}=\alpha+\beta_{1} S M K T_{i, t}+\beta_{2} P O L_{i, t}+\boldsymbol{\theta} \boldsymbol{X}^{\prime}+\nu_{i}+\delta_{t}+u_{i, t}
\end{gathered}
$$

where TOTAL is the total number of firms in a country (OECD), and SELF is the selfemployment rate (World Bank WDI). Equation (4.2) examines whether and how EU integration affected the net entry rate of micro firms per labor. ${ }^{12}$ Equation (4.3) studies how the share (percentage) of microfirms in total number of firms per country changes in the levels of integration, while Equation (4.4) examines self-employment rate as another indicator for entrepreneurship.

Results from Table 4.3 report that increases in single market integration are positively associated at statistically usual levels with net entry rate of microfirms per labor, share of microfirms in total number of firms in the economy, and the rate of self-employment.

\footnotetext{
${ }^{12}$ Because $\ln (x)$ is defined only for when $x>0$, this specification considers only the years in which the net entry of microfirms was positive overall. Positive effect of integration indices would indicate that this positive net entry is even faster with higher integration. Using only the ratio first-difference (can be negative or positive) of microfirms to labor force, no significant results are obtained.
} 
For a unit increase in the single market integration index, net new density (net entry rate) increases by 7.4 percent. Additionally, the share of microfirms in total firms increases by about quarter-percent while self-employment rate by a one-tenth of one percent for a unit increase in the single market integration index. For a one standard deviation increase in single market integration index (about 10 index points), net entry increases by as much as 74 percent. Moreover, the share of microfirms in total firms increases by 2.3 percent while self-employment rate increases by about 1 percentage point, which is a modest effect.

With respect to political integration, results are statistically significant in all but specification (2). Results suggest that unit increases in political integration are statistically significantly associated with a 3.5 percent increase in net new density and only 0.05 percent increases in self-employment rates. For one standard deviation increase in political integration (about 12 index point), net new density is higher by 42 percent and self-employment by 0.6 percent, again a modest effect. However, increases in both economic and political integration increased by one standard deviation would be associated with about 1.6 percent increase in self-employment rate, a quarter of its standard deviation and a non-trivial increase.

Overall, the results from this and the preceding section present some preliminary evidence in favor of the hypothesis that economic integration and ensuing changes in economic circumstances help foster a climate suitable for entrepreneurship. The results point to the existence of positive spillovers on potential entrepreneurs arising from deepening of economic cooperation with the EU in terms of trade, capital flows, and intra-European migration. In addition to economic, political integration also positively correlates with entrepreneurship measures. This finding suggests that the erasure of border checkpoints throughout EU, the adoption of euro, and better compliance with EU single market laws may provide an entrepreneurial incentive through better macroeconomic stability, lower transactions costs, more tourism, and adherence to EU competitive legislation. 


\subsection{Concluding Remarks}

In 2004, 10 new countries joined the EU's common market and committed to joint institutional evolution of the 25-member bloc. EU membership and integration have been shown in the empirical literature to positively affect economic development and institutional quality within member countries. However, the impact of the changing economic and institutional landscape on the entrepreneurship levels, an important correlate of development, has not been explored as of yet.

A globalizing economy can crowd out small firms and depress expected profits in an increasingly competitive environment. Alternatively, it can provide an impetus for entrepreneurship by generating knowledge and productivity spillovers arising from increased cross-national flows of goods, capital, and migration that enterprising individuals can exploit. Has the linkage between globalization/regional integration and entrepreneurship been operative, and if so, in which direction? To provide a preliminary answer to this question, this chapter examines how EU integration, or EU-specific globalization, affected the prevalence of business startups and self-employment rate within its member states.

This chapter explores whether and how might EU economic and political integration have have affected the prevalence of microfirms and self-employment within member countries between 2004 and 2012. Entrepreneurial activity is proxied by the rates of self-employment, density of microfirms (1-9 employees) per labor, (net) entry rate of microfirms per labor, and share of microfirm startups in total number of firms in the economy. The main finding is that single market integration - expressed through greater intra-EU flows of goods, capital, and people as the share of national economy - is significantly and positively associated with the above measures of entrepreneurship. Similar results are found for political integration,

although I find non-association between political integration and the share of microfirms in total number of firms within a country. These results provide preliminary empirical evidence in favor of the conjecture of positive effects of regional (i.e., European) integration on industrial restructuring toward an entrepreneurial economy across the world. 


\subsection{Appendix}

Figure 4.1: Average share of micro firms in total number of firms per country, 2004-2012.

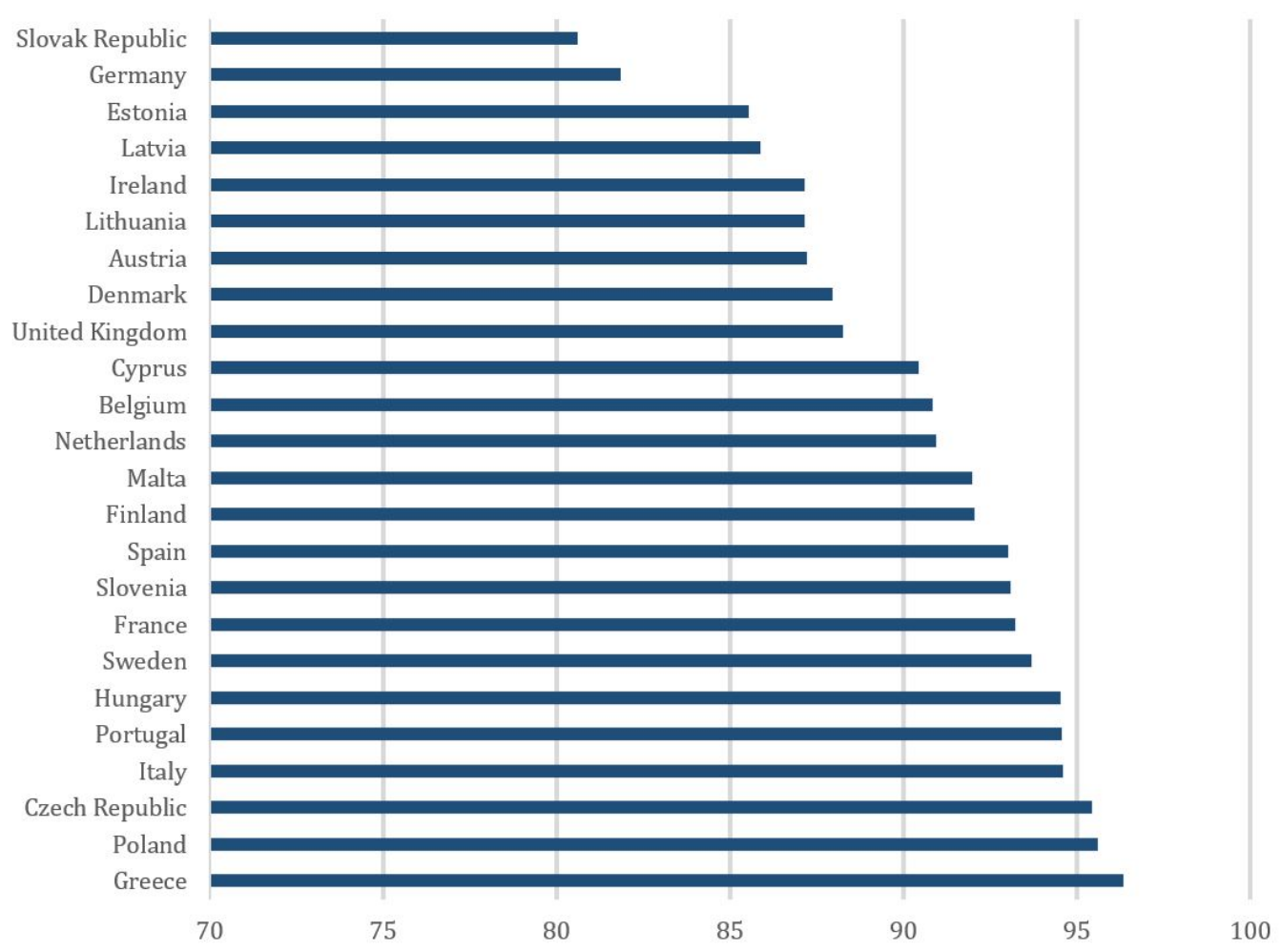


Table 4.1: Summary statistics for regression subsample variables.

\begin{tabular}{lcccc}
\hline \hline Variable & Mean & Std. Dev. & Min & Max \\
\hline Share of micro firms in total number of firms (\%) & 90.54 & 5.13 & 69.75 & 97.43 \\
(Log) micro firm density & -2.686 & 0.447 & -3.855 & -1.853 \\
(Log) new net micro firm density & -6.219 & 1.145 & -10.536 & -3.134 \\
Single market integration & 40.92 & 10.29 & 21.68 & 75.88 \\
Political integration & 77.36 & 11.76 & 46.78 & 97.95 \\
Real GDP per capita (USD) & $\$ 26,557$ & $\$ 13,526$ & $\$ 7,634$ & $\$ 50,695$ \\
Labor force participation rate (\%) & 58.67 & 4.70 & 48.10 & 71.1 \\
Unemployment rate (\%) & 8.61 & 4.00 & 2.80 & 25.20 \\
Population density & 165.11 & 209.33 & 17.16 & 1310.80 \\
Urban population (\%) & & & & \\
Secondary education (\%) & 72.64 & 11.54 & 49.85 & 97.73 \\
Tertiary education (\%) & & & & \\
EFW index & 82.90 & 11.47 & 45.90 & 97.68 \\
\hline \hline
\end{tabular}

Notes: summary statistics calculated from table 2 specification (3) and specification (4) (only for self-employment rate). 
Table 4.2: Fixed effects regressions of micro firm density on EU economic and political integration indices for 24 EU countries, 2004-2012.

\begin{tabular}{|c|c|c|c|}
\hline Dep. Var.: Log Micro Firm Density & $(1)$ & $(2)$ & $(3)$ \\
\hline Single market integration & $\begin{array}{c}0.024^{*} \\
(0.013)\end{array}$ & $\begin{array}{c}0.024^{*} \\
(0.012)\end{array}$ & $\begin{array}{l}0.016^{*} \\
(0.009)\end{array}$ \\
\hline Political integration & $\begin{array}{c}0.007 \\
(0.006)\end{array}$ & $\begin{array}{l}0.006 \\
(.004)\end{array}$ & $\begin{array}{l}0.006^{*} \\
(0.004)\end{array}$ \\
\hline Unemployment rate & & $\begin{array}{c}0.002 \\
(0.012)\end{array}$ & $\begin{array}{c}0.025 \\
(0.017)\end{array}$ \\
\hline Population density & & $\begin{array}{l}-0.004 \\
(0.007)\end{array}$ & $\begin{array}{c}0.004 \\
(0.006)\end{array}$ \\
\hline Urban population share & & $\begin{array}{l}-0.052 \\
(0.075)\end{array}$ & $\begin{array}{l}-0.001 \\
(0.036)\end{array}$ \\
\hline Labor force participation rate & & $\begin{array}{l}-0.033 \\
(0.021)\end{array}$ & $\begin{array}{l}-0.039 \\
(0.024)\end{array}$ \\
\hline (Log) real GDP per capita & & & $\begin{array}{l}2.940^{*} \\
(1.525)\end{array}$ \\
\hline Secondary education (\%) & & & $\begin{array}{l}-0.029 \\
(0.025)\end{array}$ \\
\hline Tertiary education (\%) & & & $\begin{array}{l}-0.028 \\
(0.031)\end{array}$ \\
\hline Economic Freedom (EFW) index & & & $\begin{array}{c}-0.595^{*} \\
(0.303)\end{array}$ \\
\hline Observations & 206 & 206 & 205 \\
\hline Countries & 24 & 24 & 24 \\
\hline$R^{2}$ & 0.28 & 0.31 & 0.44 \\
\hline
\end{tabular}

Notes: standard errors (in parentheses) are clustered at the country-level. All specifications include country and year fixed effects. Specifications (1) and (2) additionally control for the number of remaining firms in the economy. $* p<0.1, * * p<0.05, * * * p<0.01$. 


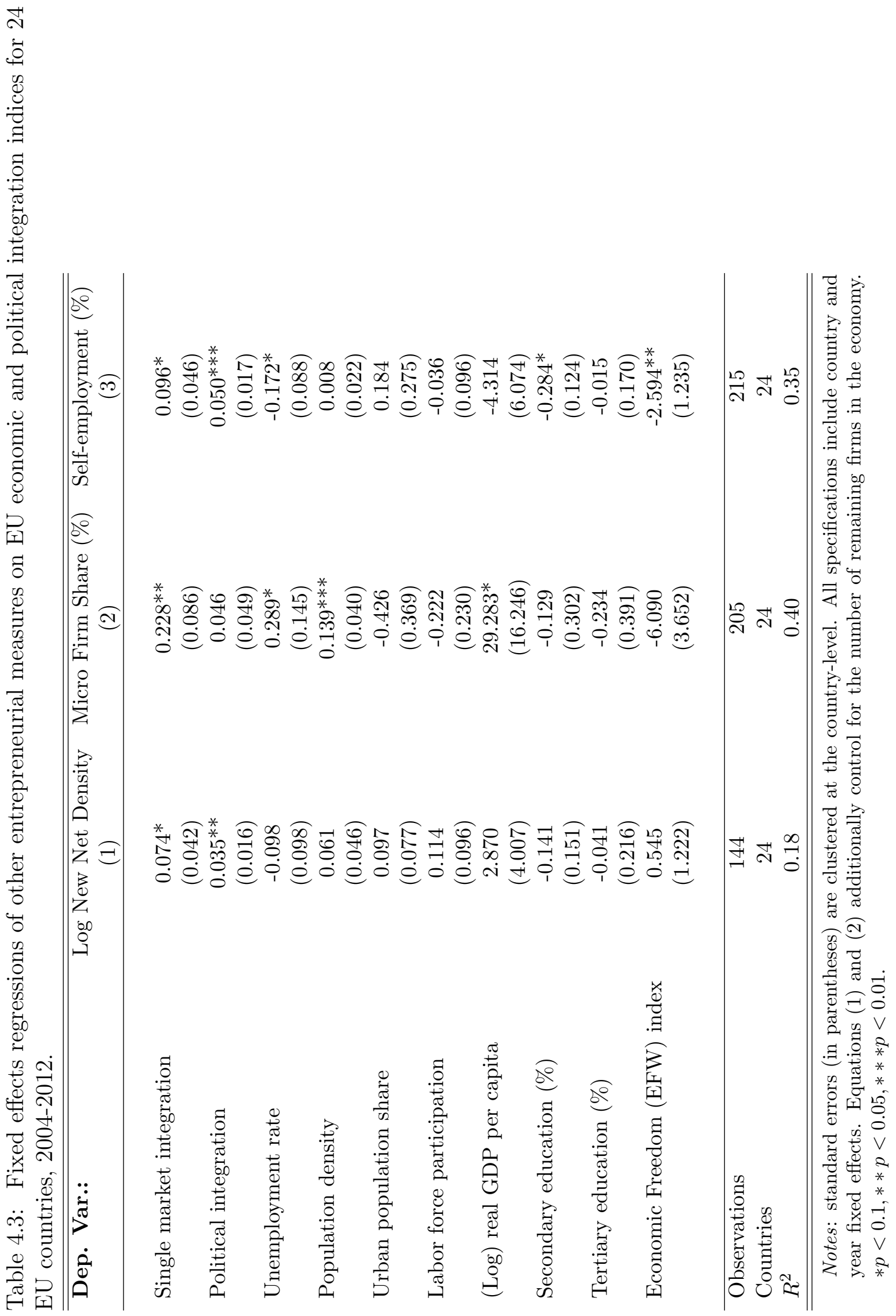




\section{Chapter 5}

\section{Conclusion}

The purpose of this dissertation was to better understand the factors contributing to institutional change across countries, as well as to uncover the economic consequences of cross-national economic and political integration. To this end, the three empirical essays presented herein focus largely on the countries of the European continent.

The reasons for this European focus are two-fold. First, the European Union stands as one of the most prominent examples in regional integration, whereby 500 million people across 28 countries share a common market and commit to join institutional evolution. The socio-economic effects of regional integration have recently re-entered the policy spotlight as evidenced by the ongoing Eurozone crisis and the "Brexit" referendum.

Second, the post-communist economies of Eastern Europe and Central Asia provided unprecedented insights into the issues concerning institutional change. Addressing the factors driving institutional transition towards free markets and private property, I hypothesize that culture had a significant moderating influence on the effectiveness of democratization in promoting the adoption of market-based reforms in these countries.

In Chapter 2, I examine cultural orientations, based on (Hofstede and Hofstede, 2001; Hofstede, 1980) typologies, and their interplay with political liberalization in promoting market reforms over the 1989-2001, in the immediate aftermath of communism's collapse. The main finding is that a sense of individualism and intolerance for inherently unequal power hierarchies improved the effectiveness of democracy, suggesting that democratization in societies strongly fostering these sentiments enhanced reform efforts in these countries. 
This finding is robust to a number of additional controls, including an IV specification that treats democracy as endogenous and instruments for domestic democracy by a weighted average of a country's neighboring democracy levels.

Chapter 3 looks at the entirety of the European continent and studies the impact of EU integration on the long-run institutional convergence among the countries of Europe between 1970 and 2010. The two mechanisms of EU integration - the accession process and the membership stage - may promote institutional improvement via institutional anchoring in the pre-membership stage, and Tiebout-like competition in the membership stage. This chapter finds that there exists a small (though often statistically insignificant) positive effect of joining EU on the promotion the institutions of economic freedom, consistent with the hypothesis of inter-jurisdictional competition existing within the EU's common market; also, of liberalizing reform implementation as a conditioning mechanism of EU membership.

Chapter 4 examines how the deepening of economic and political integration affected industrial restructuring within 24 EU member states between 2004 and 2012. Drawing from recent literature that highlights the forces of globalization as important drivers of the switch to an entrepreneurial economy, I ask whether European regional integration contributed to the increases in microfirm and self-employment prevalence over the observed period. The chapter provides suggestive evidence that the deepening of EU member countries' reliance on the largest competitive common market in the world, rather than suppressed it, spurred entrepreneurial activity, an important correlate of economic development, by encouraging entrepreneurial learning, innovation, and attitudes.

The contributions of this dissertation call attention to the challenges associated with institutional improvement across countries, as well as the issues concerning the costs and benefits of EU integration. Findings suggest that regional integration creates the environment for faster economic institutional reform, encourages industrial restructuring towards an entrepreneurial-based economy, and that the underlying culture must be taken into account when considering the impact of political liberalization on institutional change. 


\section{References}

Acs, Z. J. (2010). Entrepreneurship and economic development: the valley of backwardness. Annals of Innovation 83 Entrepreneurship, 1(1):1-18.

Aghion, P. and Howitt, P. (1992). A model of growth through creative destruction. Econometrica, 60(2):323-351.

Alesina, A., Algan, Y., Cahuc, P., and Giuliano, P. (2015). Family values and the regulation of labor. Journal of the European Economic Association, 13(4):599-630.

Alesina, A. and Fuchs-Schündeln, N. (2007). Good-bye lenin (or not?): The effect of communism on people's preferences. The American Economic Review, 97(4):1507-1528.

Alesina, A. and Giuliano, P. (2015). Culture and institutions. Journal of Economic Literature, 53(4):898-944.

Amin, M. and Djankov, S. (2014). Democratic institutions and regulatory reforms. Journal of Comparative Economics, 42(4):839-854.

Arellano, M. and Bond, S. (1991). Some tests of specification for panel data: Monte carlo evidence and an application to employment equations. The Review of Economic Studies, 58(2):277-297.

Arellano, M. and Bover, O. (1995). Another look at the instrumental variable estimation of error-components models. Journal of Econometrics, 68(1):29-51.

Ariely, D., Garcia-Rada, X., Hornuf, L., and Mann, H. (2015). The (true) legacy of two really existing economic systems. Munich Discussion Paper No. 2014-26.

Armingeon, K., Isler, C., Knöpfel, L., Weisstanner, D., and Engler, S. (2013). Codebook: Comparative political data set 1960-2013. Bern: Institute of Political Science, University of Bern.

Audretsch, D., Carree, M., Stel, A. V., and Thurik, R. (2002a). Impeded industrial restructuring: the growth penalty. Kyklos, 55(1):81-98. 
Audretsch, D. and Sanders, M. (2008). Globalization and the rise of the entrepreneurial economy. Discussion Paper Series/Tjalling C. Koopmans Research Institute, 8(21).

Audretsch, D. and Thurik, R. (2003). Entrepreneurship, industry evolution and economic growth. In Koppl, R., Birner, J., and Kurrild-Klitgaard, P., editors, Austrian Economics and Entrepreneurial Studies, volume 6, pages 39-56. Emerald Group Publishing Limited.

Audretsch, D. and Thurik, R. (2004). A model of the entrepreneurial economy. International Journal of Entrepreneurship, 2(2):143-166.

Audretsch, D., Thurik, R., Verheul, I., and Wennekers, S. (2002b). Understanding entrepreneurship across countries and over time. In Audretsch, D., Thurik, R., Verheul, I., and Wennekers, S., editors, Entrepreneurship: Determinants and Policy in a European-US Comparison, volume 27, pages 1-10. Springer.

Ayal, E. B. and Karras, G. (1998). Components of economic freedom and growth: an empirical study. The Journal of Developing Areas, 32(3):327-338.

Babecky, J. and Havranek, T. (2014). Structural reforms and growth in transition. Economics of Transition, 22(1):13-42.

Badinger, H. (2005). Growth effects of economic integration: evidence from the eu member states. Review of World Economics, 141(1):50-78.

Badinger, H. and Breuss, F. (2011). The quantitative effects of european post-war economic integration. In Jovanovic, M. N., editor, International Handbook on the Economics of Integration: Factor Mobility, Agriculture, Environment and Quantitative Studies, volume 3, pages 285-315. Edward Elgar Publishing.

Barro, R. J. (1996). Democracy and growth. Journal of Economic Growth, 1(1):1-27.

Baskaran, T. and Hessami, Z. (2012). Public education spending in a globalized world. International Tax and Public Finance, 19(5):677-707. 
Baycan-Levent, T. and Nijkamp, P. (2005). Determinants of migrant entrepreneurship in europe. In ERSA conference papers, number ersa05p776. European Regional Science Association.

Beck, T., Clarke, G., Groff, A., Keefer, P., and Walsh, P. (2001). New tools in comparative political economy: The database of political institutions. The World Bank Economic Review, 15(1):165-176.

Beck, T. and Laeven, L. (2006). Institution building and growth in transition economies. Journal of Economic Growth, 11(2):157-186.

BenYishay, A. and Grosjean, P. (2014). Initial endowments and economic reform in 27 post-socialist countries. Journal of Comparative Economics, 42(4):892-906.

Berggren, N. and Jordahl, H. (2006). Free to trust: Economic freedom and social capital. Kyklos, 59(2):141-169.

Bergh, A. and Nilsson, T. (2014). Is globalization reducing absolute poverty? World Development, 62:42-61.

Beugelsdijk, S., Maseland, R., and Hoorn, A. (2015). Are scores on hofstede's dimensions of national culture stable over time? a cohort analysis. Global Strategy Journal, $5(3): 223-240$.

Beugelsdijk, S., Maseland, R., and Van Hoorn, A. (2013). Are hofstede's culture dimensions stable over time? a generational cohort analysis. SSRN Working Paper Version.

Bjørnskov, C. (2005). Political ideology and economic freedom. Working Paper 05-8. Aarhus School of Busines.

Bjørnskov, C. and Foss, N. J. (2008). Economic freedom and entrepreneurial activity: Some cross-country evidence. Public Choice, 3(134):307-328.

Bjørnskov, C. and Méon, P.-G. (2013). Is trust the missing root of institutions, education, and development? Public Choice, 157(3-4):641-669. 
Bjørnskov, C. and Potrafke, N. (2012). Political ideology and economic freedom across canadian provinces. Eastern Economic Journal, 38(2):143-166.

Bjørnskov, C. and Potrafke, N. (2013). The size and scope of government in the us states: does party ideology matter? International Tax and Public Finance, 20(4):687-714.

Blanchflower, D. G. (2000). Self-employment in oecd countries. Labour economics, $7(5): 471-505$.

Blundell, R. and Bond, S. (1998). Initial conditions and moment restrictions in dynamic panel data models. Journal of Econometrics, 87(1):115-143.

Boettke, P. J., Coyne, C. J., and Leeson, P. T. (2008). Institutional stickiness and the new development economics. American Journal of Economics and Sociology, 67(2):331-358.

Börzel, T. A. and Hosli, M. O. (2003). Brussels between bern and berlin: comparative federalism meets the european union. Governance, 16(2):179-202.

Brambor, T., Clark, W. R., and Golder, M. (2006). Understanding interaction models: Improving empirical analyses. Political Analysis, 14(1):63-82.

Busemeyer, M. R. and Tober, T. (2015). European integration and the political economy of inequality. European Union Politics, 16(4):536-557.

Campos, N. F., Coricelli, F., and Moretti, L. (2014). Economic growth and political integration: estimating the benefits from membership in the european union using the synthetic counterfactuals method. IZA Discussion Paper No. 8162.

Campos, N. F. and Horváth, R. (2009). Reform redux: measurement, determinants and reversals. Česká národní banka Working Paper Series.

Campos, N. F. and Horváth, R. (2012). Reform redux: Measurement, determinants and growth implications. European Journal of Political Economy, 28(2):227-237.

Carree, M., Van Stel, A., Thurik, R., and Wennekers, S. (2002). Economic development and business ownership: an analysis using data of 23 oecd countries in the period 1976-1996. Small Business Economics, 19(3):271-290. 
Carree, M., Van Stel, A., Thurik, R., and Wennekers, S. (2007). The relationship between economic development and business ownership revisited. Entrepreneurship 6 Regional Development, 19(3):281-291.

Carree, M. A. and Thurik, A. R. (2010). The impact of entrepreneurship on economic growth. In Acs, Z. J. and Audretsch, D. B., editors, Handbook of Entrepreneurship Research, volume 5, part VI, pages 557-594. Springer.

Carvalho, A., Nepal, R., and Jamasb, T. (2016). Economic reforms and human development: evidence from transition economies. Applied Economics, 48(14):1330-1347.

Chavance, B. (2008). Formal and informal institutional change: the experience of postsocialist transformation. The European Journal of Comparative Economics, 5(1):57.

Crespo Cuaresma, J., Ritzberger-Grünwald, D., and Silgoner, M. A. (2008). Growth, convergence and eu membership. Applied Economics, 40(5):643-656.

Dawson, J. W. (2006). Regulation, investment, and growth across countries. Cato Journal, $26(3): 489-509$.

De Haan, J. and Sturm, J.-E. (2000). On the relationship between economic freedom and economic growth. European Journal of Political Economy, 16(2):215-241.

De Melo, M., Denizer, C., Gelb, A., and Tenev, S. (2001). Circumstance and choice: The role of initial conditions and policies in transition economies. The World Bank Economic Review, 15(1):1-31.

Di Tommaso, M. L., Raiser, M., and Weeks, M. (2007). Home grown or imported? initial conditions, external anchors and the determinants of institutional reform in the transition economies. The Economic Journal, 117(520):858-881.

Dimitrova-Grajzl, V. (2007). The great divide revisited: Ottoman and habsburg legacies on transition. Kyklos, 60(4):539-558.

Dimitrova-Grajzl, V. and Simon, E. (2010). Political trust and historical legacy: The effect of varieties of socialism. East European Politics 85 Societies, 24(2):206-228. 
Dreher, A. (2006). Does globalization affect growth? evidence from a new index of globalization. Applied Economics, 38(10):1091-1110.

Durlauf, S. N. and Fafchamps, M. (2005). Social capital. In Aghion, P. and Durlauf, S. N., editors, Handbook of Economic Growth, volume 1, Part B, pages 1639 - 1699. Elsevier.

Eeckhout, J. and Jovanovic, B. (2012). Occupational choice and development. Journal of Economic Theory, 147(2):657-683.

Epple, D. and Zelenitz, A. (1981). The implications of competition among jurisdictions: does tiebout need politics? Journal of Political Economy, 89(6):1197-1217.

Erken, H., Donselaar, P., and Thurik, R. (2016). Total factor productivity and the role of entrepreneurship. The Journal of Technology Transfer, forthcoming, pages 1-29.

Falcetti, E., Lysenko, T., and Sanfey, P. (2006). Reforms and growth in transition: Re-examining the evidence. Journal of Comparative Economics, 34(3):421-445.

Falcetti, E., Raiser, M., and Sanfey, P. (2002). Defying the odds: Initial conditions, reforms, and growth in the first decade of transition. Journal of Comparative Economics, $30(2): 229-250$.

Fernandez, R. and Rodrik, D. (1991). Resistance to reform: Status quo bias in the presence of individual-specific uncertainty. The American Economic Review, 81(5):1146-1155.

Fidrmuc, J. (2003). Economic reform, democracy and growth during post-communist transition. European Journal of Political Economy, 19(3):583-604.

Fish, M. S. (1997). The determinants of economic reform in the post-communist world. East European Politics and Societies, 12(1):31-78.

Freytag, A. and Thurik, R. (2007). Entrepreneurship and its determinants in a cross-country setting. Journal of Evolutionary Economics, 17(2):117-131.

Gehring, K. (2013). Who benefits from economic freedom? unraveling the effect of economic freedom on subjective well-being. World Development, 50:74-90. 
Giuliano, P., Mishra, P., and Spilimbergo, A. (2013). Democracy and reforms: evidence from a new dataset. American Economic Journal: Macroeconomics, 5(4):179-204.

Goetz, S. J., Fleming, D. A., and Rupasingha, A. (2012). The economic impacts of self-employment. Journal of Agricultural and Applied Economics, 44(03):315-321.

Gorodnichenko, Y. and Roland, G. (2011). Which dimensions of culture matter for long-run growth? The American Economic Review, 101(3):492-498.

Gorodnichenko, Y. and Roland, G. (2012). Understanding the individualism-collectivism cleavage and its effects: Lessons from cultural psychology. In Aoki, M., Kuran, T., and Roland, G., editors, Institutions and Comparative Economic Development, pages 213-236. Springer.

Gorodnichenko, Y. and Roland, G. (2015). Culture, institutions and democratization. Working Paper 21117, National Bureau of Economic Research.

Gorodnichenko, Y. and Roland, G. (2016). Culture, institutions and the wealth of nations. Review of Economics and Statistics, forthcoming.

Grilo, I. and Irigoyen, J.-M. (2006). Entrepreneurship in the eu: to wish and not to be. Small Business Economics, 26(4):305-318.

Grilo, I. and Thurik, A. (2006). Entrepreneurship in the old and new europe. In Santarelli, E., editor, Entrepreneurship, Growth, and Innovation, pages 75-103. Springer.

Grilo, I. and Thurik, R. (2005a). Entrepreneurial engagement levels in the european union. International Journal of Entrepreneurship, 3(2):143-168.

Grilo, I. and Thurik, R. (2005b). Latent and actual entrepreneurship in europe and the us: some recent developments. International Entrepreneurship and Management Journal, $1(4): 441-459$.

Grilo, I. and Thurik, R. (2008). Determinants of entrepreneurial engagement levels in europe and the us. Industrial and Corporate Change, 17(6):1113-1145. 
Grosjean, P. (2011). The institutional legacy of the ottoman empire: Islamic rule and financial development in south eastern europe. Journal of Comparative Economics, $39(1): 1-16$.

Grosjean, P. and Senik, C. (2011). Democracy, market liberalization, and political preferences. The Review of Economics and Statistics, 93(1):365-381.

Guiso, L., Sapienza, P., and Zingales, L. (2003). People's opium? religion and economic attitudes. Journal of Monetary Economics, 50(1):225-282.

Guiso, L., Sapienza, P., and Zingales, L. (2004). The role of social capital in financial development. The American Economic Review, 94(3):526-556.

Guiso, L., Sapienza, P., and Zingales, L. (2006). Does culture affect economic outcomes? The Journal of Economic Perspectives, 20(2):23-48.

Guiso, L., Sapienza, P., and Zingales, L. (2009). Cultural biases in economic exchange? The Quarterly Journal of Economics, 124(3):1095-1131.

Guiso, L., Sapienza, P., and Zingales, L. (2010). Civic capital as the missing link. Working Paper 15845, National Bureau of Economic Research.

Gwartney, J., Lawson, R., and Hall, J. (2016). 2016 economic freedom dataset, published in economic freedom of the world: 2016 annual report.

Gwartney, J. D. and Lawson, R. A. (2006). The impact of tax policy on economic growth, income distribution, and allocation of taxes. Social Philosophy and Policy, 23(2):28-52.

Gwartney, J. D., Lawson, R. A., and Holcombe, R. G. (1999). Economic freedom and the environment for economic growth. Journal of Institutional and Theoretical Economics (JITE)/Zeitschrift für die gesamte Staatswissenschaft, 155(4):643-663.

Hall, J., Lawson, R., and Wogsland, R. (2011). The european union and economic freedom. Global Economy Journal, 11(3):1-14.

Hall, J. C. and Lawson, R. A. (2014). Economic freedom of the world: an accounting of the literature. Contemporary Economic Policy, 32(1):1-19. 
Heckelman, J. C. and Stroup, M. D. (2000). Which economic freedoms contribute to growth? Kyklos, 53(4):527-544.

Hirschman, A. O. (1978). Exit, voice, and the state. World Politics: A Quarterly Journal of International Relations, 31(1):90-107.

Hofstede, G. (1980). Culture's Consequences: International Differences in Work-Related Values, volume 5. Sage Publications.

Hofstede, G., Hofstede, G. J., and Minkov, M. (2010). Cultures and organizations: Software of the mind. revised and expanded. McGraw-Hill, New York.

Hofstede, G. H. and Hofstede, G. (2001). Culture's Consequences: Comparing Values, Behaviors, Institutions and Organizations Across Nations. Sage.

Kim, B.-Y. and Pirttilä, J. (2006). Political constraints and economic reform: Empirical evidence from the post-communist transition in the 1990s. Journal of Comparative Economics, 34(3):446-466.

Kirzner, I. M. (1997). Entrepreneurial discovery and the competitive market process: An austrian approach. Journal of Economic Literature, 35(1):60-85.

Klapper, L., Amit, R., and Guillén, M. F. (2010). Entrepreneurship and firm formation across countries. In Lerner, J. and Schoar, A., editors, International Differences in Entrepreneurship, pages 129-158. University of Chicago Press.

Klasing, M. J. (2013). Cultural dimensions, collective values and their importance for institutions. Journal of Comparative Economics, 41(2):447-467.

Knack, S. and Keefer, P. (1997). Does social capital have an economic payoff? a cross-country investigation. The Quarterly Journal of Economics, 112(4):1251-1288.

Kogut, B. and Singh, H. (1988). The effect of national culture on the choice of entry mode. Journal of International Business Studies, 19(3):411-432.

König, J. (2015). European integration and the effects of country size on growth. Journal of Economic Integration, 30(3):501-531. 
König, J. and Ohr, R. (2013). Different efforts in european economic integration: implications of the eu index. Journal of Common Market Studies, 51(6):1074-1090.

Kornai, J. (1992). The Socialist System: The Political Economy of Communism. Oxford University Press.

Koster, S. and Karlsson, C. (2009). New firm formation and economic development in a globalizing economy. Cesis Working Paper $16 \%$.

Kreft, S. F. and Sobel, R. S. (2005). Public policy, entrepreneurship, and economic freedom. Cato Journal, 25:595.

Kutan, A. M. and Yigit, T. M. (2007). European integration, productivity growth and real convergence. European Economic Review, 51(6):1370-1395.

Landier, A., Thesmar, D., and Thoenig, M. (2008). Investigating capitalism aversion. Economic Policy, 23(55):466-497.

Lawson, R. A. and Clark, J. R. (2010). Examining the hayek-friedman hypothesis on economic and political freedom. Journal of Economic Behavior $\&$ Organization, $74(3): 230-239$.

Leeson, P. T. and Dean, A. M. (2009). The democratic domino theory: an empirical investigation. American Journal of Political Science, 53(3):533-551.

Licht, A. N., Goldschmidt, C., and Schwartz, S. H. (2005). Culture, law, and corporate governance. International Review of Law and Economics, 25(2):229-255.

Licht, A. N., Goldschmidt, C., and Schwartz, S. H. (2007). Culture rules: The foundations of the rule of law and other norms of governance. Journal of Comparative Economics, $35(4): 659-688$.

Mann, K. (2015). The eu, a growth engine? the impact of european integration on economic growth in central eastern europe. FIW Working Paper 136.

Marshall, M., Jaggers, K., and Gurr, T. (2012). Political regime characteristics and transitions, 1800-2008, polity iv project. 
McCleary, R. and Barro, R. (2003). Religion and economic growth across countries. American Sociological Review, 68(5):760-781.

McKeon, H., Johnston, K., and Henry, C. (2004). Multinational companies as a source of entrepreneurial learning: examples from the it sector in ireland. Education + Training, 46(8/9):433-443.

Melitz, M. J. (2003). The impact of trade on intra-industry reallocations and aggregate industry productivity. Econometrica, 71(6):1695-1725.

Merlevede, B. (2003). Reform reversals and output growth in transition economies. Economics of Transition, 11(4):649-669.

Mrak, M. and Rojec, M. (2013). Eu accession as an instrument for speeding up transition. In Hare, P. and Turley, G., editors, Handbook of the Economics and Political Economy of Transition, pages 198-205. Taylor \& Francis.

Nannicini, T., Stella, A., Tabellini, G., and Troiano, U. (2013). Social capital and political accountability. American Economic Journal: Economic Policy, 5(2):222-250.

Nickell, S. (1981). Biases in dynamic models with fixed effects. Econometrica, 49(6):1417-1426.

Nikolaev, B. (2014). Economic freedom \& subjective well-being-revisiting the relationship. Mimeo, pages 1-31.

Norbäck, P.-J., Persson, L., and Douhan, R. (2014). Entrepreneurship policy and globalization. Journal of Development Economics, 110:22-38.

North, D. (1992). Institutions, ideology, and economic performance. Cato Journal, 11(3):477-496.

North, D. C. (2005). The contribution of the new institutional economics to an understanding of the transition problem. In Shorrocks, A., editor, Wider Perspectives on Global Development, pages 1-15. Springer. 
Nyström, K. (2008). The institutions of economic freedom and entrepreneurship: evidence from panel data. Public Choice, 136(3):269-282.

Ovaska, T. and Takashima, R. (2006). Economic policy and the level of self-perceived well-being: An international comparison. The Journal of Socio-Economics, $35(2): 308-325$.

Pejovich, S. (2003). Understanding the transaction costs of transition: it's the culture, stupid. The Review of Austrian Economics, 16(4):347-361.

Potrafke, N. (2013). Economic freedom and government ideology across the german states. Regional Studies, 47(3):433-449.

Potrafke, N. (2015). The evidence on globalisation. The World Economy, 38(3):509-552.

Potrafke, N. and Ursprung, H. W. (2012). Globalization and gender equality in the course of development. European Journal of Political Economy, 28(4):399-413.

Putnam, R. D., Leonardi, R., and Nanetti, R. Y. (1994). Making democracy work: Civic Traditions in Modern Italy. Princeton University Press.

Qian, Y. and Weingast, B. R. (1997). Federalism as a commitment to perserving market incentives. The Journal of Economic Perspectives, 11(4):83-92.

Roland, G. (2004). Understanding institutional change: Fast-moving and slow-moving institutions. Studies in Comparative International Development (SCID), 38(4):109-131.

Roland, G. (2015). Economics and culture. In Scott, R. A. and Kosslyn, S. A., editors, Emerging Trends in the Social and Behavioral Sciences: An Interdisciplinary, Searchable, and Linkable Resource, pages 1-18. John Wiley \& Sons, Inc.

Rosenbaum, E. F. (2001). Culture, cognitive models, and the performance of institutions in transformation countries. Journal of Economic Issues, 35(4):889-909.

Sambharya, R. and Musteen, M. (2014). Institutional environment and entrepreneurship: An empirical study across countries. Journal of International Entrepreneurship, $12(4): 314-330$. 
Schwartz, S. (1994). Beyond Individualism-Collectivism: New Cultural Dimensions of Values. Sage.

Schweickert, R., Melnykovska, I., Belke, A., and Bordon, I. (2011). Prospective nato or eu membership and institutional change in transition countries. Economics of Transition, 19(4):667-692.

Sell, C. W. (2005). Economic freedom in the 25-member european union: Insights using classification tools. In Weihs, C. and Gaul, W., editors, Classification-the Ubiquitous Challenge, pages 553-560. Springer.

Sobel, R. S. (2008). Testing baumol: Institutional quality and the productivity of entrepreneurship. Journal of Business Venturing, 23(6):641-655.

Spolaore, E. (2015). The political economy of european integration. Working Paper 21250, National Bureau of Economic Research.

Stern, N. (1997). The transition in eastern europe and the former soviet union: some strategic lessons from the experience of 25 countries over six years. In Zecchini, S., editor, Lessons from the Economic Transition, pages 35-57. Springer.

Stroup, M. D. (2007). Economic freedom, democracy, and the quality of life. World Development, 35(1):52-66.

Tabellini, G. (2010). Culture and institutions: economic development in the regions of europe. Journal of the European Economic Association, 8(4):677-716.

Thompson, M., Ellis, R., and Wildavsky, A. (1990). Cultural Theory. Westview Press.

Thurik, A., Stam, E., and Audretsch, D. B. (2013). The rise of the entrepreneurial economy and the future of dynamic capitalism. Technovation, 33(8):302-310.

Thurik, A. R., Carree, M. A., Van Stel, A., and Audretsch, D. B. (2008). Does self-employment reduce unemployment? Journal of Business Venturing, 23(6):673-686.

Tiebout, C. M. (1956). A pure theory of local expenditures. Journal of Political Economy, $64(5): 416-424$. 
Trauner, F. (2009). Post-accession compliance with eu law in bulgaria and romania: a comparative perspective. In Schimmelfennig, F. and Trauner, F., editors, Post-accession compliance in the EUs new member states, volume 13, chapter 21. European Integration online Papers (EIoP).

Ugur, M. (2013). Europeanization, eu conditionality, and governance quality: Empirical evidence on central and eastern european countries. International Studies Quarterly, $57(1): 41-51$.

Valliere, D. and Peterson, R. (2009). Entrepreneurship and economic growth: Evidence from emerging and developed countries. Entrepreneurship $\&$ Regional Development, 21(5-6):459-480.

Van Stel, A., Carree, M., and Thurik, R. (2005). The effect of entrepreneurial activity on national economic growth. Small Business Economics, 24(3):311-321.

Verheul, I., Thurik, R., and Grilo, I. (2006). Determinants of self-employment preference and realization of women and men in europe and the united states. SCALES-paper N200513.

Verheul, I., Wennekers, S., Audretsch, D., and Thurik, R. (2002). An eclectic theory of entrepreneurship: policies, institutions and culture. In Audretsch, D., Thurik, R., Verheul, I., and Wennekers, S., editors, Entrepreneurship: Determinants and Policy in a European-US comparison, pages 11-81. Springer.

Villaverde, J. and Maza, A. (2011). Globalisation, growth and convergence. The World Economy, 34(6):952-971.

Vinig, T. and De Kluijver, J. (2008). Does globalization impact entrepreneurship? comparative study of country level indicators. All Sprouts Content. 194.

Voigt, S. and Engerer, H. (2002). Institutions and transformationpossible policy implications of the new institutional economics. In Zimmermann, K. F., editor, Frontiers in Economics, pages 127-184. Berlin: Springer Berlin Heidelberg. 
Weber, M., Tawney, R. H., and Parsons, T. (1930). The Protestant Ethic and the Spirit of Capitalism. New York: Scribner.

Weingast, B. R. (1995). The economic role of political institutions: Market-preserving federalism and economic development. Journal of Law, Economics, $\&$ Organization, pages 1-31.

Wennekers, S., Thurik, R., van Stel, A., and Noorderhaven, N. (2007). Uncertainty avoidance and the rate of business ownership across 21 oecd countries, 1976-2004. Journal of Evolutionary Economics, 17(2):133-160.

Wennekers, S., Van Wennekers, A., Thurik, R., and Reynolds, P. (2005). Nascent entrepreneurship and the level of economic development. Small Business Economics, 24(3):293-309.

Williamson, C. R. (2009). Informal institutions rule: institutional arrangements and economic performance. Public Choice, 139(3-4):371-387.

Williamson, O. E. (2000). The new institutional economics: taking stock, looking ahead. Journal of Economic Literature, 38(3):595-613.

Winiecki, J. (2001). Formal rules, informal rules, and economic performance. Acta Oeconomica, 51(2):147-172.

Wiseman, T. and Young, A. T. (2013). Economic freedom, entrepreneurship, \& income levels: Some us state-level empirics. American Journal of Entrepreneurship, 6(1):104.

Wyplosz, C. et al. (2015). The centralization-decentralization issue. Technical report, Directorate General Economic and Financial Affairs (DG ECFIN), European Commission.

Young, A. T. and Lawson, R. A. (2014). Capitalism and labor shares: a cross-country panel study. European Journal of Political Economy, 33:20-36.

Young, A. T. and Sheehan, K. M. (2014). Foreign aid, institutional quality, and growth. European Journal of Political Economy, 36:195-208. 
Zak, P. J. and Knack, S. (2001). Trust and growth. The Economic Journal, 111(470):295-321. 